\title{
STRUTTURE ARCHITETTONICHE E RESTAURI IN SANTA GIULIA DI BRESCIA: LA CRIPTA DI SAN SALVATORE
}

\section{MASSIMO DE PAOLI}

\author{
UDC: $726.821(450.25)$ \\ $726.71(450.25)$ \\ Original scientific paper \\ Manuscript received: 27. 01. 2017. \\ Revised manuscript accepted: 07. 02. 2017. \\ DOI: 10.1484/J.HAM.5.113712
}

\author{
M. De Paoli \\ Università degli Studi di Brescia \\ Dipartimento di Ingegneria Civile, Architettura, Territorio, Ambiente e di Matematica \\ Via Branze, 43 \\ 25123 Brescia, Italia \\ massimo.depaoli@unibs.it
}

\begin{abstract}
The monastery of San Salvatore of Brescia, after the suppression of the late eighteenth century, was the scene of numerous interventions of functional adaptation that have profoundly changed the appearance and the destination of use. These works, which ended with the recent organization in the city's Museum, allow you to not only understand the architectural evolution of the ancient monastic foundation but also the complex role that it has had in representing the construction of the city's identity with the Unity of Italy. The contribution, which is part of a scientific research project directed by Gabriele Archetti, presents the first significant results on the nineteenth-century reconstruction of the crypt and on the structural work carried out in the basilica of San Salvatore. The parametric modeling of Santa Giulia complex is being built.
\end{abstract}

Keywords: capital, column, crypt, Lombard, Middle Ages, nave basilica, cloister, nun, monk, architecture, archeology Romanesque, Italy, France, sculpture, fresco

Con la soppressione napoleonica del monastero di Santa Giulia si chiudeva la quasi millenaria vicenda religiosa del cenobio benedettino femminile bresciano, fondato dal re longobardo Desiderio a metà dell'VIII secolo'. Smantellato in poco tempo di tutti gli apparati liturgici, alienato il vasto patrimonio e dispersi gli arredi e le opere d'arte sacra, il complesso claustrale fu al centro di una serie di pesantissime trasformazioni che ne minarono definitivamente l'aspetto fino a cancellarne la fisionomia originaria e renderlo quasi irriconoscibile. La nuova destinazione d'uso, come caserma a scopi militari, guidò gli interventi di adattamento funzionale che avvennero in tutto il perimetro del circuito monastico, dalla chiesa ai chiostri, dagli alzati ai portici, dalle strutture residenziali ai magazzini, ai corridoi, alle aperture

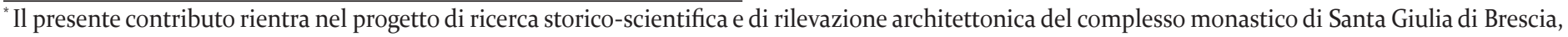
promosso dal Centro studi longobardi in collaborazione con il Dipartimento di Storia moderna e contemporanea dell'Università Cattolica del Sacro Cuore e il Dipartimento di Ingegneria Civile, Architettura, Territorio, Ambiente e di Matematica dell'Università degli Studi di Brescia, diretto dal prof. Gabriele Archetti; in particolare, per i documenti d'archivio e di restauro, per le immagini e i rilievi storico-artistici si rimanda a F. STROPPA, Desiderio. La basilica di San Salvatore, Atti del Primo convegno internazionale del Centro studi longobardi (Brescia, 21-24 marzo 2013), a cura di G. Archetti, Spoleto 2016 (Centro studi longobardi. Convegni 1.2), d'ora in poi semplicemente = F. STROPPA 2016.

${ }^{1}$ Senza alcuna pretesa di ripercorrere la complessa e stratificata storiografia legata alla grande abbazia cittadina, si vedano almeno i seguenti riferimenti nell'ultimo quarto di secolo: S. Giulia di Brescia. Archeologia, arte e storia di un monastero regio dai longobardi al Barbarossa, Atti del convegno internazionale (Brescia, 4-5 maggio 1990), a cura di C. Stella, G. Brentegani, Brescia 1992; G. ARCHETTI, Per la storia di S. Giulia nel medioevo. Note storiche in margine ad alcune pubblicazioni recenti, «Brixia sacra. Memorie storiche della diocesi di Brescia», terza serie, V, 1-2 (200o), pp. 5-44; San Salvatore- Santa Giulia a Brescia. Il monastero nella storia, a cura di R. Stradiotti, Milano 20o1; Il futuro dei longobardi. L'Italia e la costruzione dell'Europa di Carlo Magno. Saggi, a cura di C. Bertelli, G.P. Brogiolo, Milano 200o; G. ARCHETTI, Il monachesimo bresciano nella storiografia di fine secolo, in Dove va la storiografia monastica in Europa? Temi e metodi di ricerca per lo studio della vita monastica e regolare in età medievale alle soglie del terzo millennio, Atti del convegno internazionale (Brescia-Rodengo, 23-25 marzo 2000), a cura di G. Andenna, Milano 2001, pp. 457-471; ID., Pellegrini e ospitalità nel medioevo. Dalla storiografia locale all'ospedale di Santa Giulia di Brescia, in Lungo le strade della fede. Pellegrini e pellegrinaggio nel Bresciano, Atti della giornata di studio (Brescia, 16 dicembre 2000), a cura di G. Archetti, Brescia 2001 (Brixia sacra, VI, 3-4), pp. 69-128; M. BETTELLI, G. BERGAMASCHI, Le chiese minori del monastero bresciano di S. Salvatore-S. Giulia: S. Nicola, «Nuova rivista storica», 85 (2001), pp. 95-110; Culto e storia in Santa Giulia, Atti del convegno (Brescia, 20 ottobre 2000), a cura di G. Andenna, Brescia 2001; P. PERSIANI, Le proprietà immobiliari del monastero di S. Giulia dal ms. quer. O.VI.6, «Annali queriniani», IV (2003), pp. 115-190; G. BERGAMASCHI, Una redazione "bresciana" della «Passio sanctae Iuliae», in Toscana, «Nuova rivista storica», 87 (2003), pp. 625-668; S. GAVINELLI, L'Omeliario del monastero di S. Salvatore-S. Giulia di Brescia, «Aevum», 78 (2004), pp. 345-377; Arte, cultura e religione in Santa Giulia, a cura di G. Andenna, Brescia 2004; E. MAZZETTI, L'ospedale di Santa Giulia di Brescia. Vicende e patrimonio tra XIII e XV secolo, Brescia 2006; S. LOMARTIRE, Architettura e decorazione nel S. Salvatore di Brescia tra alto medioevo e 'romanico': riflessioni e prospettive di ricerca, in Società bresciana e sviluppi del Romanico (XI-XIII secolo), Atti del convegno di studi (Brescia, 9-10 maggio 2002), a cura di G. Andenna, M. Rossi, Milano 2007, pp. 117-239; S. GAVINELLI, Santa Sofia e le figlie, Fede, Speranza e Carità, dipinte in S. Salvatore - S. Giulia di Brescia?, in "Inquirere veritatem". Studi in memoria di mons. Antonio Masetti Zannini, a cura di G. Archetti, Brescia 2007 (Brixia sacra, XII, 1-2), pp. 83-88; M. IBSEN, "Magno et optimo tesauro": intorno a reliquie e altari in San Salvatore di Brescia, Ibidem, pp. 219-242; G.P. BROGIOLO, M. IBSEN, V. GHEROLDI, Nuovi dati sulla cripta di San Salvatore di Brescia, in Monasteri in Europa occidentale (secoli VIII-XI): topografia e strutture, Atti del convegno internazionale (Castel San Vincenzo, 23-26 settembre 2004), a cura di F. De Rubeis, F. Marazzi, Roma 2008, pp. 211-238; G. BERGAMASCHI, "Felix Gorgona... felicior tamen Brixia": la traslazione di santa Giulia, in Profili istituzionali della santità medioevale. Culti importati, culti esportati e culti autoctoni nella Toscana occidentale e nella circolazione mediterranea ed europea, a cura di C. Alzati, G. Rossetti, Pisa 2010 (Piccola biblioteca Gisem, 24), pp. 143-204; G.P. BROGIOLO, V. GHEROLDI, M. IBSEN, J. MITCHELL, Ulteriori ricerche sul San Salvatore II di Brescia, «Hortus artium medievalium», 16 (2010), pp. 219-242; F. STROPPA, Santa Giulia di Brescia. Un percorso sull'iconografia claustrale della martire cartaginese, «Brixia sacra. Memorie storiche della diocesi di Brescia», terza serie, XVI, 1-2 (2011), pp. 61-172; EAD., Santa Giulia percorsi artistici nell'agiografia monastica. L'esempio di San Salvatore a Brescia, Roma 2012; Dalla corte regia al monastero di
} 
fino al brolo con il vigneto. Tenere conto di tutto questo è fondamentale per capire ciò che resta dell'antica abbazia giuliana e ricollocare spazi, edifici e lacerti decorativi nella loro coerente evoluzione storico-architettonica.

Prima di fare alcuni rilievi di approfondimento su aspetti specifici di questa involuzione, è utile ricordare che, una volta indemaniato il complesso monastico, alcune sue parti, considerate più preziose e "sensibili" dal punto di vista storico-artistico e religioso - come la chiesa di San Salvatore, il coro, il sottocoro e forse Santa Maria in Solario - furono dapprima date in gestione e poi gradualmente riscattate dal Comune di Brescia con finalità temporanea di deposito o di magazzino e in seguito di nuovo contenitore museale. Trovano così spiegazione le soppalcature realizzate in San Salvatore subito dopo la soppressione, di cui sono ancora visibili le tracce degli assiti sopra i capitelli e i fori di appoggio delle travi nella muratura, come pure la ripartizione dell'area absidale su tre livelli soppalcati dall'amministrazione militare per gli usi della caserma ${ }^{2}$. Nella seconda metà dell'8oo, grazie alla nuova sensibilità nazionalistica seguita alla costituzione del Regno d'Italia 3 , si procedette a musealizzare l'interno della basilica allo scopo di collocarvi la sezione medievale dei resti monumentali delle memorie cittadine e si consegnò a quegli spazi claustrali il compito di raccogliere l'identità della storia bresciana essendone uno degli esempi più emblematici e percepito come tale ${ }^{4}$.

Della progettualità avviata all'interno della chiesa monastica sono un preciso riferimento documentario i testi corredati da disegni di Federico Odorici del 1845, in cui si dà conto dei lavori che stavano per essere avviati e quelli di Ferdinand De Dartein del 1869, a conferma che tali opere erano ormai in corso e sarebbero giunte a completamento all'inizio del Novecento ${ }^{5}$. Ciò vale anche per la stampa di metà Ottocento con la riproduzione dell'interno della cripta e la sua fitta selva di colonnette, quale rappresentazione grafica delle finalità museali di quello spazio claustrale, appositamente ricostruito allo scopo di reinventare un contesto medievale adatto ad orientare i nuovi sentimenti patriottici. Di una decina di anni dopo sono gli interventi di Pietro da Ponte, che nel 1876-1878 avviò una vasta campagna di scavo nella chiesa e nei chiostri, bene attestata nelle carte conservate nell'archivio storico dell'Ateneo di Brescia ${ }^{6}$, anche là dove nel 1810 un devastante scoppio accidentale aveva distrutto per intero l'ala occidentale del chiostro centrale - solo in parte successivamente ripristinata ex novo - con le cucine, $\mathrm{i}$ magazzini, il portico e le scale, disegnate da Antonio Tagliaferri nel 1874 in una pianta dell'intero cenobio di rilevante interesse, da cui si apprende la volontà dell'amministrazione cittadina di ripristinare quegli ambienti, lo stato degli edifici esistenti e delle strutture da costruire o ricostruire ${ }^{7}$.

Intorno alla cripta, in particolare, che all'inizio del XIX secolo con l'innalzamento di tramezze e la creazione di soppalchi nella parte absidale superiore del presbiterio, era stata resa inagibile e ridotta a terrapieno per scongiurare crolli e cedimenti dovuti all'eccessivo carico superiore, si concentrarono alcune delle opere più rilevanti per il nuovo apparato museale di San Salvatore ${ }^{8}$. Svuotata dai detriti e centinata, la cripta venne interamente riedificata con gusto neomedievale, riempita di colonne e arcatelle, inventate aperture o finestrelle per vedere l'interno della basilica, il tutto seguendo solo in parte la sua architettura originale e le trasformazioni avvenute nel medioevo e in età moderna per adattarla alle varie esigenze liturgiche; si aggiunsero invece, all'interno e all'esterno delle absidiole, muretti di sostegno e due robusti semiarchi per dare sostegno all'arcone superiore e sopportare così il peso delle nuove murature erette al posto del catino absidale antico 9 .

Questi interventi, effettuati a fine Ottocento, modificarono in modo sostanziale le strutture monastiche e la loro percezione nella zona presbiteriale con l'intendimento di renderle funzionali a ricevere l'esposizione di reperti del patrimonio cristiano medievale urbano in vista di un riallestimento museale e della collocazione di pezzi e oggetti. Stando così le cose appare chiaro come le ricostruzioni recenti, i dati d'archivio, le analisi chimiche e i rilievi architettonici debbano essere rivisti in base agli interventi di restauro

\footnotetext{
San Salvatore - Santa Giulia di Brescia, a cura di G.P. Brogiolo con F. Morandini, Mantova 2014; F. STROPPA, L’immagine della martire Giulia nel complesso monastico di San Salvatore di Brescia: mobilità di maestranze, di materiali e di idee, «Hortus artium medievalium», 22 (2016), pp. 265-281 e il saggio della medesima studiosa in questo volume, che ringrazio per il continuo confronto e le proficue indicazioni, oltre che per aver condiviso in anticipo i risultati del suo lavoro di ricerca poi apparsi in EAD., La basilica di San Salvatore: i cicli pittorici altomedievali. Per una rilettura del complesso monastico di Santa Giulia di Brescia, in F. STROPPA 2016; G. ARCHETTI, "Secundum monasticam disciplinam". San Salvatore di Brescia e le trasformazioni istituzionali di un monastero regio, in Desiderio. Il progetto politico dell'ultimo re longobardo, Atti del Primo convegno internazionale di studio (Brescia, 21-24 marzo 2013), a cura di G. Archetti, Spoleto 2015 (Centro studi longobardi. Convegni, 1), pp. 631-680.

${ }^{2} \mathrm{Al}$ riguardo si vedano le documentate ricostruzioni proposte in F. STROPPA 2016.

3 Per questi aspetti e gli interventi di rinnovo urbanistico della città in seguito all'unità nazionale, si rimanda a F. STROPPA, Collezioni longobarde e identità religiosa. Percorsi museali, oggetti liturgici e restauri a Brescia tra Otto e Novecento, «Brixia sacra. Memorie storiche della diocesi di Brescia», terza serie, XX, 1-4 (2016), pp. 23-90; EAD., Oreficeria longobarda nel patrimonio bresciano, in “Erat hoc sane mirabile in regno Langobardorum...." Insediamenti montani e rurali nell'Italia longobarda, alla luce degli ultimi studi, Atti del convegno di studi (Monte Sant'Angelo, 9-12 ottobre 2014), Napoli, in corso di stampa.

${ }^{4}$ Cfr. al riguardo STROPPA, L'immagine della martire Giulia in San Salvatore, pp. 273-276; EAD., Collezioni longobarde e identità religiosa, pp. oo-oo; F. STROPPA 2016; inoltre, per il valore che già alla fine del medioevo la memoria longobarda e il cenobio giuliano assunsero nella coscienza cittadina, si rimanda a G. ARCHETTI, Per l'onore e la libertà della patria, in Le cronache medievali di Giacomo Malvezzi, a cura di G. Archetti, trascrizione e note di I. Bonini Valetti, Roma 2016 (Quaderni di Brixia sacra, 7), pp. 9-49; ID., Memorie longobarde nel "Chronicon brixianum" di Giacomo Malvezzi, in "Erat hoc sane mirabile in regno Langobardorum...", cit., in corso di stampa.

${ }_{5}^{5}$ Si vedano documenti e ricostruzioni proposti da F. STROPPA 2016.

${ }^{6}$ Per la documentazione degli scavi condotti dal Da Ponte all'interno del complesso claustrale del monastero giuliano e della chiesa di San Salvatore, cfr. F. STROPPA 2016.

7 Per tutti questi aspetti e le carte d'archivio si rimanda a F. STROPPA 2016.

${ }^{8}$ Per la funzionalità della cripta e i suoi usi, cfr. ARCHETTI, Per la storia di S. Giulia nel medioevo, pp. 5-44; ID., Vita e ambienti del monastero dopo il Mille, in San Salvatore Santa Giulia di Brescia. Il monastero nella storia, pp. 109-132; STROPPA, Santa Giulia percorsi artistici, pp. 33-57; EAD., L'immagine della martire Giulia, pp. 265-281; per le sue trasformazioni dopo la soppressione del cenobio, F. STROPPA 2016.

${ }_{9}$ Si vedano le osservazioni puntuali di F. STROPPA 2016.
} 
appena ricordati. Appare altresì evidente che non si possa prescindere dalle intenzionalità costruttive intervenute con gli allestimenti museali del cenobio giuliano.

\section{DALLA SOPPRESSIONE NAPOLEONICA AL MUSEO DELLA CITTÀ}

Un'inarrestabile, intrigante e straordinaria metamorfosi pare celarsi tra le pieghe dell'alacre opera di disvelamento di un'autenticità così difficile da rintracciare e il frenetico susseguirsi di eventi, che hanno scandito gli ultimi duecento anni di questi luoghi, custodi d'inestimabili valori. Scorrendo le fonti storiche dal 1798 - momento in cui si completa l'inventario dei beni del monastero in attesa della soppressione dello stesso e della successiva trasformazione in caserma - al 1977, anno nel quale Andrea Emiliani elabora un progetto per la trasformazione del complesso di Santa Giulia in Museo della città, si individuano puntualmente sia le diverse istituzioni sia le figure che hanno avuto un ruolo di rilievo nelle campagne di scavi, succedutesi negli interventi di restauro, nella determinazione delle differenti destinazioni d'uso del complesso e di ogni sua singola parte. Temporalmente, dalla soppressione napoleonica ad oggi, si possono identificare alcune fasi salienti, ciascuna delle quali è di seguito succintamente compendiata.

Primo Ottocento. Nei primi decenni del XIX secolo lo Stato diviene proprietario dell'intero complesso e si attua la trasformazione del monastero in caserma. È al Museo Patrio $^{10}$, allora allestito negli spazi ricavati dagli scavi del Capitolium, coordinati da Luigi Basiletti" ${ }^{11}$, che nel 1825 giungeranno le otto colonnette asportate dalla cripta di San Salvatore. Come rileva Gaetano Panazza in un contributo del 1973, la conoscenza degli scavi effettuati in quellarco temporale non può dirsi completa nonostante "le acqueforti di Luigi Basiletti che illustrano lo stato del Capitolium prima e dopo gli scavi da lui diretti" siano "un insostituibile completamento dell'importante opera Il Museo Bresciano Illustrato pubblicato a cura dell'Ateneo nel 1838 , dove le esatte e accurate incisioni, dovute a vari autori guidati e sorvegliati da Pietro Anderloni, e i pregevoli testi di Rodolfo Vantini per la parte architettonica e di Giovanni Labus per la parte antiquaria ed epigrafica, non sono però sufficienti per

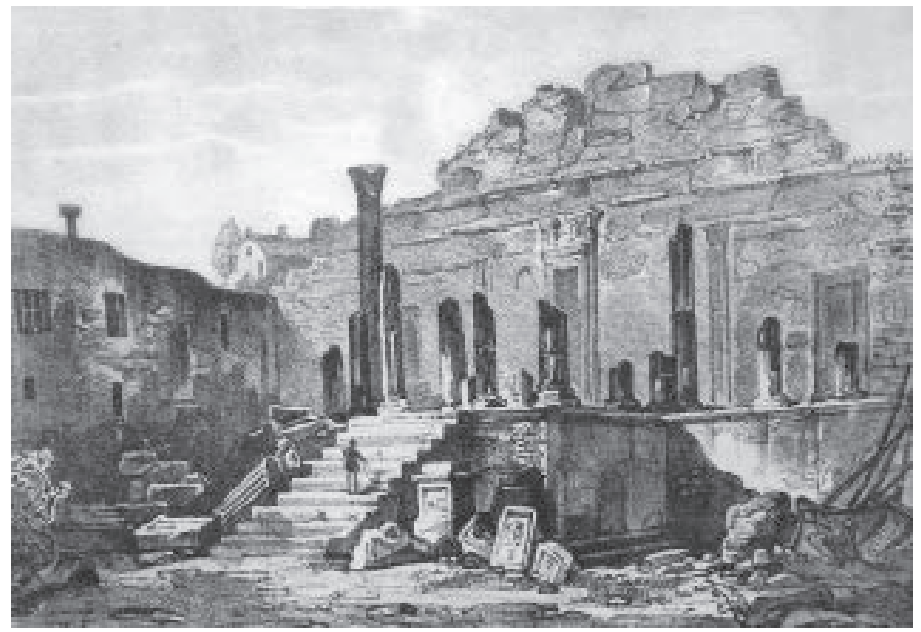

Rappresentazione del Capitolium di Luigi Basiletti da cui risulta evidente il gusto per i resti e le rovine, scoperti in questo periodo, mediante gli scavi.

illuminarci pienamente (come oggi vorremmo) sul 'come' si svolsero i primi scavi”'

Questo periodo culmina nel 1850 con la demolizione dell'ala ovest del chiostro sud-occidentale del monastero ridotta poi a scuderia nelle trasformazioni successive. Si manifesta in questi anni a Brescia un grande interesse per lo studio dei periodi antichi, in particolare per i secoli di dominazione longobarda. Fondamentale a questo proposito è il concorso indetto dall'Ateneo di scienze, lettere e arti di Brescia il 21 settembre 1826, il cui programma recitava "Determinare lo stato dell'architettura adoperata in Italia all'epoca della dominazione Longobarda", vinto da Giulio Cordero di San Quintino'3. Treccani sostiene che "il volume di Giulio Cordero di San Quintino Dell'Italiana Architettura durante la dominazione Longobarda, edito a Brescia nel 1829, ebbe un grande rilievo nella storiografia architettonica di primo Ottocento", contribuì alla promozione dell'architettura dei cosiddetti "secoli bui" ${ }^{14}$.

Metà Ottocento. Poco oltre la metà dell'Ottocento il Comune e l'Ateneo di Brescia iniziarono il lungo percorso, fatto di richieste, mancate risposte e ricerca di interesse da parte delle istituzioni, per trasferire la proprietà delle tre chiese di Santa Giulia, di San Salvatore e di Santa Maria in Solario dal Demanio al Comune. È datata 1862 la lettera che la Commissione consiliare, preposta ai Monumenti del

\footnotetext{
${ }^{10}$ Il Museo patrio a Brescia rappresenta la naturale conclusione di un'intensa attività di scavo e di studio di reperti archeologici iniziata nel 1822 con l'obiettivo di ritrovare le radici culturali della storia di Brescia, di redigere una storia della città. Cfr. L. BASILETTI, Discorso parenetico sullimportanza di avere un patrio Museo di antichità, in Commentari dell'Ateneo di Brescia per l'anno 1823, Brescia 1824, pp. 31 sgg.; inoltre, STROPPA, Collezioni longobarde e identità religiosa, pp. oo-oo.

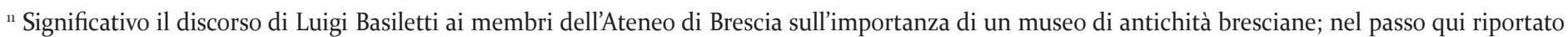
emerge l'interesse per gli scavi e l'osservazione diretta dei monumenti: "L’archeologia... nelle ultime decadi dello scorso secolo... additò col mezzo dei monumenti antichi la nuova strada per ricondurre al buono stile le arti traviate. Sugli antichi lavori non avevano mai scritto... che quegli eruditi i quali delle arti non avevano che appena una leggiera tintura e, quando in un monumento rilevavano oggetti della mitologia e della storia parea loro che null'altro vi fosse da ricercare, e ben poco curavano di esaminare il merito intrinseco dell'opera com'è l'invenzione, l'esattezza del disegno e la perfetta esecuzione; ma il genio di Winckelmann tutto questo esaminò e con chiarezza espose" (L. BASILETTI, Memorie archeologiche bresciane, a cura di V. Basiletti Martinengo, Brescia 1926, pp. 11-21).

${ }^{12}$ G. PANAZZA, La documentazione iconografica e grafica dei monumenti nell'area del Foro di Brescia fino al 1974, in Atti del Convegno internazionale per il XIX centenario della dedicazione del "Capitolium" e per il $150^{\circ}$ anniversario della sua scoperta, vol. secondo, Ateneo di Brescia, Brescia, 27-10 settembre 1973, II, Supplemento ai Commentari dell'Ateneo di Brescia per l'anno 1975, Brescia 1975, p. 67.

${ }_{13}^{13}$ Si veda STROPPA, L'immagine della martire Giulia in San Salvatore, p. 274; EAD., Collezioni longobarde e identità religiosa, pp. oo-oo; STROPPA 2016.

${ }^{14}$ G.P. TRECCANI, Dell'Italiana Architettura di Giulio Cordero di San Quintino e la cultura del restauro, in Testo, immagine, luogo, 4. Libri d'architettura a Brescia. Editoria, circolazione e impiego di fonti e modelli a stampa per il progetto tra XV e XIX secolo, a cura di I. Giustina, Palermo, 2015, pp. 215- 253; ma per questi aspetti, con riferimento al contesto giuliano, STROPPA, Collezioni longobarde e identità religiosa, pp. oo-oo; STROPPA 2016.
} 
Comune, su sollecitazione del conte Lechi invia al presidente dell'Ateneo Aleardo Aleardi raccomandando la cessione delle tre chiese del complesso di Santa Giulia per farne un Museo di arte cristiana. E sempre nel 1862 il Demanio militare concede in affitto le tre chiese che diventano magazzino comunale, a dimostrazione della distanza fra quanto auspicato dai fautori del Museo di arte cristiana e il Ministero della difesa più interessato ad un utilizzo funzionale degli spazi del complesso giuliano.

In questi anni si consolida l'interesse per le antichità classiche ma anche cristiane, in particolare le opere riguardanti i secoli VI, VII e VIII. A conferma del crescente interesse si pone l'opera di Federico Odorici, sia come storico, sia come coordinatore di una serie di rilievi dei principali monumenti cittadini, fra cui la chiesa e la cripta di San Salvatore ${ }^{15}$. Interessante notare come dopo pochi anni i medesimi monumenti siano stati rilevati da Ferdinand De Dartein a testimoniare il passaggio da un interesse locale ad uno internazionale; lo studio dell'architetto francese infatti diviene nella seconda metà dell'Ottocento il testo fondamentale per tutti gli interventi architettonici e di restauro a cavallo del XX secolo ${ }^{16}$.

È doveroso ricordare come nel medesimo periodo, in Francia, Jean Nicolas Louis Durand nelle sue lezioni di composizione tenute all'École Polytechnique cominci a diffondere l'analisi comparata degli stili antichi e in particolare lo studio dei tipi, ovvero una sorta di galleria storica dell'architettura universale per tipi di edifici, classificati per distribuzione planimetrica e funzione. I disegni di Odorici risentono sicuramente di questo processo di tipizzazione come molte rappresentazioni grafiche di architetture di metà Ottocento. Accanto a questo interesse per la tipologia si sviluppa un sentire romantico legato al gusto per le rovine e all'interesse per i resti e i ruderi rinvenuti mediante gli scavi; a Brescia le opere di Luigi Basiletti, in particolare le rappresentazioni del Capitolium, sono emblematiche del gusto per il non finito, per l'accostamento di antichità classiche con scenari caratterizzati da rovine e elementi naturali. L'incisione di Giuseppe Elena della cripta di San Salvatore riassume i due aspetti: tipizza la selva di colonne dell'aula della cripta e al contempo raffigura uno spazio non definito, caratterizzato da pietre e rovine che suggeriscono la scoperta di uno spazio antico, la presenza di uno "scavo in atto".
Secondo Ottocento. Gli ultimi decenni dell'Ottocento sono caratterizzati da una prima conclusione del passaggio di proprietà dallo Stato al Comune. Sarà infatti solo nel 1874, a seguito di una serie di trattative, che il Comune di Brescia acquisterà le tre chiese dal Demanio per trasformarle in sede di un nuovo museo. È Gabriele Rosa, in veste di presidente della Commissione provinciale per la conservazione dei monumenti, a presentare istanza, nell'autunno del 1875, agli organi comunali preposti affinché fosse accordato ai membri della Commissione (Arcioni, Conti e Tagliaferri) il permesso di accedere all'area del complesso monastico per avviare in Santa Giulia, Santa Maria in Solario e San Salvatore una serie di più approfondite indagini, in previsione dell'ordinamento del museo medievale. L'incarico di redigere il rilievo dell'intero complesso è affidato proprio ad Antonio Tagliaferri; poco dopo, nel 1876 , si dà inizio alla prima campagna di scavi nella chiesa di San Salvatore, sotto la direzione di Pietro Da Ponte e Luigi Arcioni ${ }^{17}$. Il 23 agosto 1882 si inaugura nell'ex chiesa di Santa Giulia il Museo dell'età cristiana ${ }^{18}$.

Il clima culturale nella seconda metà dell'Ottocento è indubbiamente influenzato da alcuni testi francesi che rivalutano l'architettura del medioevo. L'opera principale di Viollet Le Duc, il Dictionnaire raissonné de l'architecture française du XI au XIV siècles edito nel 1853, è il trattato fondamentale per tutte le operazioni, a cavallo del XX secolo, di restauro e di invenzione del medioevo. Fra Otto e Novecento a Brescia, come nel resto d'Europa, si assiste ad una stretta relazione fra libri di arte e architettura e opere realizzate o progetti di architettura tipica della cultura dell'eclettismo storicista.

Un recente studio su Antonio Tagliaferri ${ }^{19}$ ha evidenziato l'importanza di taluni libri custoditi nella sua biblioteca, riconoscendo quanto abbiano marcatamente influenzato la sua attività professionale ${ }^{20}$. In particolare la Storia dell'abitazione umana dai tempi preistorici fino ai giorni nostri (1877) di Viollet Le Duc, nella traduzione italiana del volume edito a Parigi nel 1875 comprato a Milano, da Tagliaferri, da Hoepli nel 1882 a dimostrazione dell'interesse crescente per i modelli architettonici e artistici contenuti nei testi dei grandi autori europei. Alcuni capitelli della cripta di San Salvatore mostrano infatti forti similitudini con un capitello raffigurato alla voce Crypte dell'Encyclopédie médiévale di Viollet Le Duc.

\footnotetext{
${ }^{15}$ È Federico Odorici a seguire le operazioni di rilievo in sito; val la pena qui rammentare l'affranta testimonianza di quando, nel 1882, nella cripta di San Salvatore egli assiste sgomento e impotente all'accidentale distacco - ascrivibile all'imperizia se non alla negligenza di colui che operava i rilievi - di un frammento, effigiante il volto di sant’Epimeneo, del "diligentissimo" affresco del Romanino; STROPPA 2016.

${ }^{16}$ Irene Giustina sottolinea l'impiego dei volumi di De Dartein a fini progettuali: "Vi è poi la monumentale opera in due volumi di Ferdinand de Dartein, Étude sur l'architecture lombarde et sur les origines de l'architecture romano-byzantine (1865-1882), che come è noto fu alla base della conoscenza globale delle chiese lombarde dell'XI-XII secolo, secondo un approccio scientifico, accompagnato da preziose tavole di rilievi analitici" (I. GIUSTINA, Fonti a stampa per l'eclettismo a Brescia tra secondo Ottocento e primo Novecento: libri e repertori nell'architettura di Antonio Tagliaferri, in Testo, immagine, luogo, p. 279; inoltre, anche STROPPA 2016).

${ }^{17}$ Pietro da Ponte, il più importante archeologo bresciano, attivo fra il 1870 e il primo decennio del XX secolo, nella lettera della Commissione provinciale per la conservazione dei monumenti al Ministero della Guerra, del 25 maggio 1876, custodita nell'Archivio di Stato di Brescia (Archivio Ateneo Brescia, busta 183), esprime la volontà di "rinvenire oggetti antichi" e, in qualità di ispettore agli scavi e ai monumenti, predispone dei sondaggi all'interno del monastero di Santa Giulia. Per il quadro generale di questi interventi v. STROPPA 2016.

${ }^{18}$ L'idea di istituire un Museo dell'età cristiana - inteso come luogo di conservazione, studio, ricerca, divulgazione di una eredità inestimabile - nasce e matura nel corso di almeno due decenni prima che se ne celebri l'inaugurazione, avvenuta nel 1882. Un progetto per un luogo del sapere, della formazione, della valorizzazione e della diffusione dell'arte cristiana, sorto e germogliato dal raffinato intuito e per l'esortazione di una serie di figure di spicco del panorama culturale; fra i molti propugnatori, si annoverano il conte Luigi Lechi e Gabriele Rosa.

${ }^{19}$ GiUstina, Fonti a stampa per l'eclettismo a Brescia, p. 277.

${ }^{20}$ Il progetto in stile neo-rinascimentale del sottocoro della chiesa di Santa Giulia è di Antonio Tagliaferri (cfr. STROPPA 2016). Nella suddivisione delle aree museali si prevedeva che la chiesa di Santa Giulia fosse sede del periodo rinascimentale, riservando a San Salvatore il periodo medievale.
} 

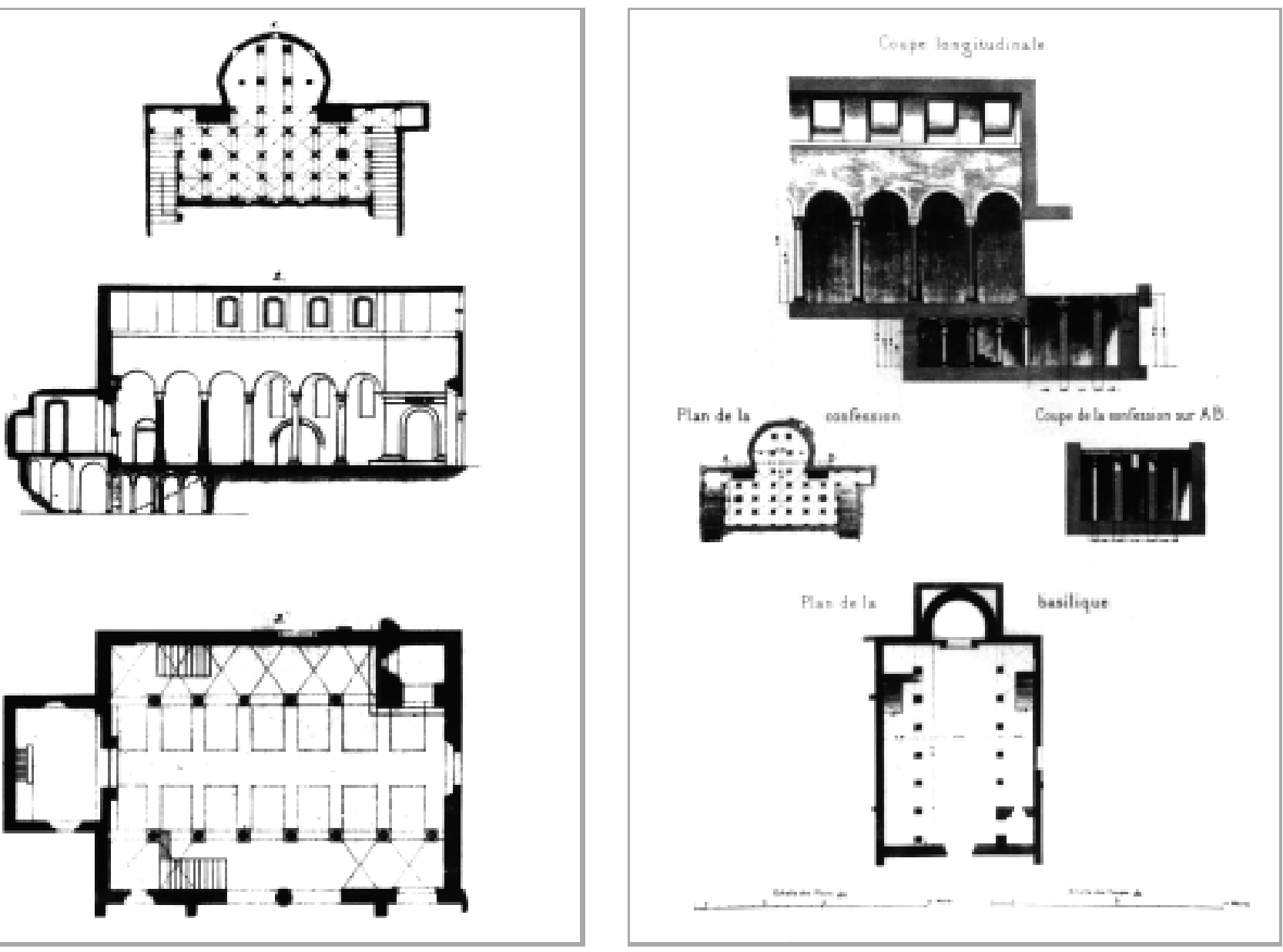

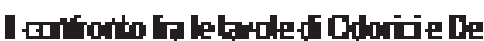

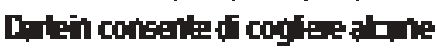

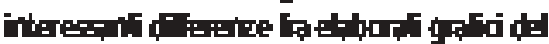
med :

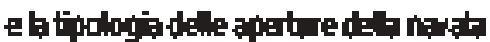

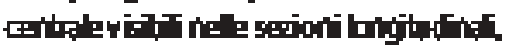

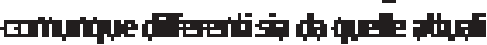

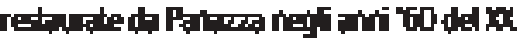

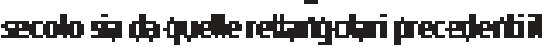

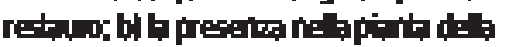

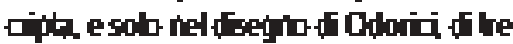

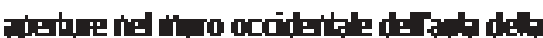

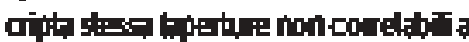

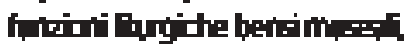

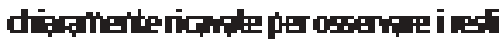

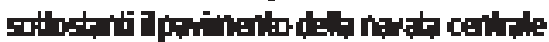

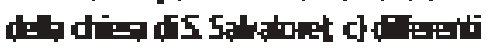

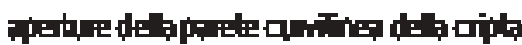

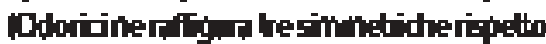

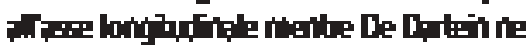

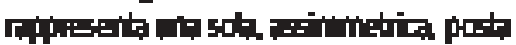
n: frectra nelaserione blthiflated

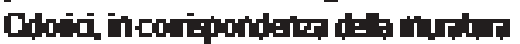

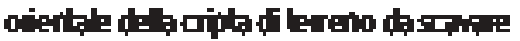

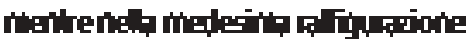

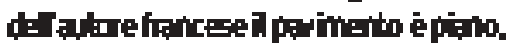

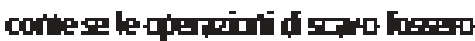

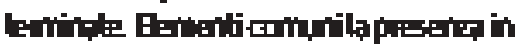

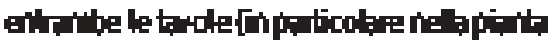

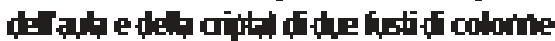

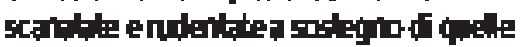
speididela ripita halo s vinistrs F Odonici 1845 l pisntse seriore lorgitudinde delb diess di S Salvistore in Brescia Nels parte e.periore dela tav ola particolare dela piarta dela cripta

habo a destra: F. De Dartein |1859|, ancora ta chiesse ta cipta di 5 Sdvatore disegnata dalo storico francese. Da notare la difierente impaginxione proposta dalfasore francese e la particolare importanua assurta, in questa tavda, dolsarsperesentrrione dei devogl archisetionici e decorativi dela cipta e della parte di collegamento fra la nasa s.periore e lo sprrioipogen.

hbasso incigione di Guseppe Elens che gyggerisce b preserras di uno scovo in stto Alla precisone del numero df colorne e irtecolumri corrisponde una loro tipizzaione I focus d quesf opera è rivotio al gusto per le novine ela scoperts e linivilezo di resti amichi non tanto ala precigione del rilevo mensorio

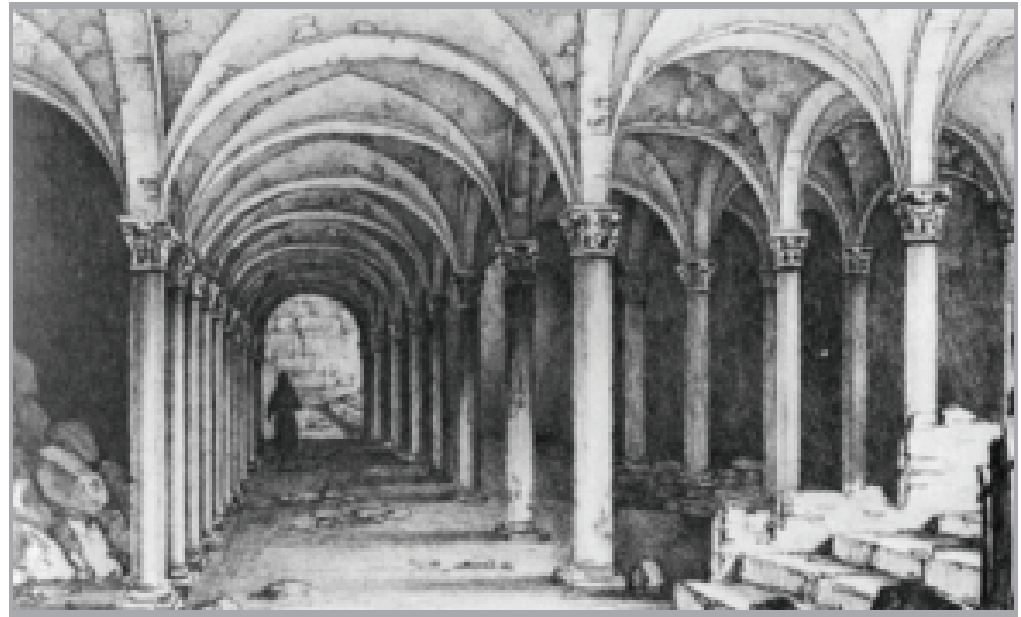




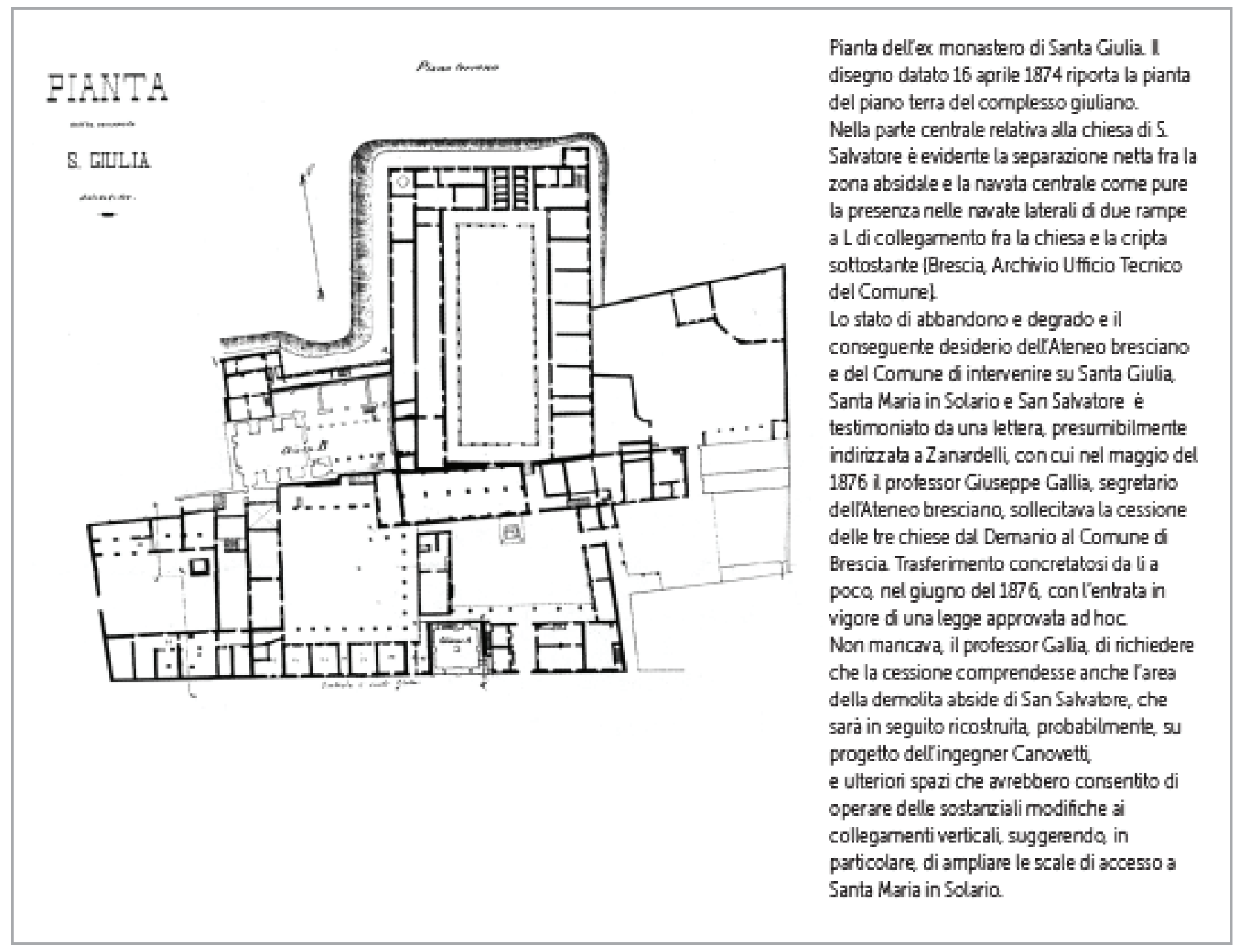

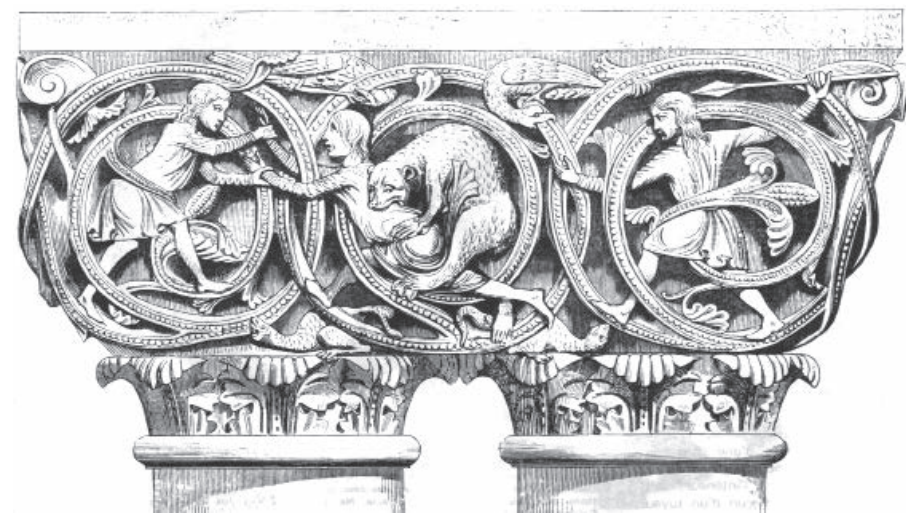

Viollet Le Duc, voce Crypte dell'Encyclopédie Médiévale, particolare di un capitello caratterizzato da motivi spiraliformi a intreccio e figure antropomorfe.

Primo Novecento. La prima metà del Novecento, periodo fortemente segnato dalle due guerre, è caratterizzata da due campagne di restauri della chiesa di San Salvatore. Iniziati alla fine dell'Ottocento, precisamente nel 1889, i primi interventi di restauro si estenderanno fino al 1906. Di particolare rilievo è la relazione tecnica e un piccolo ma significativo disegno che il 10 ottobre del 1900 l'ingegner Ca- novetti allega ad una lettera inviata dal Municipio di Brescia all'Ufficio regionale per la Conservazione dei Monumenti della Lombardia in Milano. In esso è rappresentato il progetto per la ricostruzione dell'abside maggiore della chiesa di San Salvatore, in corrispondenza con la cripta ipogea. In questa relazione e sulle scritte a margine del disegno della cripta, si fa riferimento alla ricostruzione dell'antica cripta di San Salvatore. Il testo della relazione consente di datare alla seconda metà dell'Ottocento le arcate poste nella cripta, a sostegno della copertura piana. Nel 1903 il Demanio vende al Comune i locali sovrastanti la cripta; fra il 1914 e il 1919, in concomitanza con il primo conflitto mondiale, il Museo dell'età cristiana rimane chiuso.

Cofinanziati a livello centrale e periferico, dal ministero e dal Comune, i lavori di manutenzione e restauro condotti nel periodo successivo alla grande guerra nella chiesa e nella cripta di San Salvatore non possono certo intendersi come meramente conservativi. Per avere un'idea degli stravolgimenti verosimilmente operati, può essere utile la lettura di documenti che rivelano come, a seguito di sopralluoghi avvenuti nella primavera del 1920, gli stanziamenti dovessero far fronte alla necessità di completare la cripta, restaurare l'abside - previa eliminazione dell'arcone e delle stanze di

${ }^{21}$ Conferma questi elementi con una serie di altri dati sulla portata dei lavori di restauro v. STROPPA 2016. 


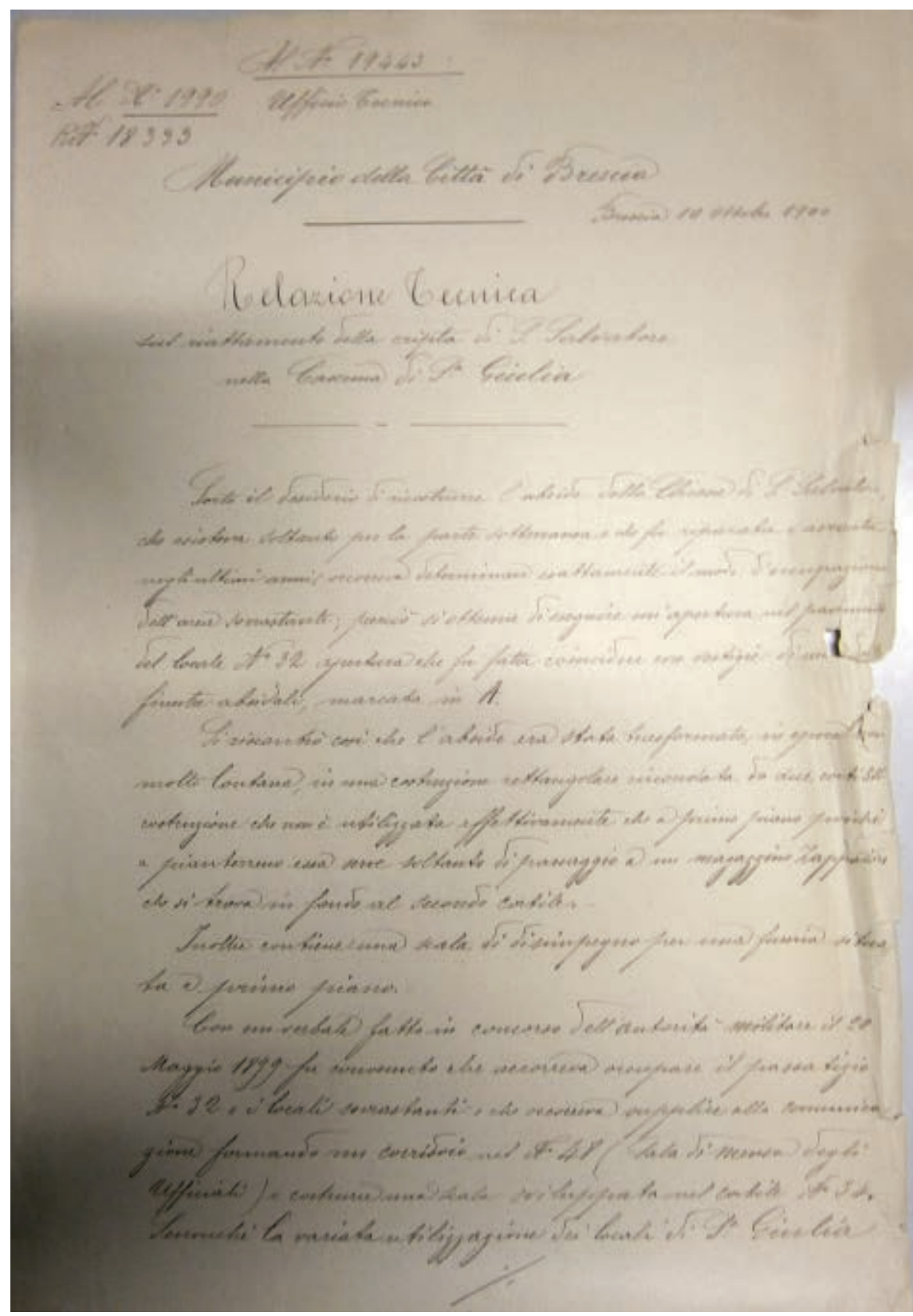

Relazione tecnica allegata ad una lettera inviata il 10 ottobre 1900 all'Ufficio Regionale per la Conservazione dei Monumenti della Lombardia in Milano. Nella relazione, firmata dall'ingegner Cosimo Canovetti, è indicata la volontà di ricostruire l'antica cripta e l'abside della chiesa di S. Salvatore.

servizio soprastanti - rifare le coperture e la pavimentazione, scrostare gli interni e, finanche, aprire nuove finestre.

Che le straordinarie opere di ristrutturazione e restauro della chiesa di San Salvatore e della cripta necessitassero di ingenti finanziamenti lo testimoniano le richieste di stanziamento di contributi ministeriali ${ }^{21}$. Somme più che triplicate nel corso di pochi mesi, allorquando si segnala come doveroso che la cifra inizialmente statuita nel 1920, lire diciassettemila, si incrementi - conformemente ad una perizia del 1921 - a lire sessantamila per la conduzione di lavori che, ponendo fine al degrado della basilica, le consentiranno di rinascere e vivere nuovi fasti, divenendo altresì museo dei marmi ${ }^{22}$.
Non v'è dubbio che cavallo dei XX secolo e attorno al 1920 si pongono in essere invasive operazioni di restauro atte a mutare il volto di San Salvatore. Uno sguardo alle categorie d'opera incluse in un preventivo presentato nel 1921, inerente i lavori da eseguirsi nella chiesa e nella cripta della basilica, è sufficiente a comprendere la determinazione di ridefinire lo spazio ipogeo della confessio affinché se ne possa meglio fruire all'interno di un percorso museale. L'intendimento di collegare cinque vani alla cripta, e la conseguente necessità di intervenire con collegamenti verticali e con la ridefinizione delle connessioni tra un vano e l'altro, la volontà di coprire la cripta, di abbassare il pavimento, di procedere con le operazioni di scrostamento degli intonaci e degli elementi di rivestimento, connotano indiscutibilmente il grado di invasività degli interventi che precedono gli scavi coordinati da Gaetano Panazza e da Ignazio Guarnieri negli anni 1958-1962 23 .

Curioso poi anche il fatto che il materiale lapideo derivante dagli interventi della seconda decade del Novecento fosse trasportato dalla zona di scavo alla Scuola Moretto, con quali finalità non è dato sapere. Forse affinché tale materiale fosse custodito o utilizzato dagli studenti nel corso di esercitazioni didattiche; divenendo chissà - allorquando fra i cocci fossero emersi elementi di pregio più o meno lavorati - modello da imitare. Fra il 1924 e il 1928 sotto la guida del Soprintendente ai monumenti, Augusto Brusconi la chiesa di San Salvatore viene restaurata e così le cappelle del lato nord. Il lavoro di restauro pittorico è affidato al milanese Aristide Malinverni, e Vittorio Trainini e Enrico Ragni nel 1932 restaurano gli affreschi dei chiostri di Santa Giulia. Dal 1940 al 1949, infine, il Museo dell'età cristiana rimane chiuso a causa dei tragici eventi bellici; frattanto, nel 1941, si eseguono i lavori di rafforzamento dei colonnati di San Salvatore, in previsione dei bombardamenti.

Metà Novecento. Attorno alla metà del Novecento, l'intensa attività di studio e ricerca delle antichità svolta a Brescia è ben descritta dall'allora soprintendente alle Antichità Mario Mirabella Roberti, "Brescia ha peraltro, quasi unica fra i capoluoghi della Lombardia, un'attrezzatura civica di lunga tradizione, una presenza in luogo di uomini attenti ai valori antiquari della città e della sua zona e una sensibilità conseguente, così che alle volte l'iniziativa è venuta di qui e la collaborazione con la Soprintendenza è stata fervida e puntuale. Ne va data lode al direttore dei Musei dott. Gaetano Panazza e ai suoi collaboratori, fra i quali almeno qualcuno va nominato: il dr. Ermanno Arslan, il dottor Francesco Rossi, il prof. Alessandro Damiani, il prof. Mario Serino e gli assistenti Ignazio Guarnieri e Mirella Fioni”24.

\footnotetext{
${ }^{22}$ R. BOSCHI, G. LECHI, G. PANAZZA, San Salvatore di Brescia. Materiali per un museo. I, II, Brescia 1978, pp. 37-38.

${ }_{23}$ Per questi aspetti e la documentazione d'archivio, cfr. STROPPA 2016.

${ }^{24}$ M. MIRABELLA ROBERTI, Gli ultimi dieci anni di scavi romani a Brescia, in Atti del Convegno internazionale per il XIX centenario, p. 5; più in generale per questa temperie e idee, STROPPA 2016.
} 


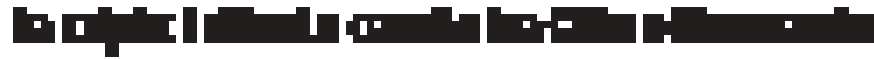

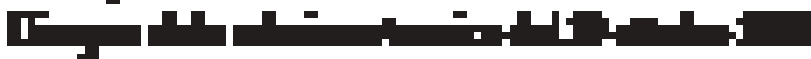
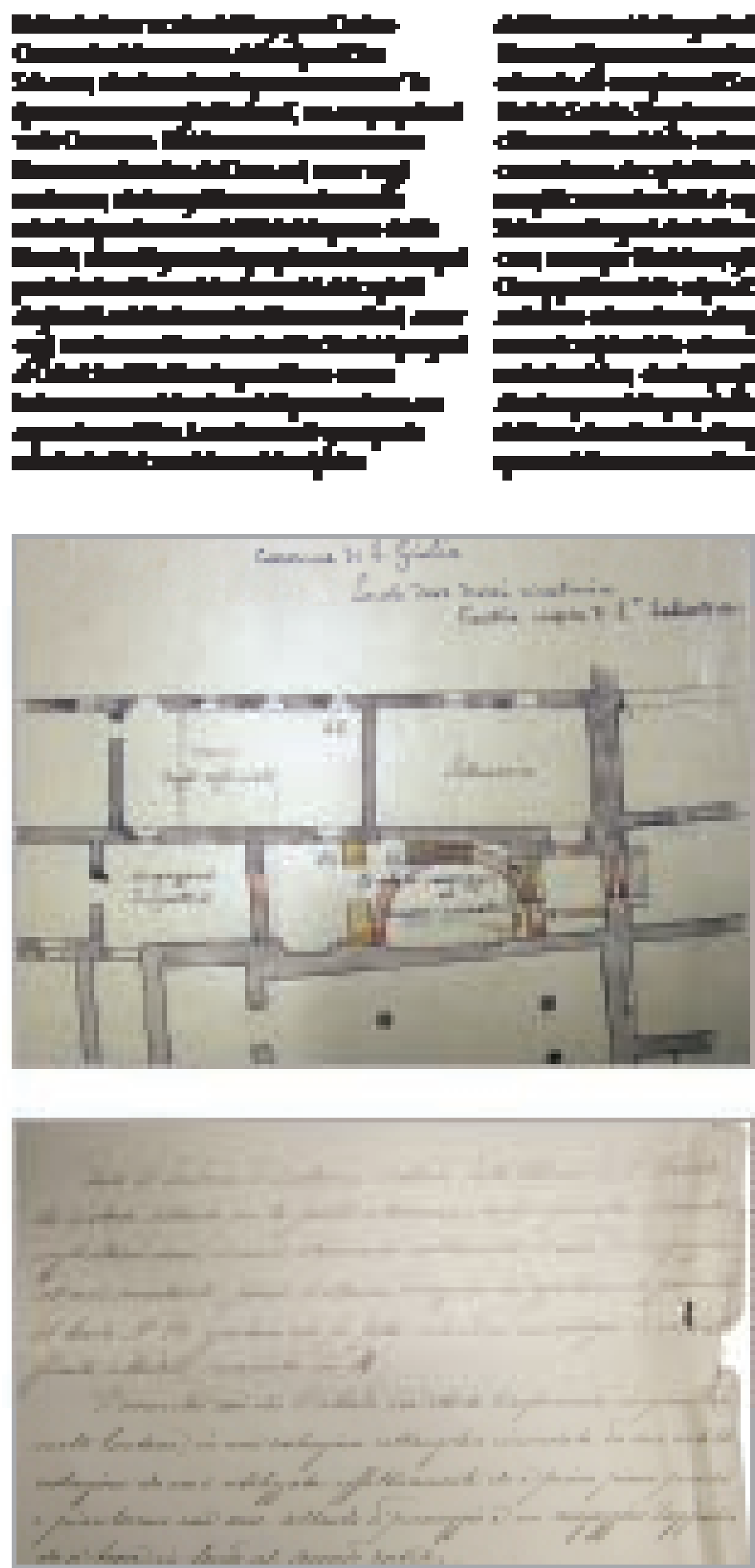

Trandrats

Lohtandmatkum

Frteratishor

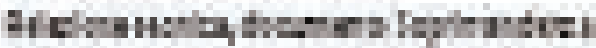

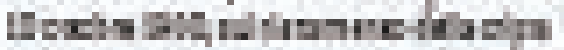

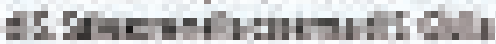

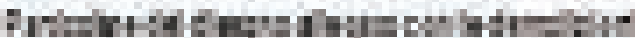

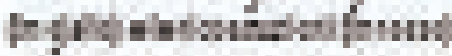

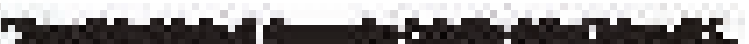

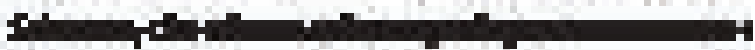

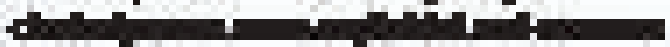

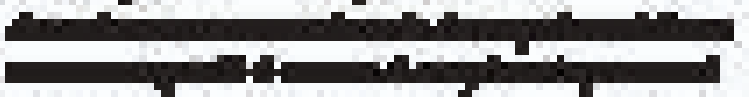

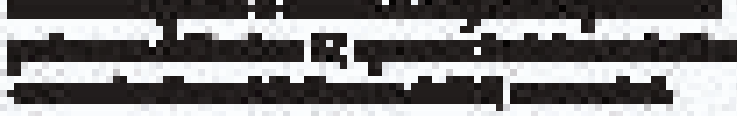

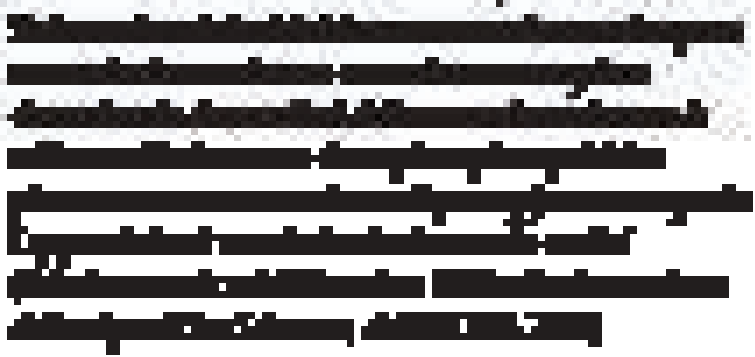




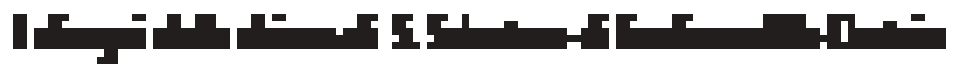
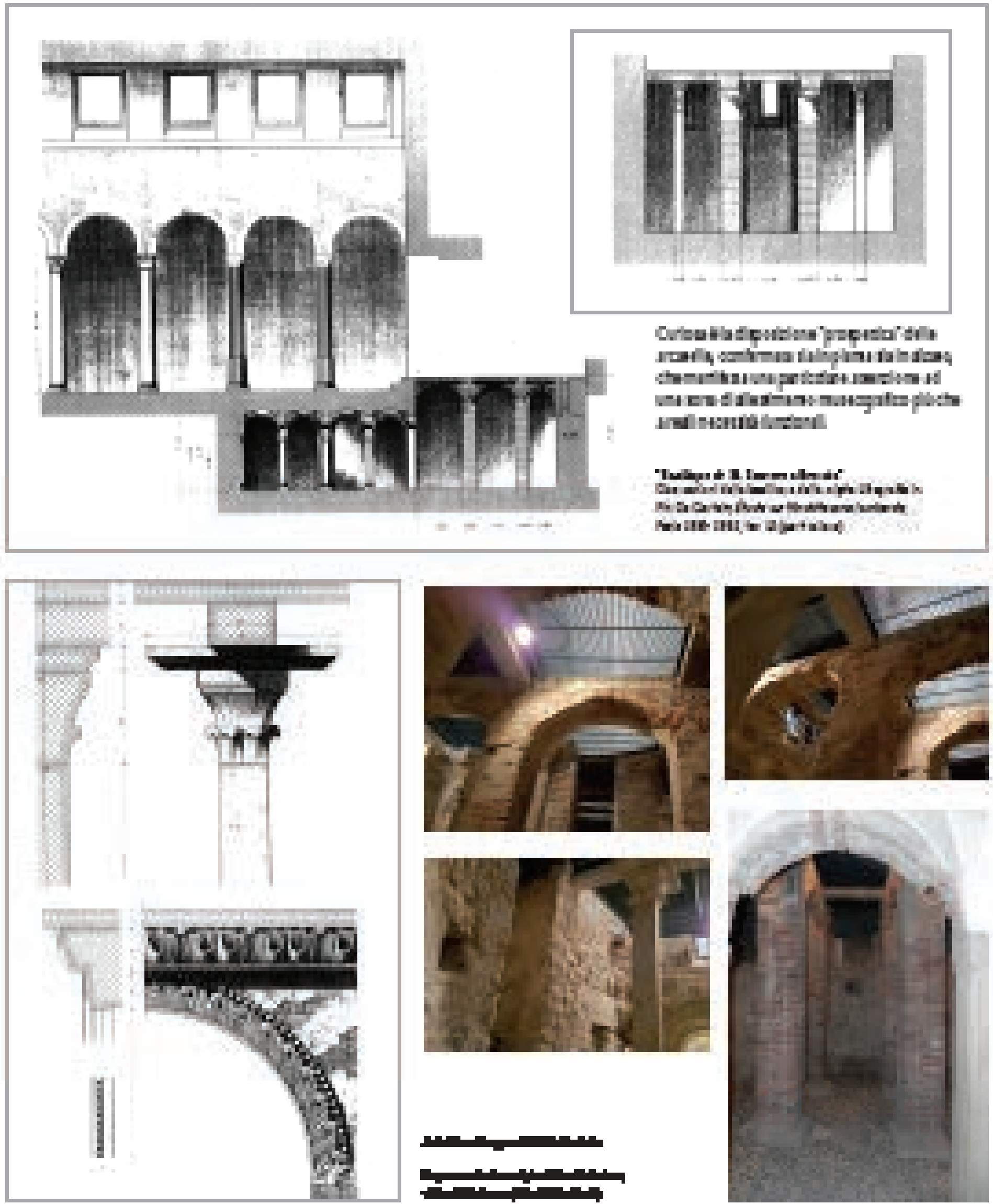


\section{I "Diari" di scavo di Ignazio Guarnieri I rilievi della cripta dal 23 maggio al 30 luglio 1959}

Dalla lettura dei Diari emerge la logica con la cuale Guarnieri ha impostato gli scavi della cripta e celliaula adiacente della chiesa di San Salvatore dal 1958 al 1960-62.

Cinque sono le zone interessate dagli scavi

1 - navata sud, ricerche transetto sud dat 2 settembre all 15 ottobre 1958

2 - cappella nord scavi dal 6 ottobre al 19 novembre 1958

3- transete nord scavi dal 7 nowembre 1958

4 - crpta scavi da: 23 maggio al 30 luglio 1959

5. cavecio nord scavi dal 25 maggio 1960 al 1 luglio 1960 e dal B febbraio 1962

5. cavedio sud scami dal 4 luglo 1960 al 16 luglio 1960
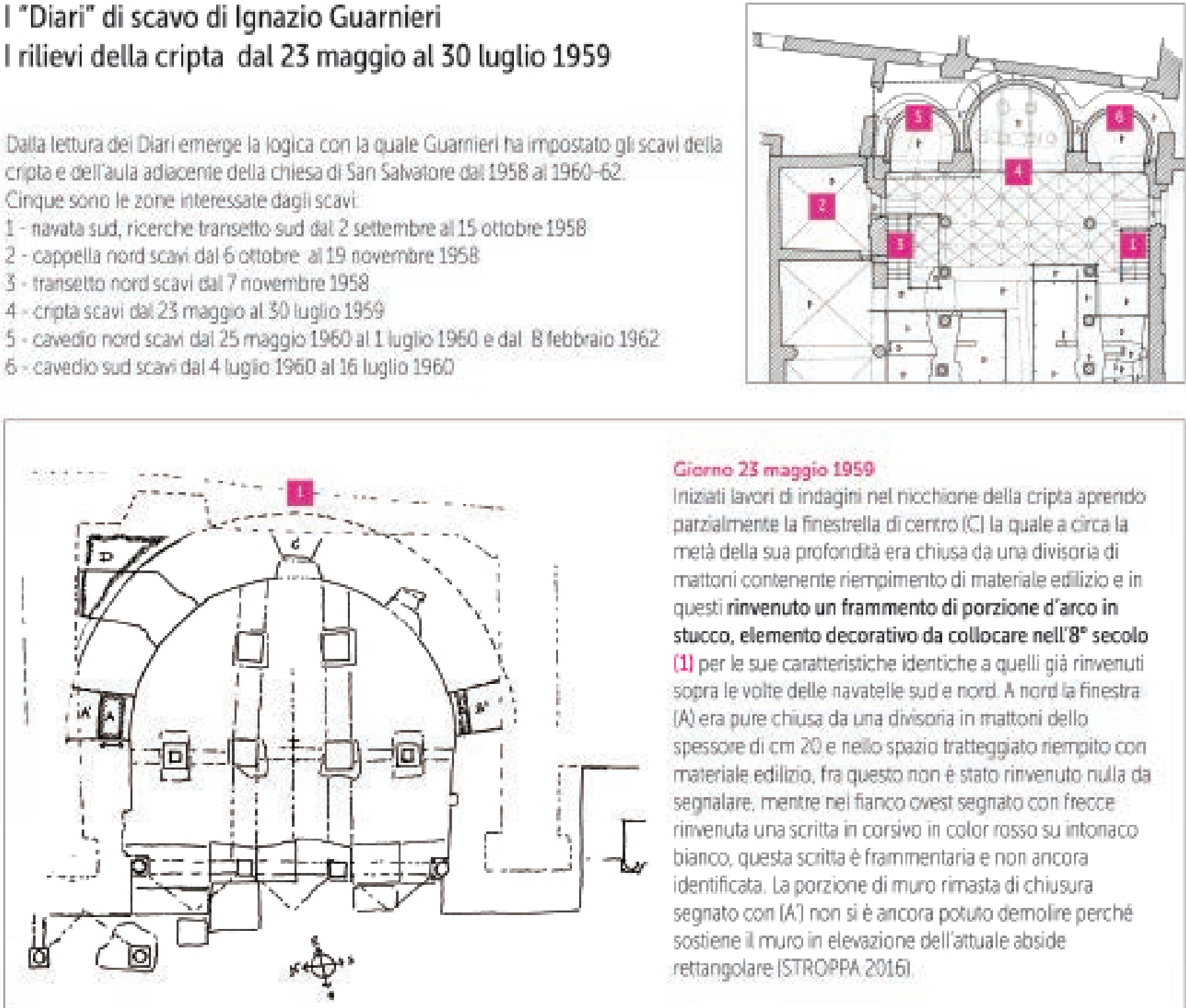

Giorno 23 maggio 1959

Inizati lavori d indagini nel nicchione della cripta aprendo parzialimente la finestrella di certro (C) la quale a circa la metá della sua profondtả era chiusa da una divisoria di mattoni contenente riernpimento di materiale edflizio e in questi rinwenuto un frammento di porzione d'arco in stucco, elemento decorativo da collocare nell' $8{ }^{\circ}$ secolo (1) per le sue caratteristiche identiche a quelli già rinvenuti sopra le volie delle navatelle sud e nord. A nord la finestra (A) era pure chiusa da una divisoria in mattoni dello spessore di cm 20 e nello spazio tratteggato riempito con materiale edilizio, fra questo non e stato rinvenuto nulla da segnalare, mentre nel fianco ovest segnato con frecce rinvenuta una scritta in corsivo in color rosso su intonaco bianco, questa scritta e frammentaria e non ancora identificata La porzione di muro rimasta di chiusura segnato con $[A$ '] non si è ancora potuso demolre perché sostiene il muro in elevazione dell'attuale abside rettangolare [STROPPA 2016].

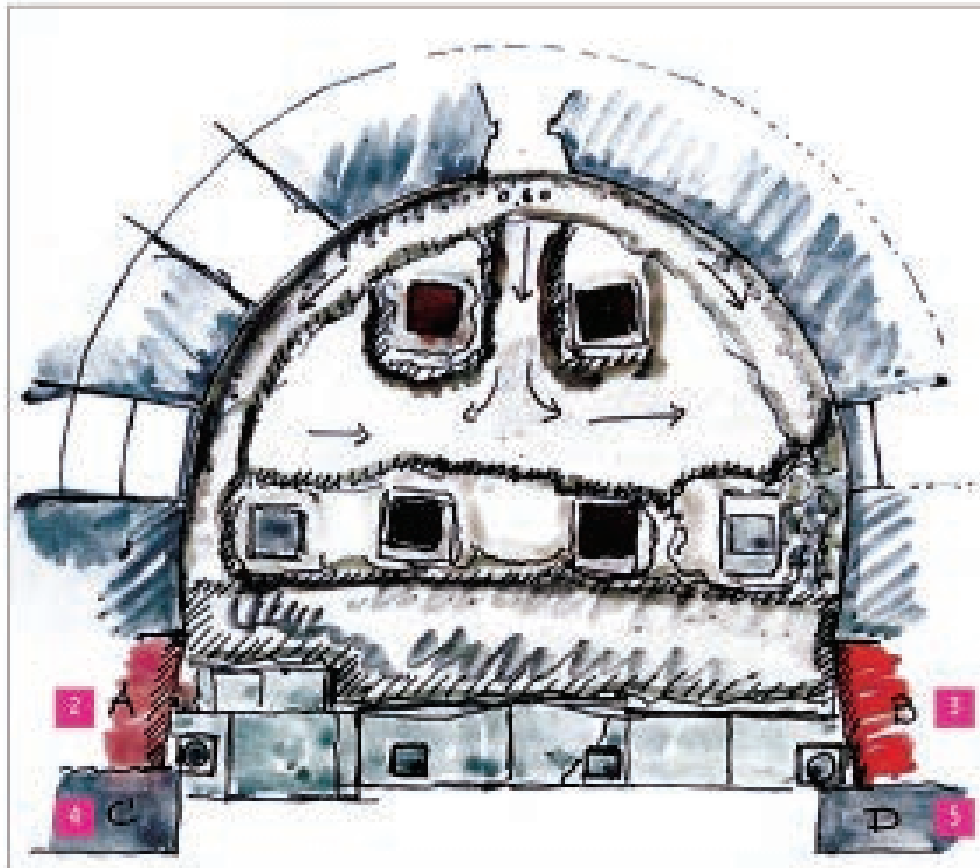

Giorno dal 27 al 30 maggio

Continuato lo scavo in tutto lo sviluppo semicircolare dal nicchione e poi scavando al centro e in tutla la larghezza solianto alla profondita di $\mathrm{m}, 060$. Questo scavo ci ha dato la possibilitá di identificare che in (Ae B) ill nicchione è stato prolungato con una aggiunta posteriore $\mathrm{di}$ muratura a sacco con evidenti caratteristiche di costruzione nettamente diversa e molto disordinata senza fondazione (2-3). Si è pure identificata la murature aggiunta in epoca ancora non ben definita la parte $(C e$ D) (4-5) la quale ha dato al nicchione la configurarione di uno sviluppo a forma di ferro di cavallo, ma sia una che Taltra sono trasformazioni avvenute in perioti successivi da condurre ulteriori e attente ricerche per identificare nettamente i periodi e le ragioni di questi mutamenti Sta di fatto che nel complesso questo grande nicchione ci porterà a notevoli mutamenti di orientamento per quanto riguarda la sua originaria costruzione e che nulla ci fa escludere che sia ancora in parte residui dell'edificio romano (STROPPA 2016). 

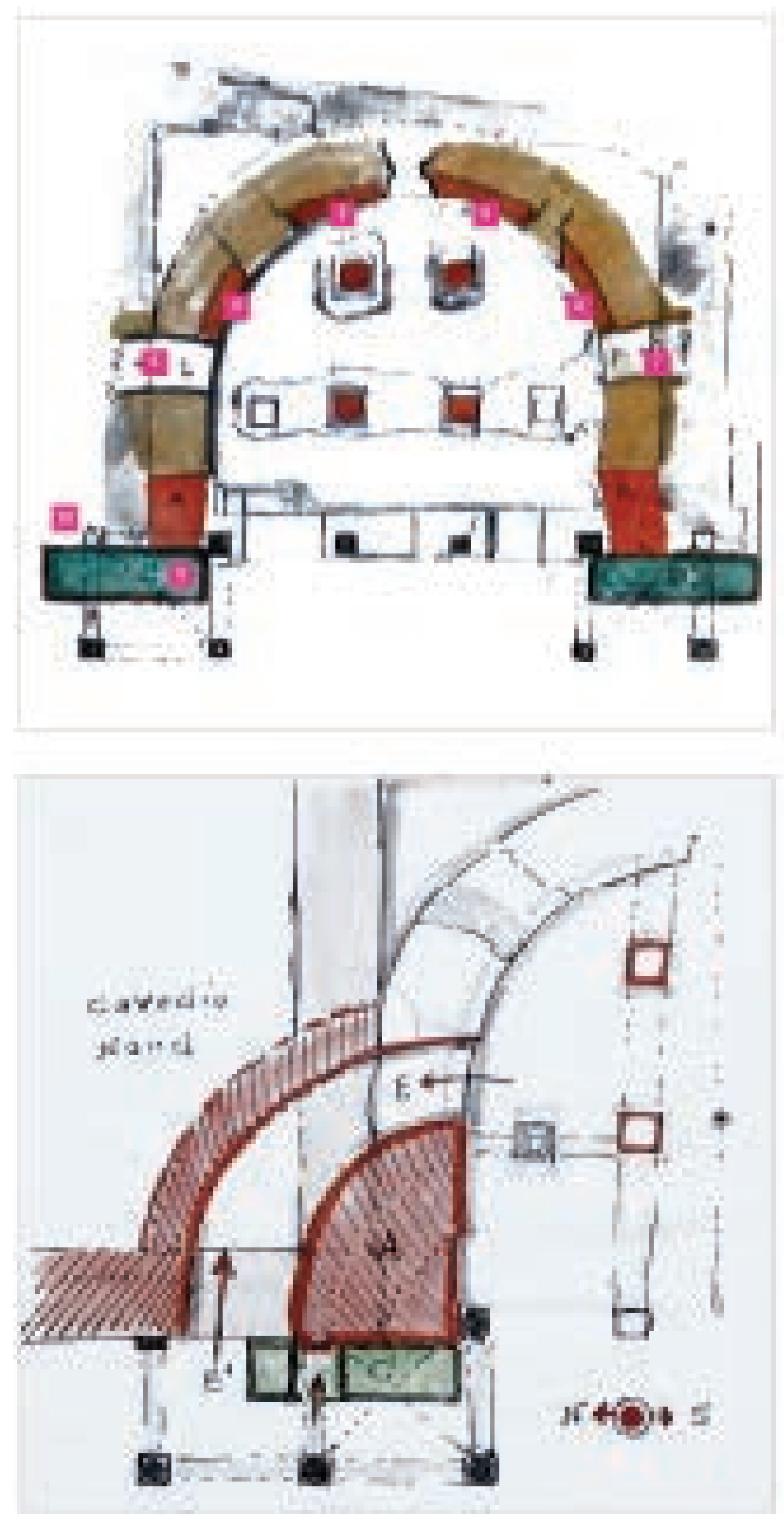

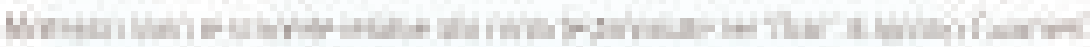

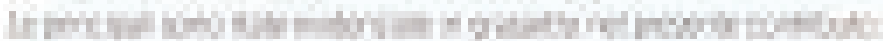

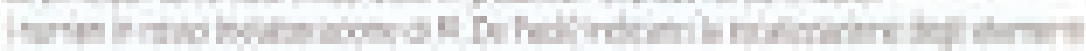

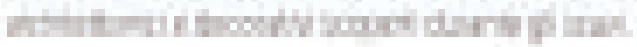

Erwalldhow

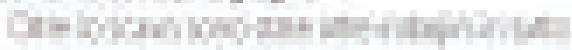

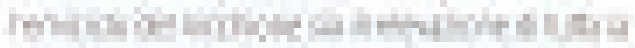

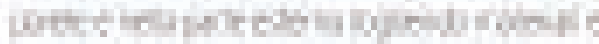

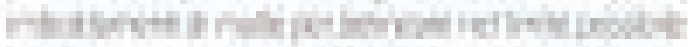

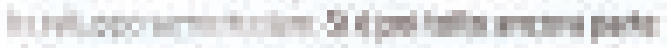

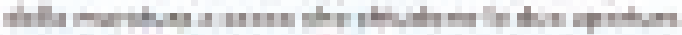

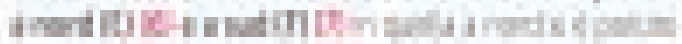

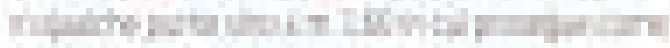

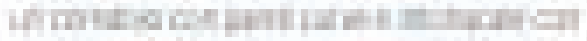

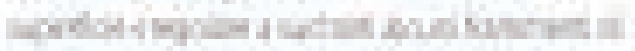

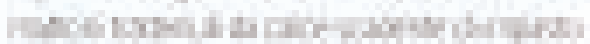

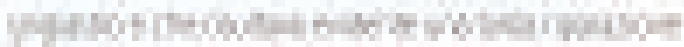

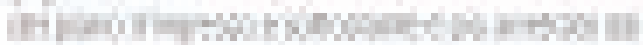

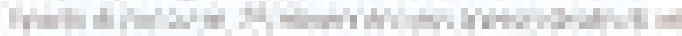

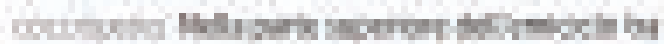

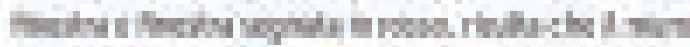

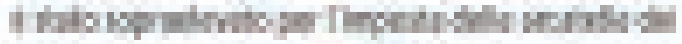

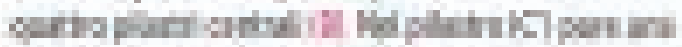

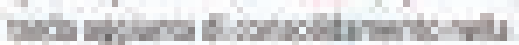

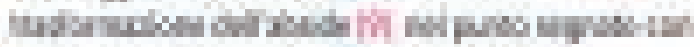

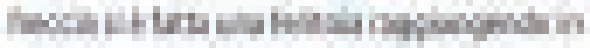

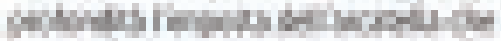

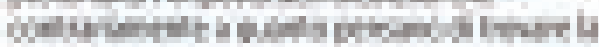

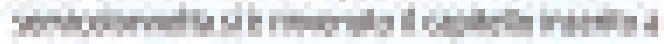

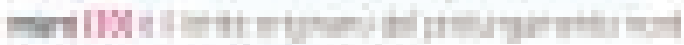

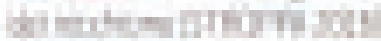

Gowathish

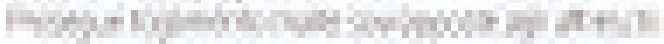

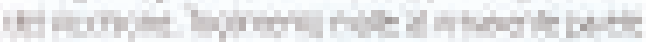

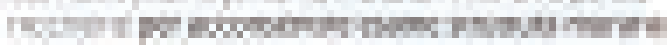

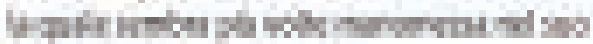

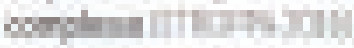

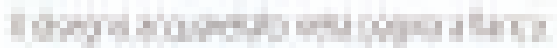

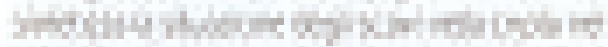

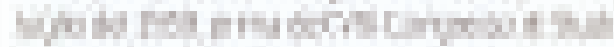

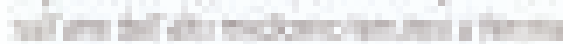

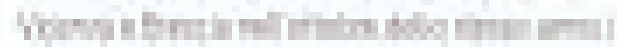

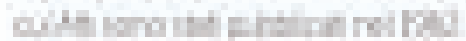

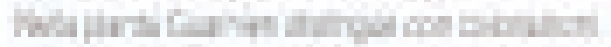

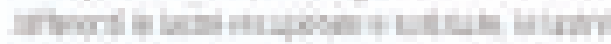

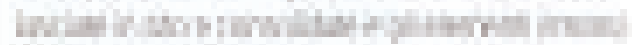

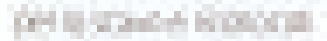

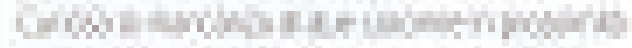

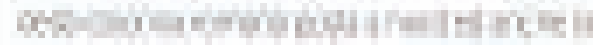

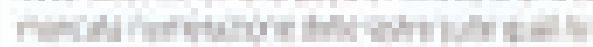

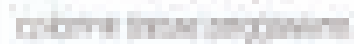

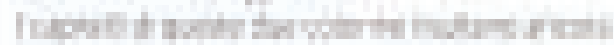

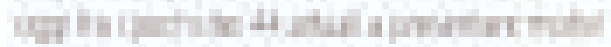

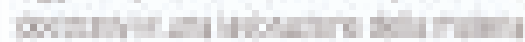

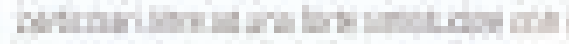

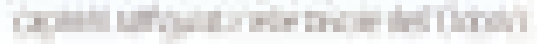




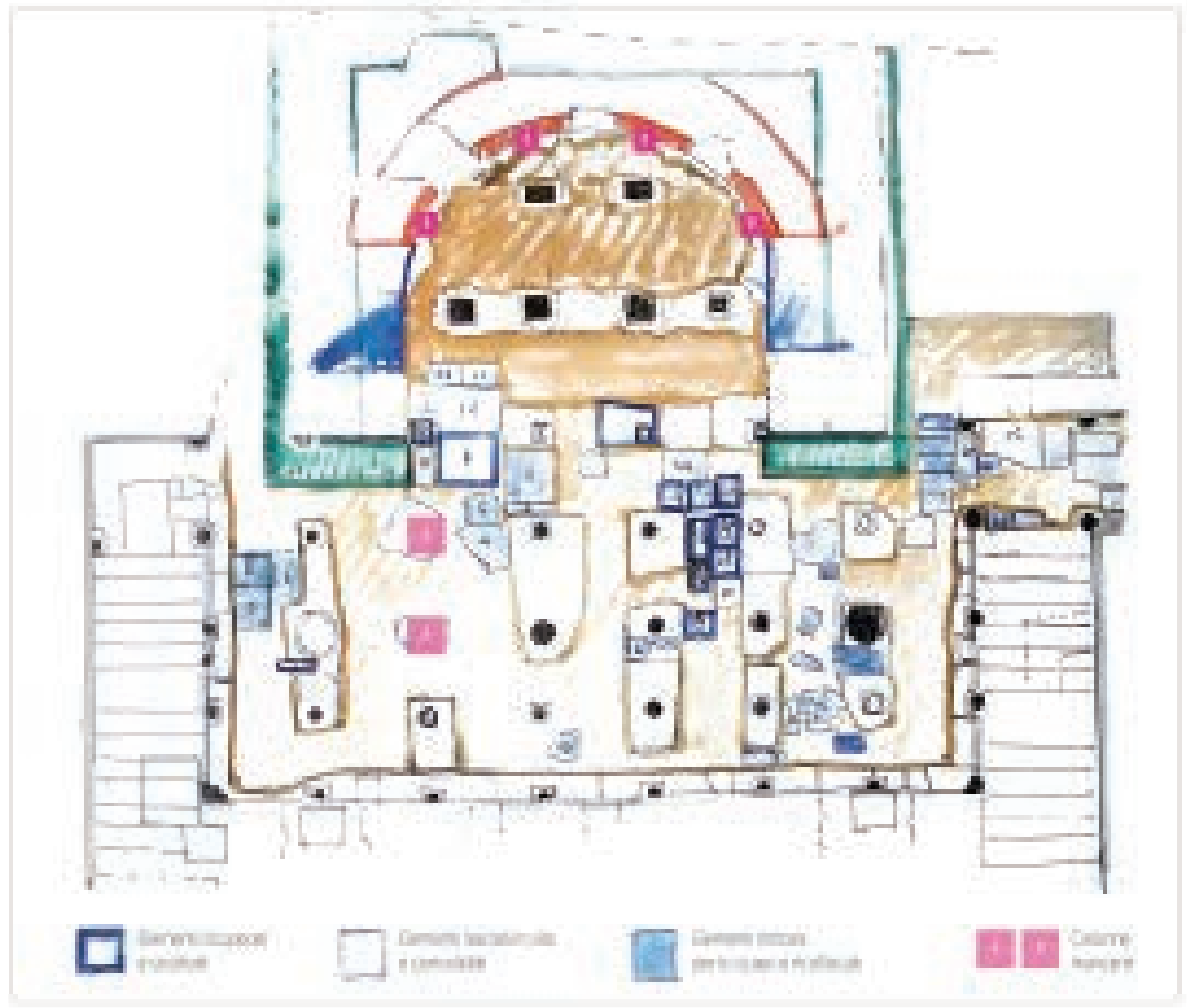

then

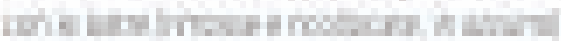

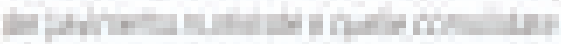

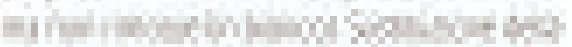

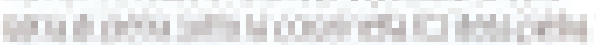

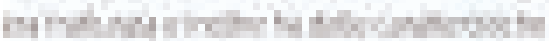

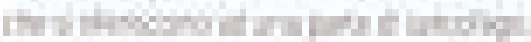

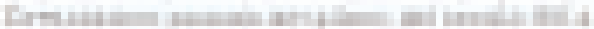

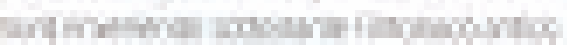

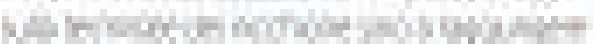

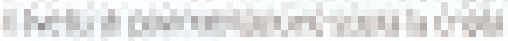
47intifll

\section{ctoril tair mi}

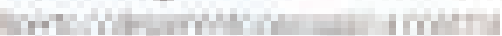

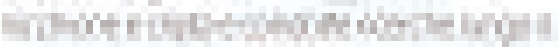

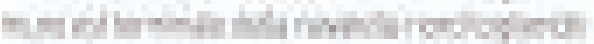

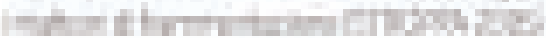

ronglatsing

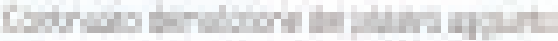

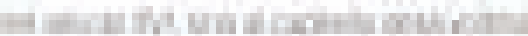

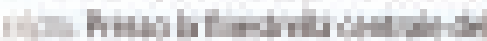

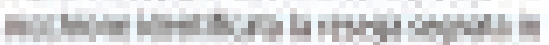

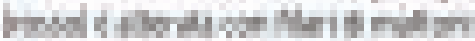

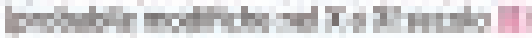

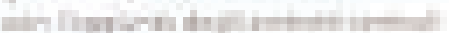
Fiph mey

\section{Dontutsim}

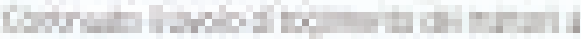

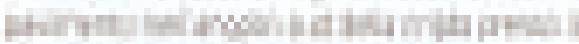

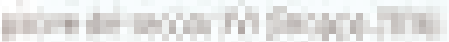

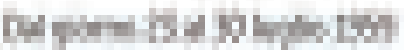

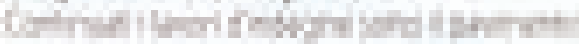

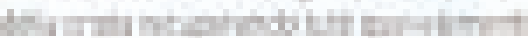

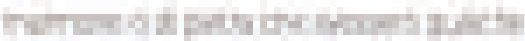

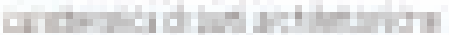

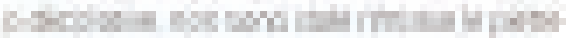

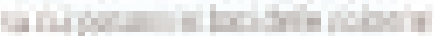

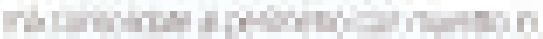

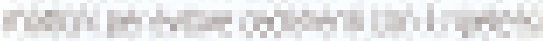

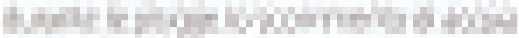

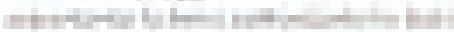

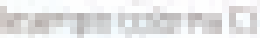

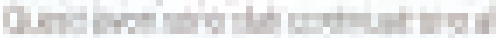

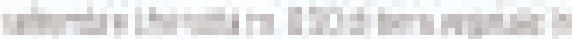

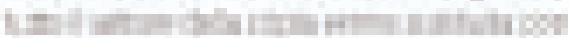

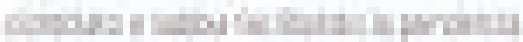

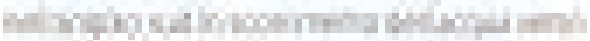

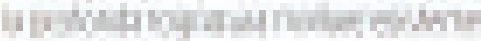

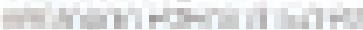

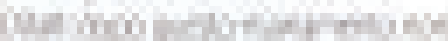

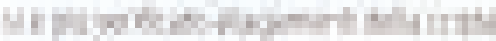
Thx meth 
Con il consenso dell'assessore alla Pubblica Istruzione all'epoca in carica, Giovanni Vezzoli, e con l'appoggio del soprintendente ai Monumenti Luigi Crema e di quello alle Antichità Mario Mirabella Roberti, il 15 gennaio 1958 ebbero inizio i primi scavi nella chiesa di San Salvatore, che diedero subito risultati superiori alle aspettative in quanto si ebbe la fortuna di ritrovare sì la prima chiesa, ma anche, sottostante, soprattutto una vasta e notevole domus romana. La direzione degli scavi fu affidata a Gaetano Panazza, storico dell'arte e direttore dei Musei con la collaborazione di un valente archeologo Ignazio Guarnieri, allievo di Nino Lamboglia, e degli architetti Giacomo Lechi e Luigi Sommaruga che misero anche a disposizione i loro rilievi.

A Brescia, il rapporto di collaborazione fra Panazza e Guarnieri testimonia l'approccio metodologico tipico di quel periodo, nel quale l'interpretazione di evidenze archeologiche era affidata alle competenze dello storico dell'arte, cui si faceva riferimento per risolvere le questioni inerenti la datazione e l'attribuzione di opere architettoniche e artistiche. Un secondo importante aspetto, che connota le ricerche di metà Novecento, è la differente importanza assegnata alle varie soglie storiche. Per molto tempo, soprattutto nel XIX secolo, era radicata la convinzione che la dignità di reperto archeologico spettasse alle testimonianze di epoca classica, greca e romana. Alla scarsa considerazione di altri periodi storici è ascrivibile la tendenza ad operare una serie di scavi incuranti delle stratificazioni.

A conferma di ciò le molteplici espressioni utilizzate da Panazza in documenti relativi agli interventi in corso in San Salvatore: "demolizione di sovrastrutture", "ricostruzione", "liberazione dall'esterno della chiesa, soffocata da brutti edifici"25. Anche Gian Pietro Brogiolo sembra avallare questa impostazione, allorquando precisa che in San Salvatore "si è deciso di valorizzare le fasi altomedievali eliminando la maggior parte degli interventi postmedievali. Scelta che ha permesso di rivedere le relazioni stratigrafiche delle fasi più antiche"26. Per una più compiuta comprensione del clima culturale che si respirava nel periodo in cui si procedette agli scavi effettuati attorno al 1960, si consideri l'ampio dibattito allora in corso sulla datazione di San Salvatore, animato da qualificati studiosi del calibro di Gian Piero Bognetti, Ermanno Arslan, Géza De Francovich, Gino Chierici e Paolo Verzone; che l'edificazione di San Salvatore risalisse all'VIII secolo o posteriormente - fra la fine del IX e l'XI secolo - dunque al periodo longobardo o a quello carolingio-ottoniano, costituiva la vexata quaestio.

Con il duplice obiettivo di dare riscontro "oggettivo" alle indicazioni presenti in uno schema planimetrico elaborato nel 1878 da Pietro Da Ponte e di rinvenire elementi per attribuire datazione certa alla chiesa e alla cripta di San Salvatore, nel 1958 iniziano in loco una serie di operazioni di scavo condotte da Guarnieri e coordinate, fino al 1960, da Panazza. Rimarchevole altresì il contributo di Lechi e Sommaruga, impegnati nell'esecuzione dei rilievi.

Secondo Novecento. Gli ultimi decenni del Novecento sono ancora caratterizzati da considerevoli interventi di scavo e restauro che influenzano il singolare processo di metamorfosi. Gian Pietro Brogiolo nel ricordare che la storia della chiesa e della cripta di San Salvatore "è il risultato non solo delle trasformazioni che hanno accompagnato dall'VIII al XVIII secolo la sua funzione di luogo di culto principale del monastero, ma anche dei profondi interventi di demolizione, scavo e restauro condotti nel 1958-1960, nel 1981, nel 1992 e ancora nel $1998^{\prime 27}$, non cita gli interventi ottocenteschi né quelli degli inizi del Novecento che costituiscono l'anello di congiunzione fra i due periodi storici cui fa cenno. Editi nel 1962, gli "Atti dell'ottavo Congresso di studi sull'arte dell'alto Medioevo", tenutosi nel 1959, danno egregiamente evidenza dei risultati cui si perviene a seguito delle operazioni di scavo condotte in San Salvatore in quegli anni e di analisi compiute nei mesi successivi al convegno fornendo risposte che per "il continuo mutare di prospettive" mettono in dubbio ipotesi formulate in precedenza dacché la scoperta di nuovi elementi di giudizio reca in sé, per definizione, la formulazione di nuove tesi e congetture, in una sorta di incertezza endemica, giacché ogni scoperta sembra aver, a volte solo limitatamente, confermato precedenti supposizioni”"28. La medesima attenzione, parzialmente dedicata agli assaggi eseguiti attorno al $1940^{29}$, andrebbe forse più compiutamente rivolta a tutte le ricerche archeologiche di cui si ha conoscenza, precedenti e successive alla soppressione napoleonica. Curiosamente pochi tasselli sembrano recare in sé una forza così impetuosa da dare consistenza alle intuizioni. Il confronto tipologico ${ }^{30} \mathrm{e}$ le evidenze archeologiche si coniugano nel tentativo di pervenire a una datazione ${ }^{31}$;

\footnotetext{
${ }_{25}$ Citazioni tratte da alcuni documenti del periodo 1957-6o, conservati in Archivio dei Civici Musei di Brescia, Museo Cristiano, cartelle 17-18.

${ }^{26}$ G.P. BROGIOLO, Archeologia e architettura delle due chiese di San Salvatore, in Dalla corte regia al monastero di San Salvatore, p. 36.

${ }^{27}$ BROGIOLO, Archeologia e architettura delle due chiese di San Salvatore, p. 35.

${ }^{28}$ G. PANAZZA, A. PERONI (a cura di), La chiesa di San Salvatore in Brescia, in Atti dell'ottavo Congresso di studi sull'arte dell'alto Medioevo, Convegno tenutosi a Verona, Vicenza e Brescia nell'ottobre 1959, Milano 1962, p. 39: "Anche gli assaggi compiuti nel 1940 con la scoperta delle arcatelle cieche su lesene che spartivano il fianco sud con il loro ritmo ripetuto, incorniciando ampie e alte finestre centinate e prive di strombature, aumentarono negli studiosi il convincimento intorno alla sua origine ravennate, da un lato, e la certezza inoltre che l'edificio era quello eretto da Desiderio".

29 PANAZZA, PERONI, La chiesa di San Salvatore in Brescia, p. 39: "Nonostante i pochi elementi visibili, era dato per certo che la chiesa a tre navate, con una sola abside e col suo impianto basilicale, mostrava nella seconda metà del secolo VIII un'evidente e chiara continuità del tipo ravennate, e si riteneva che a quella forma ancora paleocristiana si fosse apportato un lieve mutamento nell'abside (riconoscibile soltanto nella cripta) dandole la forma a ferro di cavallo, usata nell'architettura del VII-VIII secolo".

$3^{\circ}$ PANAZZA, PERONI, La chiesa di San Salvatore in Brescia, p. 36: "La cripta rivela pertanto la sua importanza architettonica, perché appartiene, benché in modo molto rudimentale, a quel tipo di oratorio che sarà poi definitivamente usato nel sec. XI, mentre non ha nulla a che fare con le cripte anulari dell'età carolingia (almeno allo stato attuale delle ricerche)".

${ }^{31}$ Ibidem, p. 32: "Riassumendo, tutti i dati offerti dallo scavo ci portano alla conclusione che lo strato più alto del riempimento dell'edificio romano sottostante risale al più tardi alla metà del VII secolo circa e che pertanto la costruzione della prima chiesa - quella cruciforme - deve essere collocata dopo questo termine; ma sarà stata costruita allora? Oppure fra il riempimento del terreno e la costruzione è passato circa un secolo, allorché nel 753 Desiderio ed Ansa fecero costruire la loro chiesa, che pertanto sarebbe quella ad aula cruciforme e non quella a tre navate, come si è sempre ritenuto? I dati acquisiti dallo scavo recente (1958-1961) ed ai relativi ritrovamenti ci porterebbero quindi a questa conclusione: la prima chiesa può essere attribuita ad un periodo posteriore alla metà del VII secolo. Ma la pianta ad aula cruciforme è particolarmente usata verso la metà del sec. VIII e intorno a quella data si può
} 
Vexata quaestio:

\section{San Salvatore I e II. Panazza e Brogiolo, ipotesi a confronto}

La nucra stagione deglistudi distona dellarte per S. Giula prese rawio dar'VIII Congresso di Studi sulliarte dellinto Medioevo, tenutos anche a Brescia nelrotrobre del 1959 C. $^{\circ}$

Spinelli in occasione del convegno internazionale S. Giulia di Brescia. Archeologid, arte, storia di un monastero tegio da Langobardia. Bartarassa; swohosi a Brescia nel 1990, sottoineo come I'ipctesi di Panazza e Perconi - indotta dagli scan coordinati da ignaso Guamicri nagli anni ' 60 - fu subito accettara e condivisa da Bognettie da tanxistudiosi inaliani e stranieri tra i quali Vallery-Rado, Meyer, Fillitz, Duwal, Rasmo, Salmi, Lorenzoni, Ragghiarti, Claussen e Belting, ma puntualizza anche che 'owviamente linterpretazione dei dasi archeologici non fu unanime e tutta una serie di argomenti di ordine stratigrafico, ancheologico e stilistico indussero invece altristudiosi quasi tutti di una generazione pù giourne |Bona, Auggiu, Zaccaria, Gioseffi, Trop, Tavano, Gaberschek, Weis, Anderson) ad attribuire ad Ansa e Desiderio la costruzione della seconda chiesa. retoodzando la prima at sec. VII: A conciusione del suo invervento relativa alla storicgratia sul monastero nelletá modema e contemporanea Spinelli ticorda il contrituto di Brogiolo 'non possiamo pero concludere questi brevissimi cenni, senza ricordare che recentissimamente Gian Pietro Brogiolo ha compiuto un nuevo esame stratigrafico dell area archeologica santagiuilaria, gungendo a conclusioniassai vicine a quele dela seconda serie distudiosi. Losservarione fondamentale del Brogiolo è. che le tre absidi del primitivo edificia non coinciderano affatto con quelle del seconda, ma erano ubicate sé matri pü a ovest. Cib́ implica che la prima chiesa non aveva augmenta anomali, come tutti credevano, ma un vero transetto a due

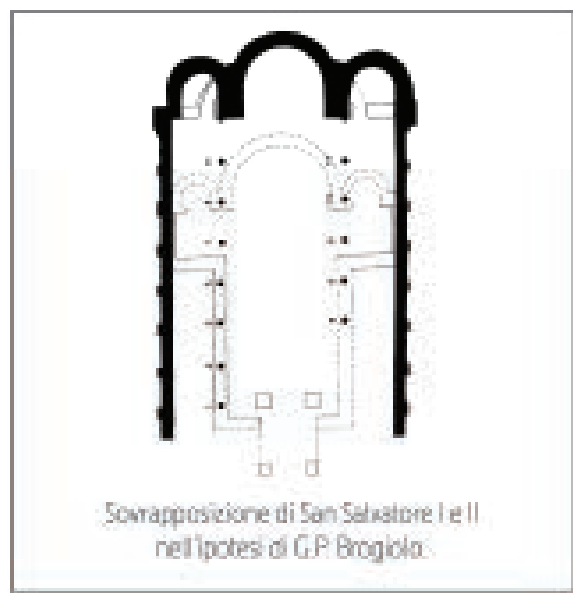

cappelle spornenti, come in tanta architectura dal $X$ al $X$ il secolo. Tale edificio inoltre non era per nulla docato dicripta. che tu invece aggiunta in una terza fase al secondo edifico, quando questo ebbe anche tre ruove absidi al posto dell 'unica abside centrale"

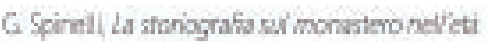

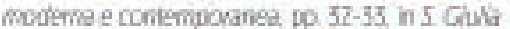
df brescla Archeologh arte stona di in monastero

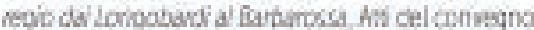
incemseionale. Buescia 4.5 mapjio 1990, Brexcia 1992
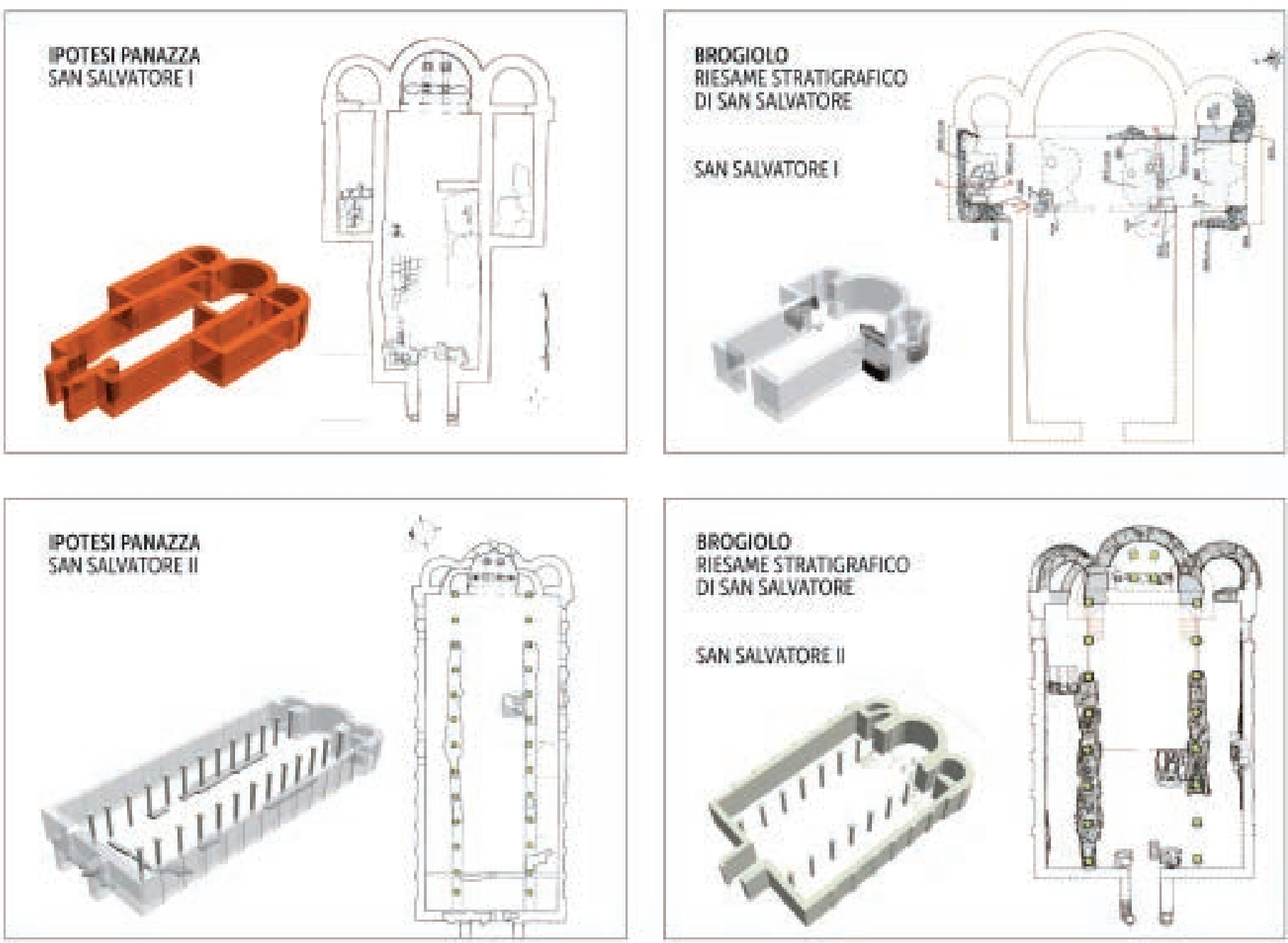
decisivo al riguardo sembra essere l'attento esame della cripta $^{32}$, che, nondimeno, si rivela un singolare mistero. Non è forse lecito supporre che quel mutamento di forma, quel semicerchio che nel tempo sembra flettersi in guisa di ferro di cavallo ${ }^{33}$, quella selva esorbitante di colonnine, giacché solo otto recano capitelli d'indubitabile valore e in numero notevolmente ridotto appaiono nei rilievi grafici rinvenuti in diverse epoche, lasci intendere che per null'affatto ci si trovi dinnanzi ad una struttura romanica perché, forse, di epoca successiva?

Gli inizi del XXI secolo. Prende forma nel secondo decennio del XXI secolo l'ultimo tassello della lunghissima stagione di studi, un autentico omaggio a San Salvatore, compendio di una encomiabile ricerca curata da Gian Pietro Brogiolo. Imprescindibile il vastissimo ed ultratrentennale contributo dello studioso che continua e perfeziona l'opera di Panazza, sviluppando - coadiuvato da una serie di collaboratori, tra cui Vincenzo Gheroldi e Monica Ibsen - un modello interpretativo differente. Il riesame degli strati susseguentisi in profondità e la rappresentazione grafica degli stessi cui giunge attraverso idonei sondaggi e tecniche di indagine degli alzati, consentono a Brogiolo di effettuare, già nel 1989, una rilettura stratigrafica, seppur parziale, dei due edifici (San Salvatore I e San Salvatore II), emendando le piante delle due chiese precedentemente congetturate da Panazza e ipotizzando come successivo l'inserimento della cripta e delle absidi.

La ripresa delle ricerche archeologiche nell'area monastica, avviate nel decennio 1989-1998 in vista della ristrutturazione di tutto l'ambito museale, interessarono chiaramente anche la chiesa di San Salvatore. Dalla seconda metà degli anni '9o, attraverso l'analisi delle stratificazioni in alzato e il riesame delle decorazione e delle iscrizioni, Brogiolo si propone di dare risposta ad alcune questioni irrisolte concernenti, tra le altre, la valenza temporale della posteriorità stratigrafica dello spazio ipogeo e la datazione delle diverse fasi costruttive della cripta ${ }^{34}$. L'autorevolezza intellettuale di Brogiolo si evidenzia anche nell'ultima ricchissima opera che, pur compendiando anni di studi rigorosi e di dedizione mirabile, lascia aperte alcune questioni a nuovi approfondimenti e formulazioni interpretative.

In primis, dal punto di vista stratigrafico, il problema della datazione delle cripta, non è ancora risolto ${ }^{35}$. La soluzione planimetrica e i particolari costruttivi, a detta di Brogiolo, non rivelano peculiarità riscontrabili in altre cripte coeve.
Curioso il fatto che anche il confronto con altre chiese parimenti commissionate da Desiderio, non lasci intravedere analogie. In secundis, riguardo alcune discontinuità stratigrafiche, Brogiolo evidenzia due anomalie: la prima concernente il posizionamento delle aperture ${ }^{36}$, la seconda riguardante un rientro della muratura rinvenibile nello spazio esistente tra le due porta finestre.

Le discontinuità stratigrafiche inducono Brogiolo a ipotizzare un ripensamento nel posizionamento delle porta finestre, pervenendo a congetturare che il progetto potesse averne previsto la collocazione ad una quota inferiore, e che, solo in corso d'opera, si fosse resa necessaria la loro differente disposizione ad un livello superiore. Certo muovendo da altre premesse, si potrebbe giungere ad una conclusione diversa, non meno folgorante. Perché non ipotizzare che le porta finestre fossero, invece, inizialmente poste in opera ad un livello più alto, per poi essere abbassate nel corso di un intervento - verosimilmente ottocentesco - di ridefinizione dell'aula adiacente alla cripta?

La seconda anomalia attiene alla risega orizzontale compresa tra le due porta finestre, già rilevata da Ignazio Guarnieri. Si scorge, al di sopra della risega, una variazione negli elementi costruttivi: la pietra, che caratterizza la parte inferiore del muro, fino alla risega, lascia verso l'alto il posto ai laterizi. Muro in laterizi che Guarnieri lascia intendere sia del X o XI secolo; una tesi assai opinabile, giacché sembra assai più probabile sia ascrivibile alla serie di interventi che Canovetti progetta ed attua dal 190o. L'esistenza della risega induce invece Brogiolo ad una duplice ipotesi: essa potrebbe interpretarsi come piano d'imposta di una copertura voltata mai realizzata (anche se, a onor del vero, in alcuni disegni del XVI secolo la cripta è rappresentata proprio con copertura voltata), oppure come appoggio delle arcatelle con andamento est-ovest, attualmente esistenti e realizzate nella seconda metà dell'Ottocento, come attesta una relazione tecnica di Canovetti.

Venendo poi al sistema di copertura della cripta, Brogiolo rileva come ora sia "costituito da due serie di tre arcatelle in muratura orientate, est-ovest innestate a est nella muratura e al centro su quattro pilastri in mattoni che nel XVI secolo hanno sostituito i supporti originari". E, per pervenire ad una datazione dei pilasti, si affida all'esame di un frammento di legno recuperato nell'interfaccia, giungendo alla conclusione che i pilastri risalgono al XVI secolo. Non v'è dubbio che l'analisi radiocarbonica abbia dato tale esito; incontrovertibilmente il frammento ligneo risale al XVI secolo; meno

raggruppare un notevole gruppo di sculture provenienti dal monastero (anzi, il gruppo di sculture più raffinate) oggi nel Museo. Inoltre è strano, qualora la chiesa sia anteriore al 754, che non sia rimasta alcuna traccia del suo titolo, salvo forse l'epigrafe liutprandea, di cui diremo più avanti, che è tuttavia di pochi decenni prima".

${ }^{32} \mathrm{Ibidem}$, p. 32: "Una decisiva risposta a questi interrogativi ci viene dall'esame accurato della parte antica della cripta, quella cioè nel vano dell'abside centrale ed ancor oggi esistente".

33 Ibidem, pp. 32-34: "Originariamente la parete perimetrale ricurva a ferro di cavallo piuttosto accentuato era soltanto a semicerchio di poco sorpassato; era chiusa verso ovest (non sappiamo però se solo parzialmente o per intero) da una parete che poi fu demolita quando si costruì la parte romanica della cripta, salvo che nei punti di congiunzione col semicerchio, dando così origine alla forma a ferro di cavallo".

${ }^{34}$ BROGIOLO, Dalla corte regia al monastero di San Salvatore, p. 65: "Dal punto di vista stratigrafico, il problema di quando sia stata costruita la cripta (se attraverso ripensamenti in corso d'opera o dopo una parziale demolizione di un edificio in fase di costruzione) non è risolto. In ogni caso è da sottolineare la peculiarità costruttiva della cripta e degli archi di collegamento tra absidi laterali e muro di testata e la planimetria, che non hanno confronti nelle cripte coeve a corridoio occidentale, comprese quelle di San Salvatore di Sirmione e di San Salvatore di Pavia, costruite sempre da Desiderio e dalla moglie Ansa". 35 BROGIOLO, Dalla corte regia al monastero di San Salvatore, p. 66: "due linee verticali di discontinuità nel paramento murario, a ovest delle due porte finestra, sono forse dovute, come si è detto, ad un ripensamento nel posizionamento delle aperture: progettate ad una quota inferiore, in corso d'opera, sarebbero state poi rialzate nella posizione attuale".

${ }^{36}$ BROGIOLO, Dalla corte regia al monastero di San Salvatore, p. 82. 


\section{Contaminazioni stilistiche}

Tre captiellivalgono uríaterzione particolare Il primo |fig 1) é posto alla sommita di una delle colorne che ritmano, oggi lo spario della cripta Forse non in passato giacché ossewando il riliero elaborato da Guarrieri nel 1958 si puỏ notare che, proprio in quella precisa area dello spario ipcoeo, non compariva alcuna colonna Incuriosiscono ancor piùi lasi del captelo tre sono definiti da semplici motivi gecmetrici e floreal, identicamerte rimenibli in un disegno d Ferdinand de Dartein, mentre uno è connotato da spparato scultoreo, un angelo, singolarmerte indistingutbile da un disegno of Federico Odorici II secondo capitello (fig. 2) - sovrastante una colorra cra custodta nel museo d Sarta Gulia ma precedentemerte posta nela cripta - è
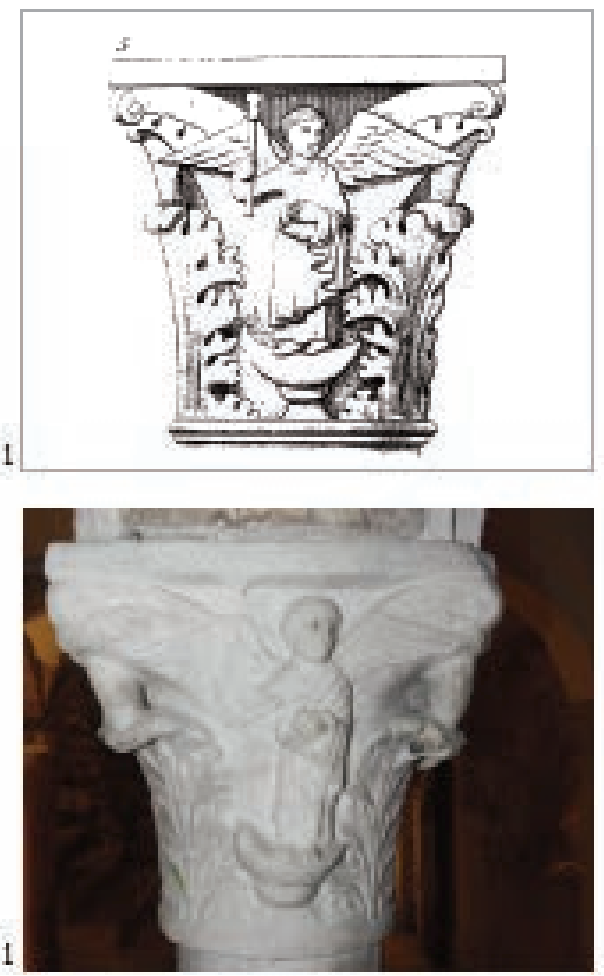

2

riccamente istoriato nei quattro lat, ciascouno del quai cspita una scena difterente: San Michele che trafigge ildrago, un Guerriero che lotta con il leone, un uccelino che becca la lota di Giaccobe con [angela. Un capitello compiuto e particolareggiato in cgri suo lata, ove si fonde una narrazione che è indubbiamerte coerente con una darzione romarica o mediazale Quel che sorprende maggiormente e che solo un bto del capitello, quelloche effigia la botta di Giacobbe con Iangela, richiami in un modo curioso un disegno di Federico Odorici Mentre nel disegno di Odorici è presente quello che potremmo definire un abbozzodela scera, i. capitello riprende identicamente il frammento scenice compleandola.

Se Odorici wessevoluto semplicemente rilerare un capitello esistente, perché mai arebbe prodotto solo uno sctizzo, un tassello non finito del captello istoriato? E, per contro possibile che ci si ga ispirati proprio al disegno d Odorici per portare a compinento il manufatto?
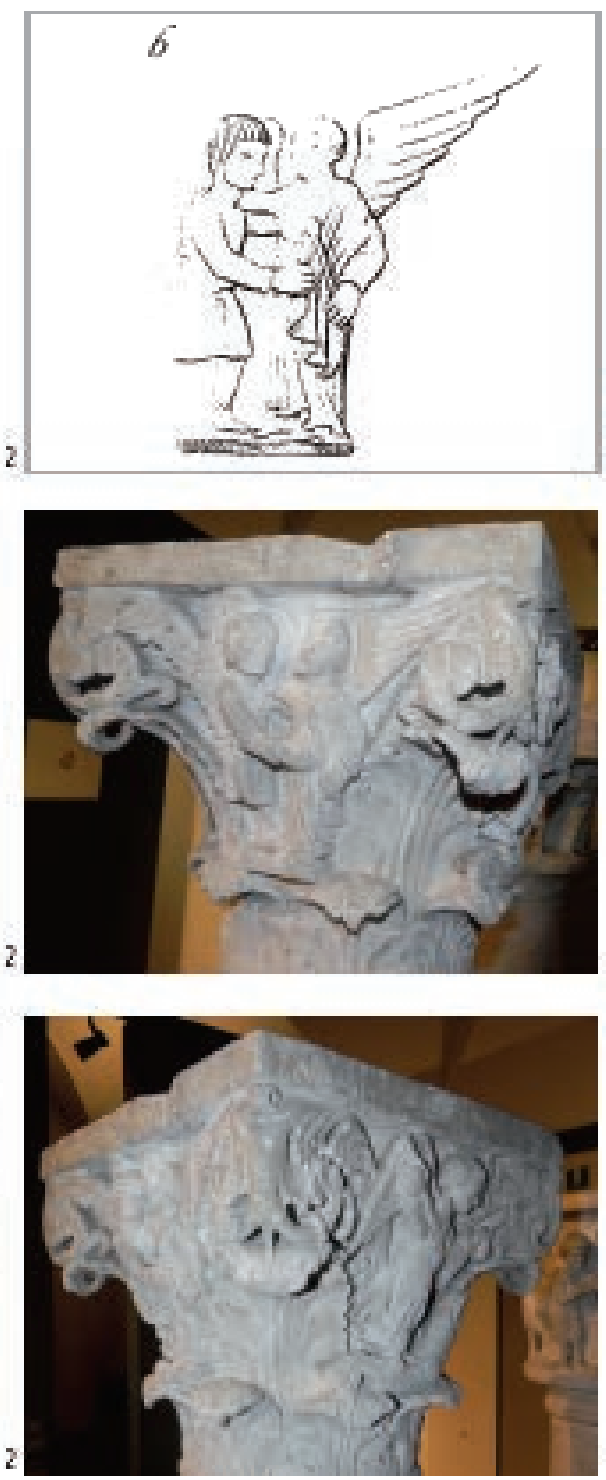

Colorrina con capidlo, pietra calcarea dals cipta dí San Stuatore Figuraioni ddfiscangdo Nichele the vcorfigge ildernorin, delfarcangdo Rsfisele con Totidn di Sareore in atio di uccoidere ileone, di unuccelo dhe beccaun fore
La singolarì̀ del tezo capitello (fig. 3) i irvela nela disomogeneta del livello di lavorazione della materia. Tre lati del capitelo ospitsno una decorazione piuttosto sempice, quasi aboom ata. - che riprende un motivo rirwenible in molti capiteli della cripta - costitutito da tre foglie lisce, due volute, un ficre centrale

DHferente il quarto bto del capitella ove appare finemente scolpito un cacciabore con a spada che lotta contro un leone Non pare inusitato che in epoca medierale un bo dol capitello potesse eviderziare un Wello di bvorazione cosl differente rispetto altri tre bs $b$ ? Uri incoererza che, $p s$ contro, apparirebbe meno bizarra se il captelo fosse rifertile ad altri periodi storici

Le colorne e i capiteli tunono axportat dalla cripta d San Salwatcrenel 1828 quando gi edfici del monastero erano desinatiad uso militare, e portat al Yuseo Patria, alora in tase di costibrione Nel 1882 pevennero al Yuseo delleti cristiana.
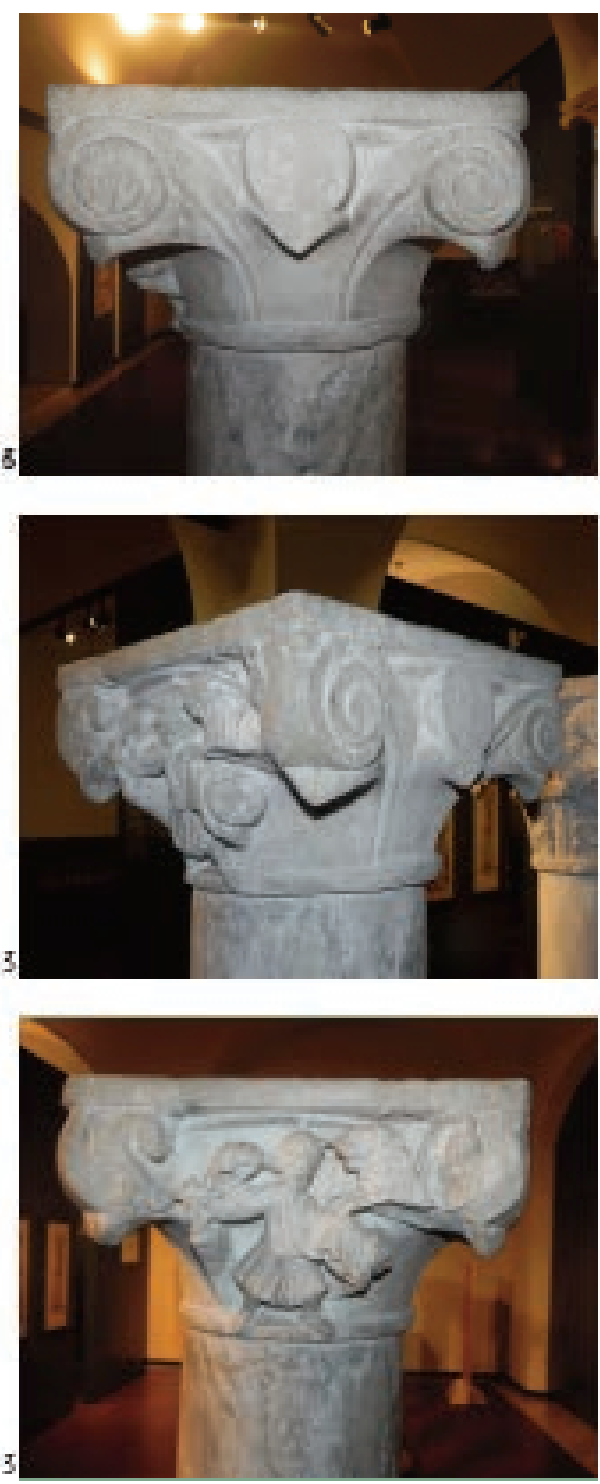

Colonira con capìela, marmo diVerza dogló e marmo cipolino dals cripto d San Sstustore Sul capitello, decorato con grosse fodie evoluts, e scolpitauno figura machile sassitia da un leone 
certo è che lo siano anche i pilastri che, sempre in ossequio alla documentazione di Canovetti, sarebbero, invece, ottocenteschi. Vi sarebbe peraltro un'ulteriore questione che appare enigmatica. Per realizzare la cripta, sarebbero state tagliate le fondazioni dei due colonnati: "Le due colonne più prossime al presbiterio, rimosse durante queste operazioni, sono state appoggiate su nuovi supporti costituiti da grosse colonne romane. Un dato forse non casuale è che tutte e quattro le colonne in corrispondenza dell'ampliamento romanico, caratterizzate da scanalature sottili e da una finitura a martellina, sono le sole medievali"37.

Invero Brogiolo suggerisce che potrebbe considerarsi, come ulteriore ipotesi di datazione (ancorché non provata), l'epoca romanica; mentre Ibsen conferma l'ipotesi prevalente, ossia che tali colonne siano coeve alla costruzione di San Salvatore II, dunque dell'VIII secolo. In questo dedalo di datazioni, è davvero impossibile districarsi.

Venendo poi alla questione dei collegamenti alla cripta, Brogiolo nel descrivere la nuova aula collegata all'abside della cripta medesima, mette in luce una interessante asimmetria: "La nuova aula è collegata alla cripta altomedioevale da un ampio varco nel muro di testata, mentre i cunicoli di accesso sono stati sostituiti da due scale che salgono direttamente nelle navate. Quella meridionale è ad una rampa, addossata alla parete della chiesa. Quella settentrionale, a metà della salita, si raccorda a 90 gradi ad una scaletta in pietra che porta nella navata centrale. Non è chiaro, sulla base di quanto si può ora osservare, se le due uscite siano contemporanee o meno. Nel caso lo fossero, si potrebbe ipotizzare che la seconda, diretta alla navata centrale, fosse riservata al clero" ${ }^{38}$.

Con esemplare lealtà Brogiolo riconosce che, a dispetto delle severe indagini, non si può ad oggi datare con certezza la costruzione delle rampe di scale. Ipotizza, invero, che un collegamento possa essere stato presumibilmente riservato al clero (senza però darne plausibile motivazione). Altrettanto efficace potrebbe peraltro rivelarsi l'idea che il collegamento possa risalire ad altra epoca e fosse preordinato all'esercizio di altre funzioni: ad esempio rendere raggiungibile un magazzino o meglio fruibile un percorso museale.

Certamente anche l'ampliamento della cripta, non è di facile lettura. Brogiolo indica come Maria Luisa Gatti Perer - su cui è tornata con più precisione Francesca Stroppa -, in base alla datazione di otto capitelli ivi presenti, collochi l'ampliamento tra gli inizi e la metà del XII secolo. E se irrefutabile appare la datazione dei capitelli, meno sicura è la determinazione, per inferenza, del luogo che li ospitava. Ma quei capitelli provenivano davvero dalla cripta? E poi: erano nella cripta che si presenta oggi ai nostri occhi, quella punteggiata da 44 colonne? o forse in un'altra cripta, simile a quella effigiata nei disegni del XVI secolo ${ }^{39}$, in cui compaiono solo dieci colonne? Forse, tenendo in debita considerazioni le descrizioni, risalenti al 1657, della badessa del monastero e prima storiografa Angelica Baitelli, quelle successive di

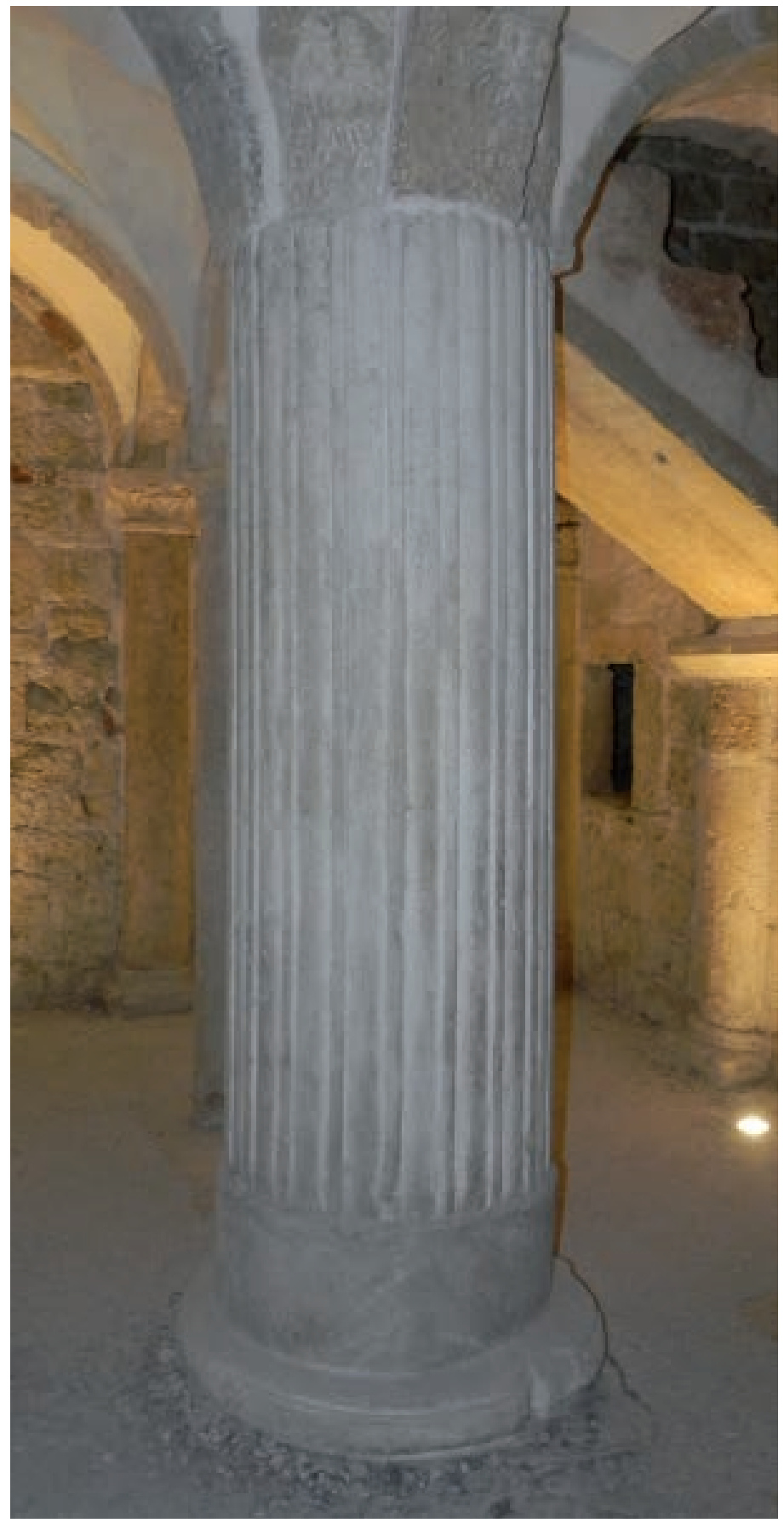

Chiesa di San Salvatore in Brescia, aula della cripta, particolare di un fusto di colonna scanalata e rudentata. Nella parte superiore del fusto si nota come siano state scalpellate le scanalature per ricavare l'appoggio delle arcatelle delle voltine di copertura dell'oratorio.

Gianandrea Astezati e la documentazione di cui disponiamo, per la quale tributiamo plauso agli studiosi, è lecito ipotizzare che l'oratorio sia stato oggetto di due ridefinizioni: una planimetrica, collocabile alla fine del XVI secolo, cui ha fatto seguito quella ottocentesca, ove si è proceduto alla sostituzione dei capitelli e al ridisegno dei collegamenti.

\footnotetext{
37 Ibidem, p. 82.

${ }^{38}$ Ibidem, p. 82.

39 R. BOSCHI, G. PANAZZA, Il recente ritrovamento di alcuni disegni del monastero di Santa Giulia in Brescia, in Atti delle «Prime Giornate di studio» sulla storia della Abazia di Rodengo, Rodengo 1980, pp. 121-125.
} 


\section{La chiesa e la cripta}

di S. Salvatore:

\section{interventi di scavo}

e di sostituzioni delle colonne

te due colonne piú prossime al presbiterio. rimosse durante queste operazioni, sono state appoggate su nuovi support costituat da grosse colonne romane Un dato torse non casjale eche tutte e quattro le colonne in corrispondenza dell'ampiamento fomanico, caratterizzate da scarialature sottilie da una finifura a motellina, sono le sole medievalli

Dalla corte regis a monastro si San Salvalove - Saxta Giuls dit ânescia, a cuesa di C.P. Erogiola con F. Marandin. Ueniona 2nse

La sezione longitudinale dela chiesa of $5 a n$ Salvatcoce conserte di viouliozare e of immaginare la complessta dell intervento, dal punto di vista satico-strutturaie dowuta alla creazone del ruowo spazo ipogeo (tavia) antotarke alla cripla. Analizzando la navara centrale emerge chiaramente la diversitd dele quatto colonne $[1,2,3,4)$ in prossimuta del presbizerio, che Brogiola definicce medicwali. dele quali due (1, 2) sostenute da grossi fusti scanalati e ndentati di colonne romane (A. 이 modificate nella parte superiore per sostenere anche le arcatelle delle votine a crociera deltaula della cripta si puo notare anche la quota isferiore del linello della cripta e delliaula fissetio a quelo delledficio romano corne osservato da Panazza "Fer la costruzione dele sette navatelle a coociera si scavó ad un limello piú basso ancora dela quota del pavimento deledifioo preesistente romano in modo che venne distrutto ognielemento sia del abitazione romarla sia della chiesa piu. antica come hanno rivelato le nostre ricerche" IPANAZZA, PERONI, La chiesa di San Sakvatore in Brescia, p. 58). E ancora Panazza a proposito dei roochi di colonne romane osserva. "Sotto le woltine romaniche si nota l'antico intonaco sul tratt rimasti del muro piis antico col quale si chiudera ad orente la cripta e su cui și impostavano al di sopra, gli archi trionfal delie tre absidici due grossi nocchi di colonne scanaiate e rudentate collocati esattarrente sottola prima coopia do colonne verso il prestinerio delle navate supeniori fanno pensare a cuesto alto aribiente della cripta pia antica" (toiden, p. 58)

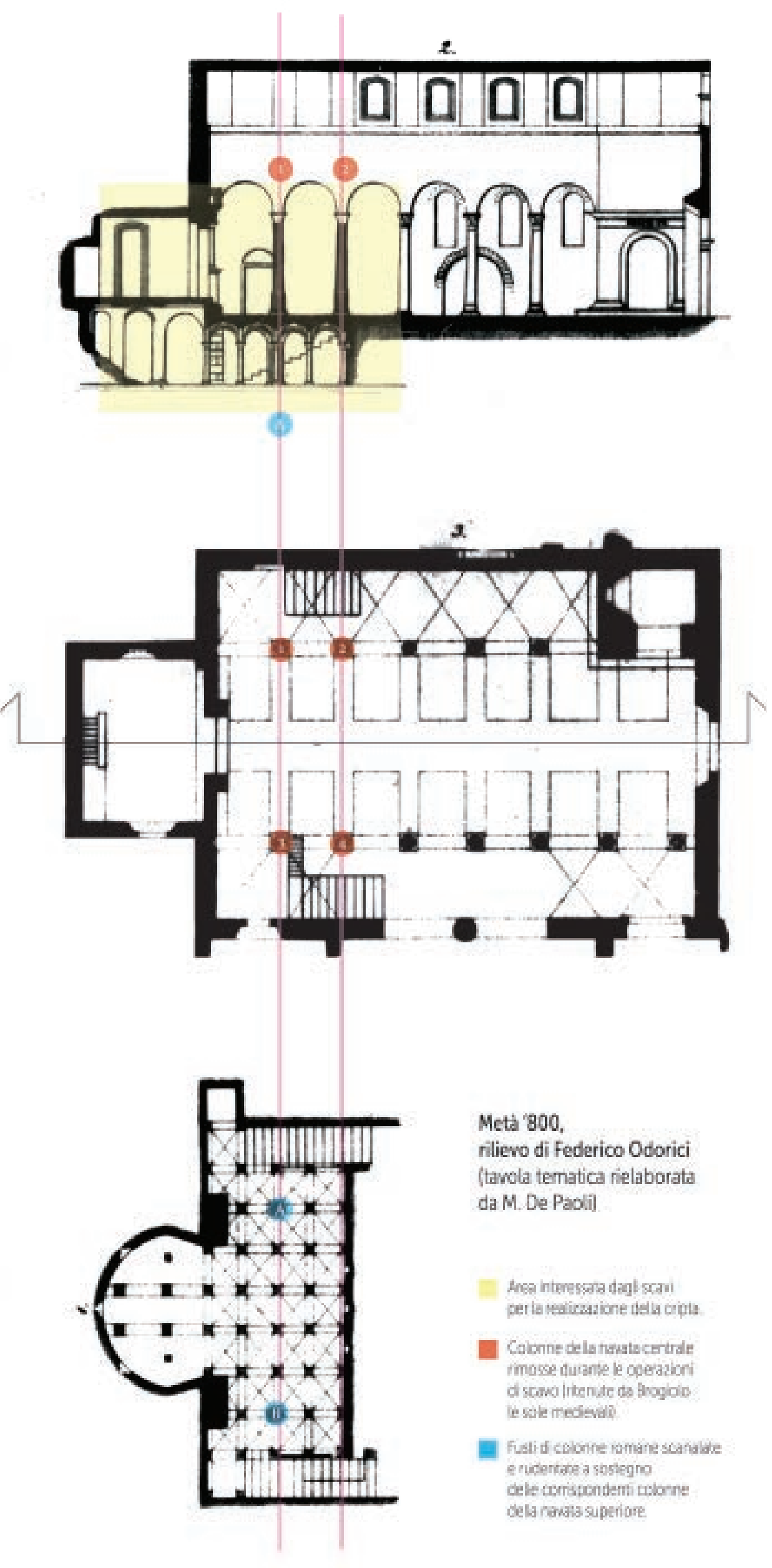

M. De Paoli: Strutture architettoniche... 157 


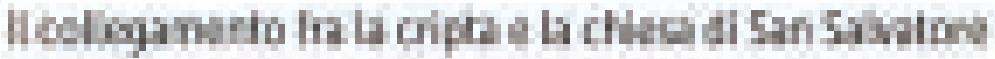

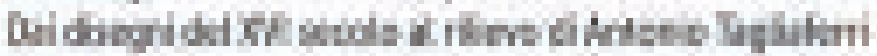

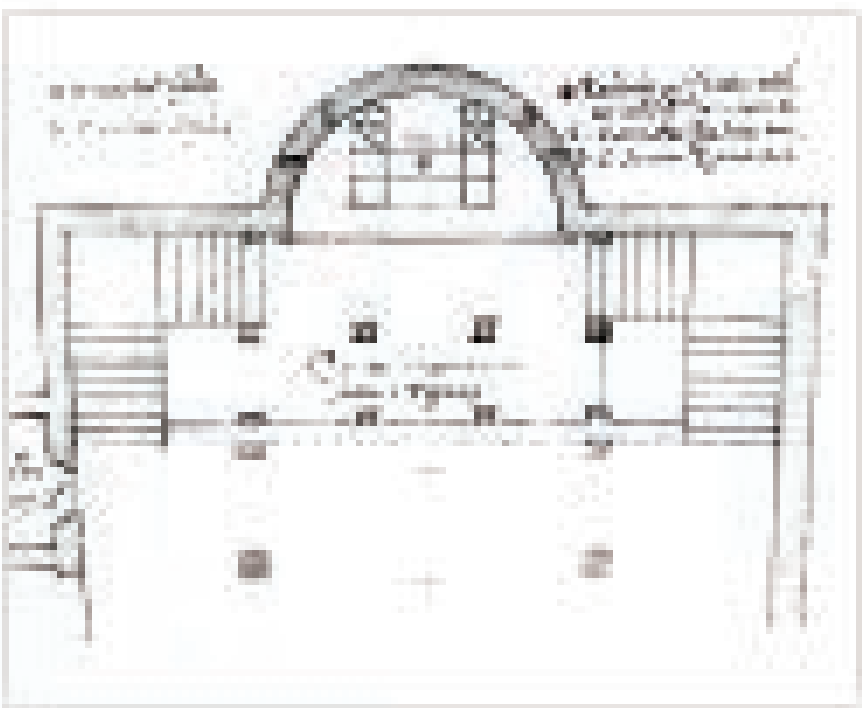

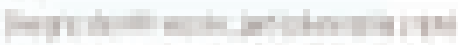

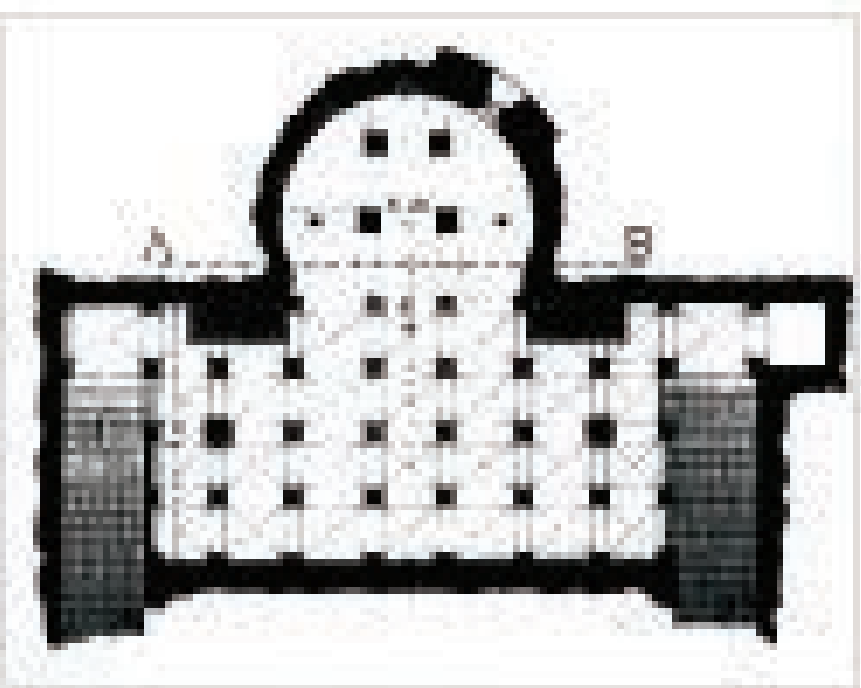

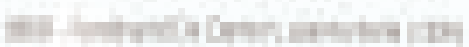

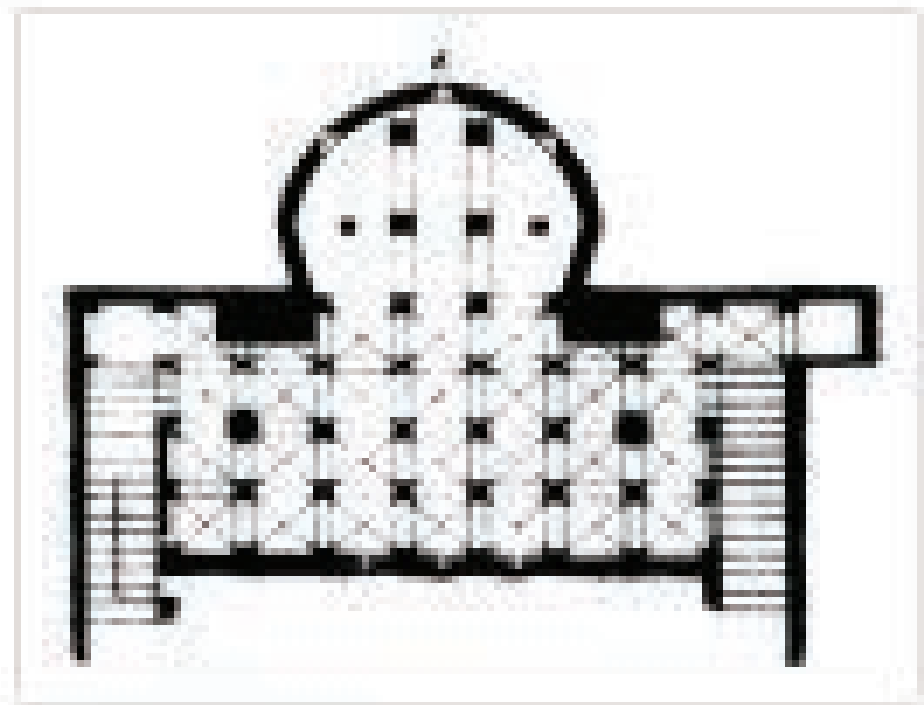

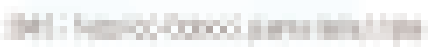

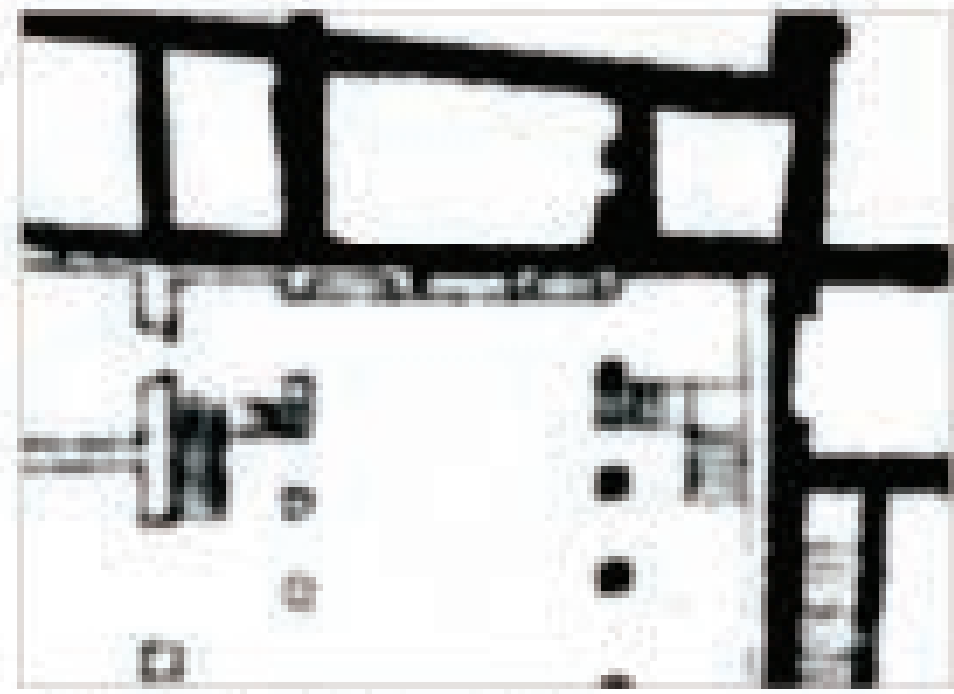

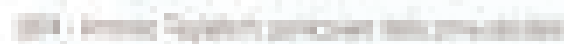

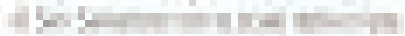

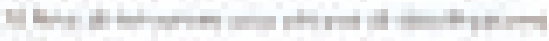

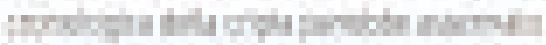

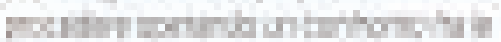

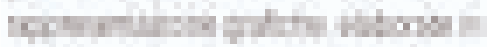

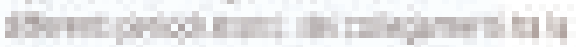

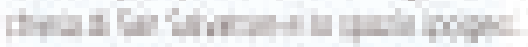

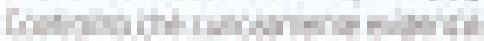

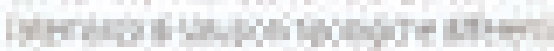

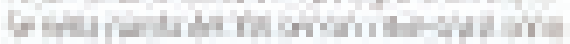

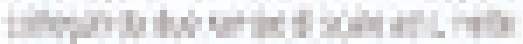

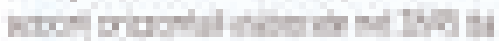

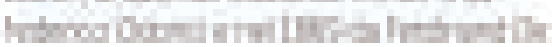

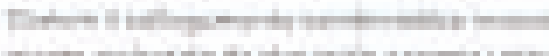

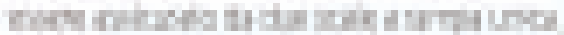

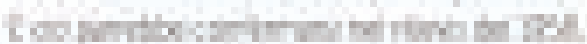

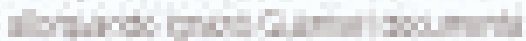
r."

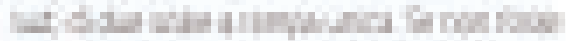

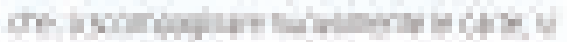

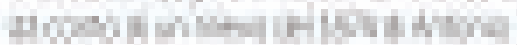

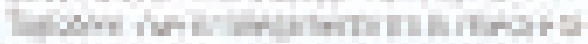

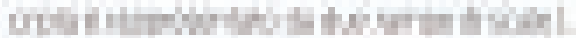

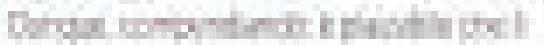

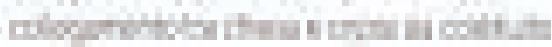

unditum in

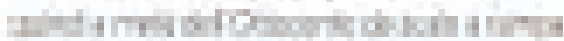

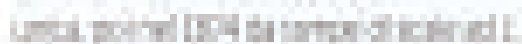

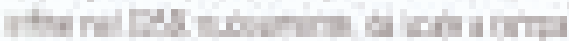

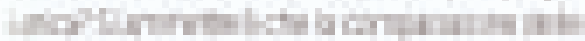

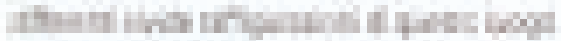

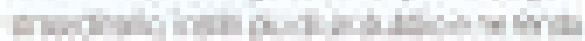

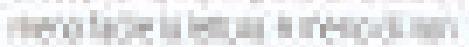

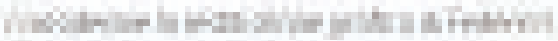

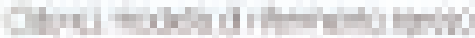

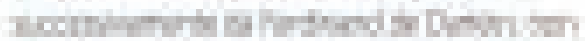

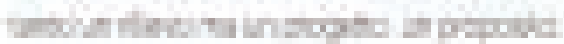



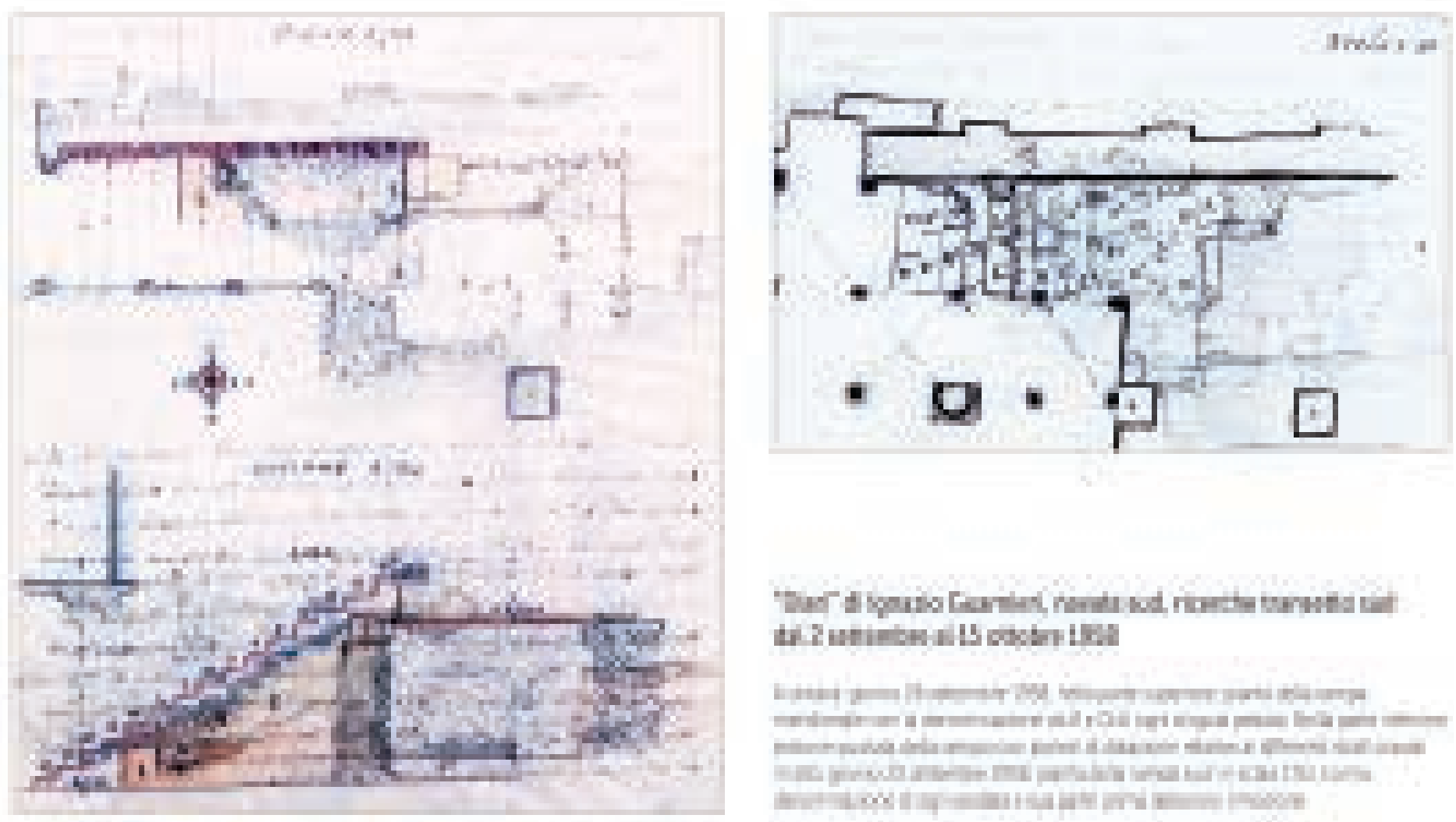

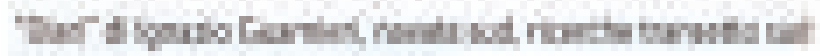
Homithulsoth
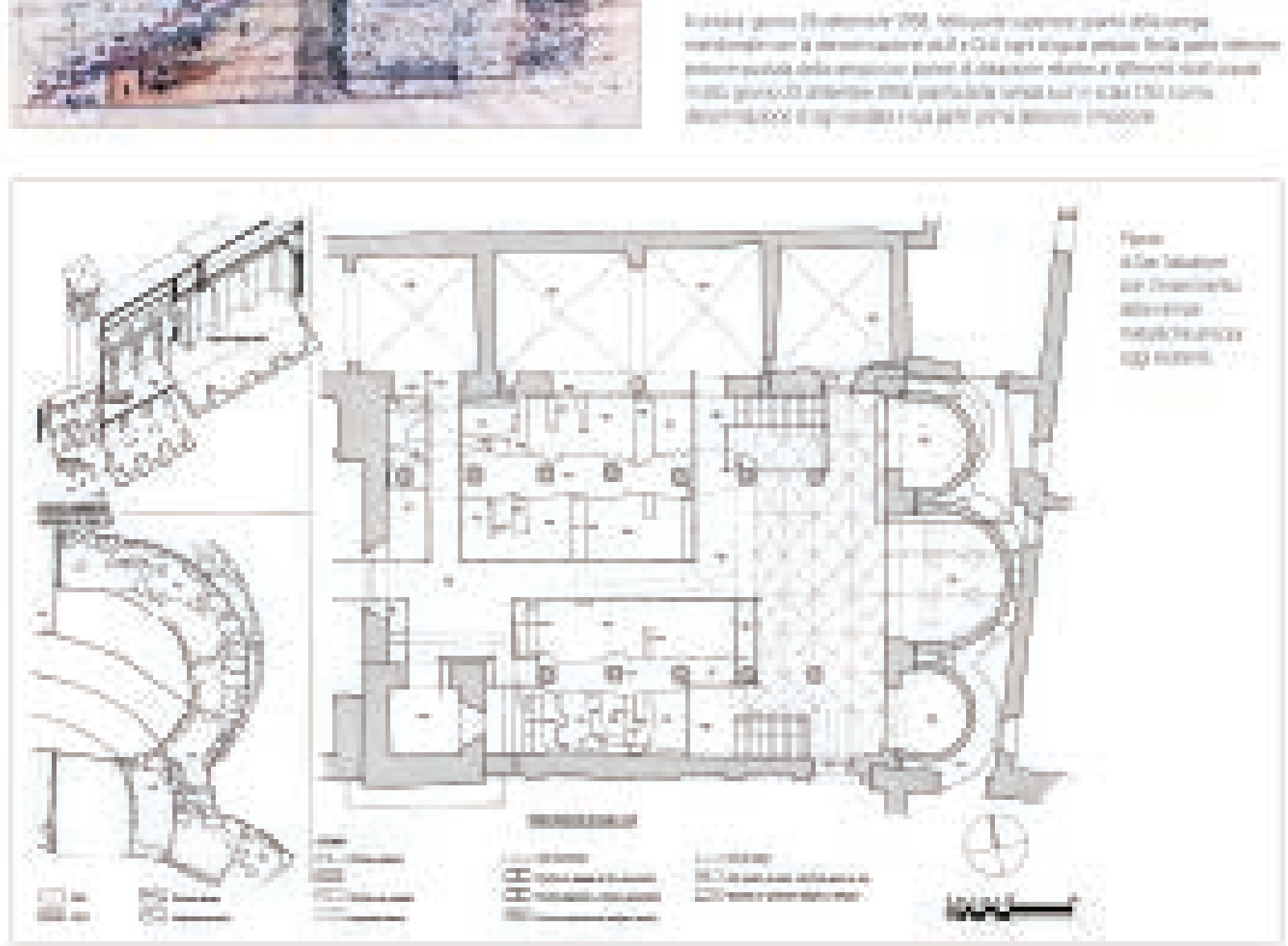
I I
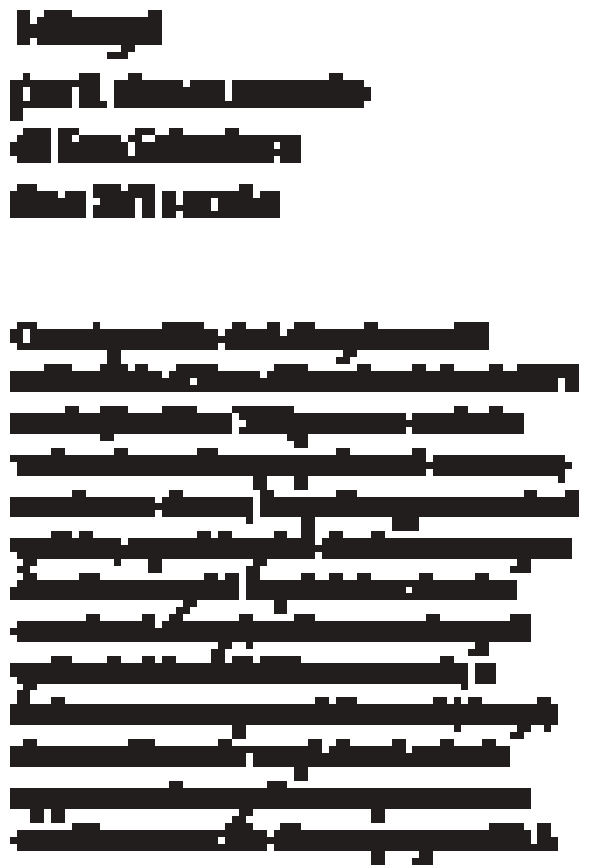
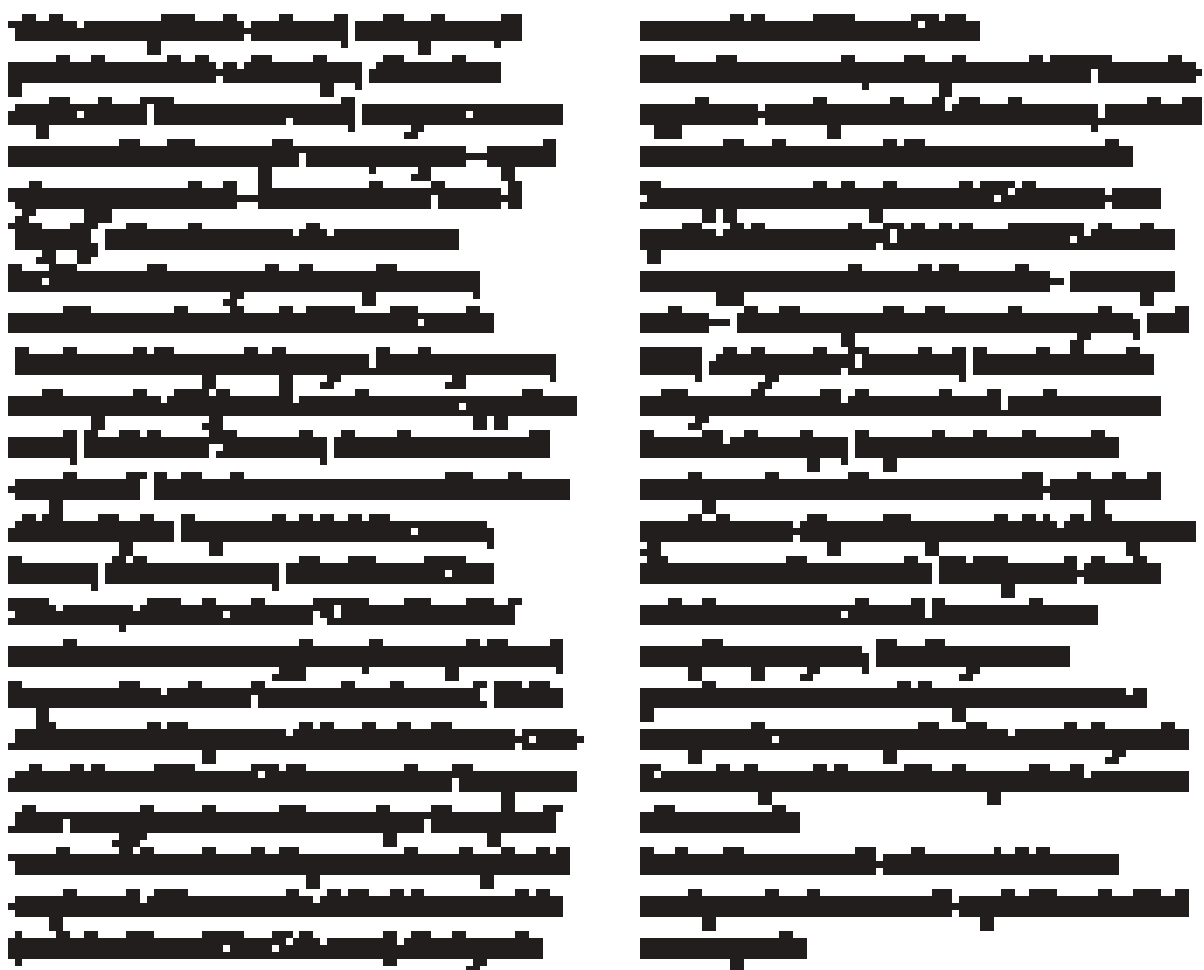
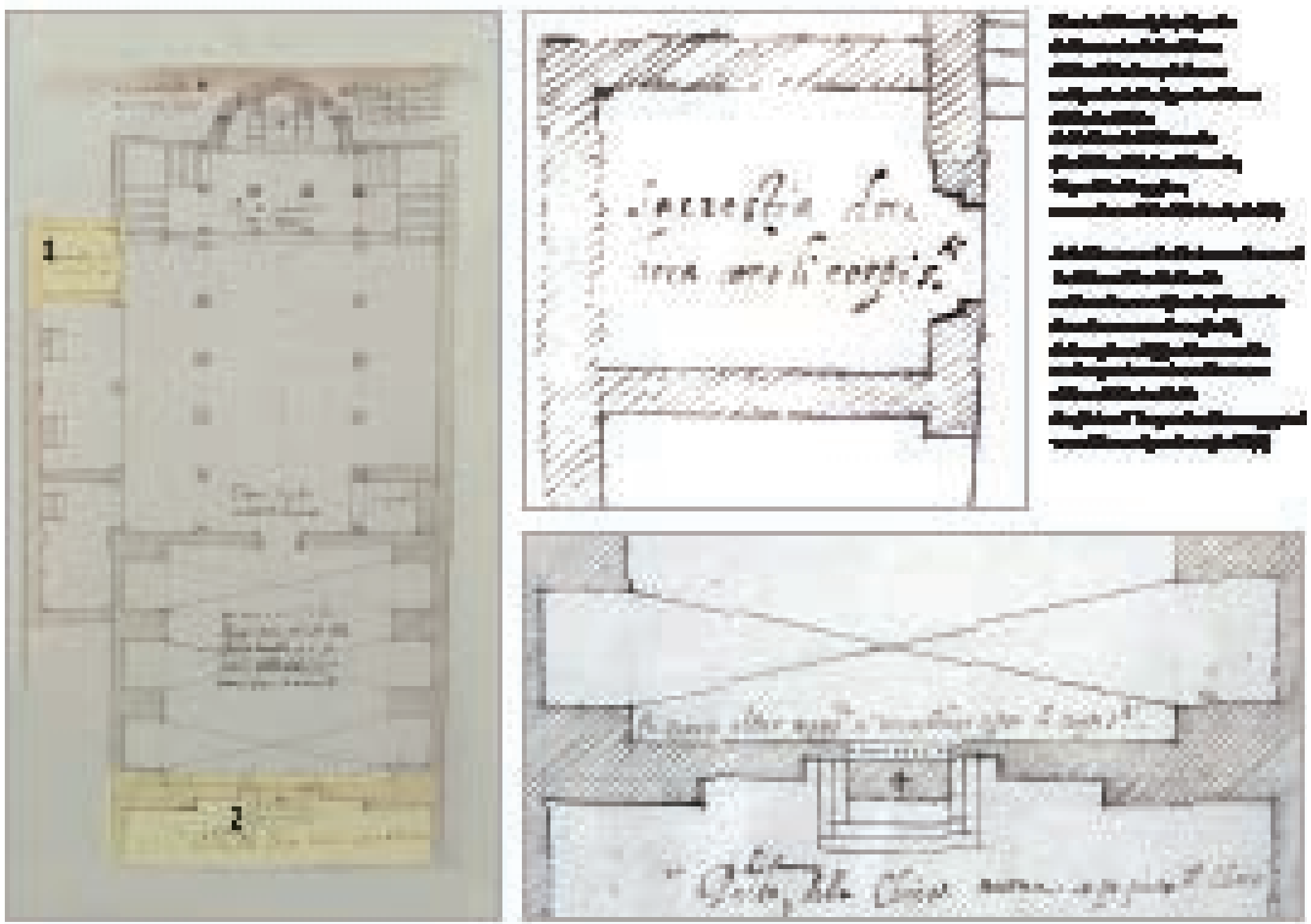

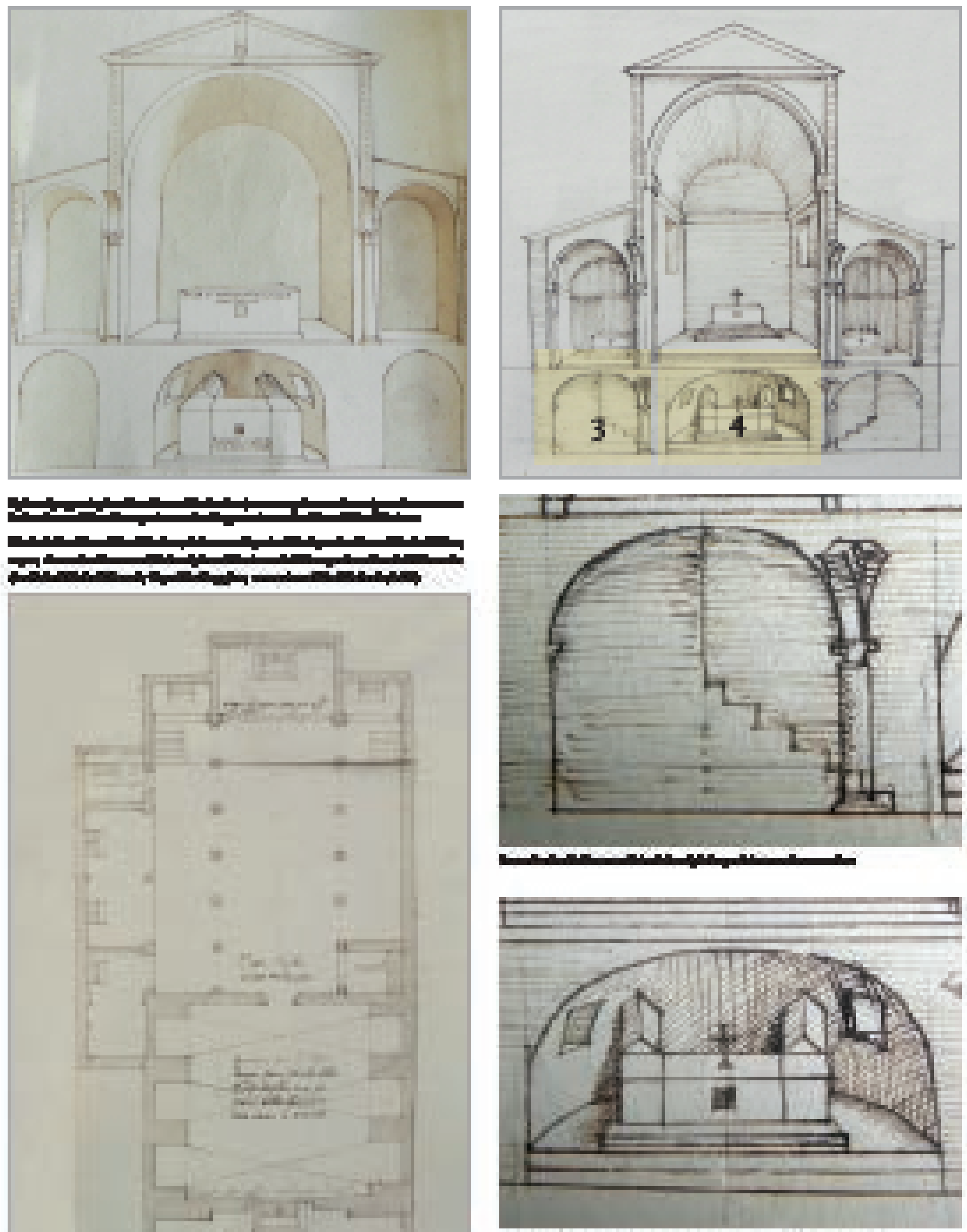

$1+1$

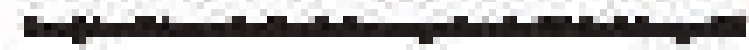


Ir:

\section{1' trath}

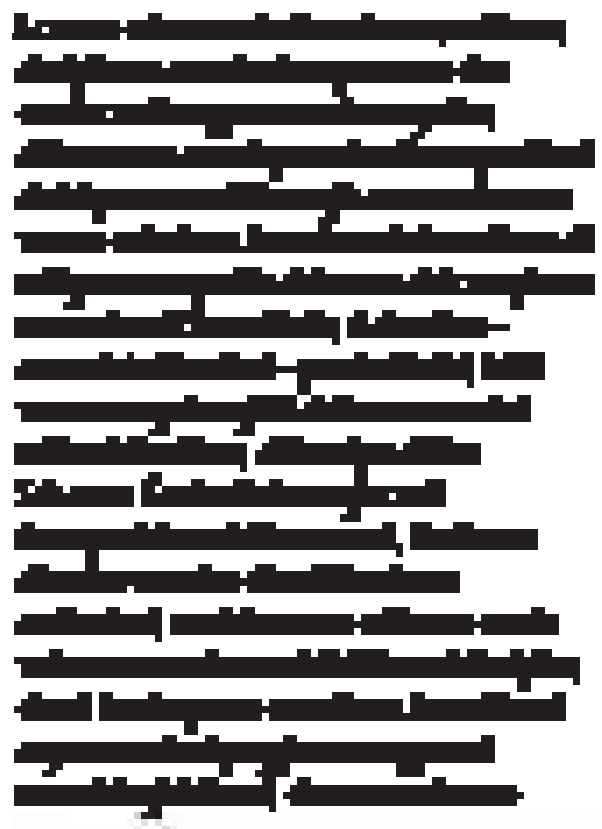

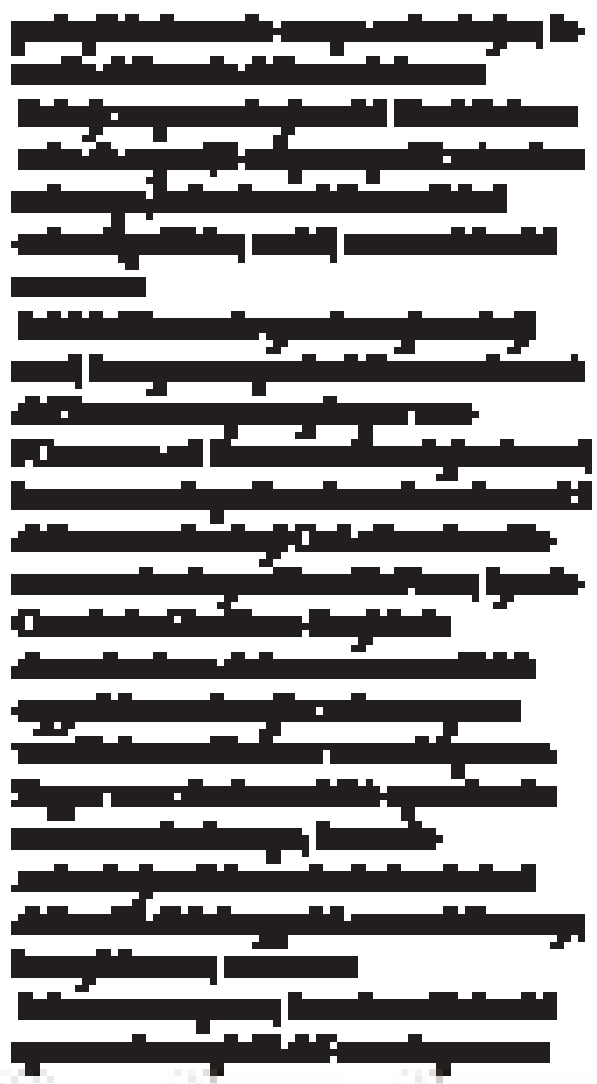

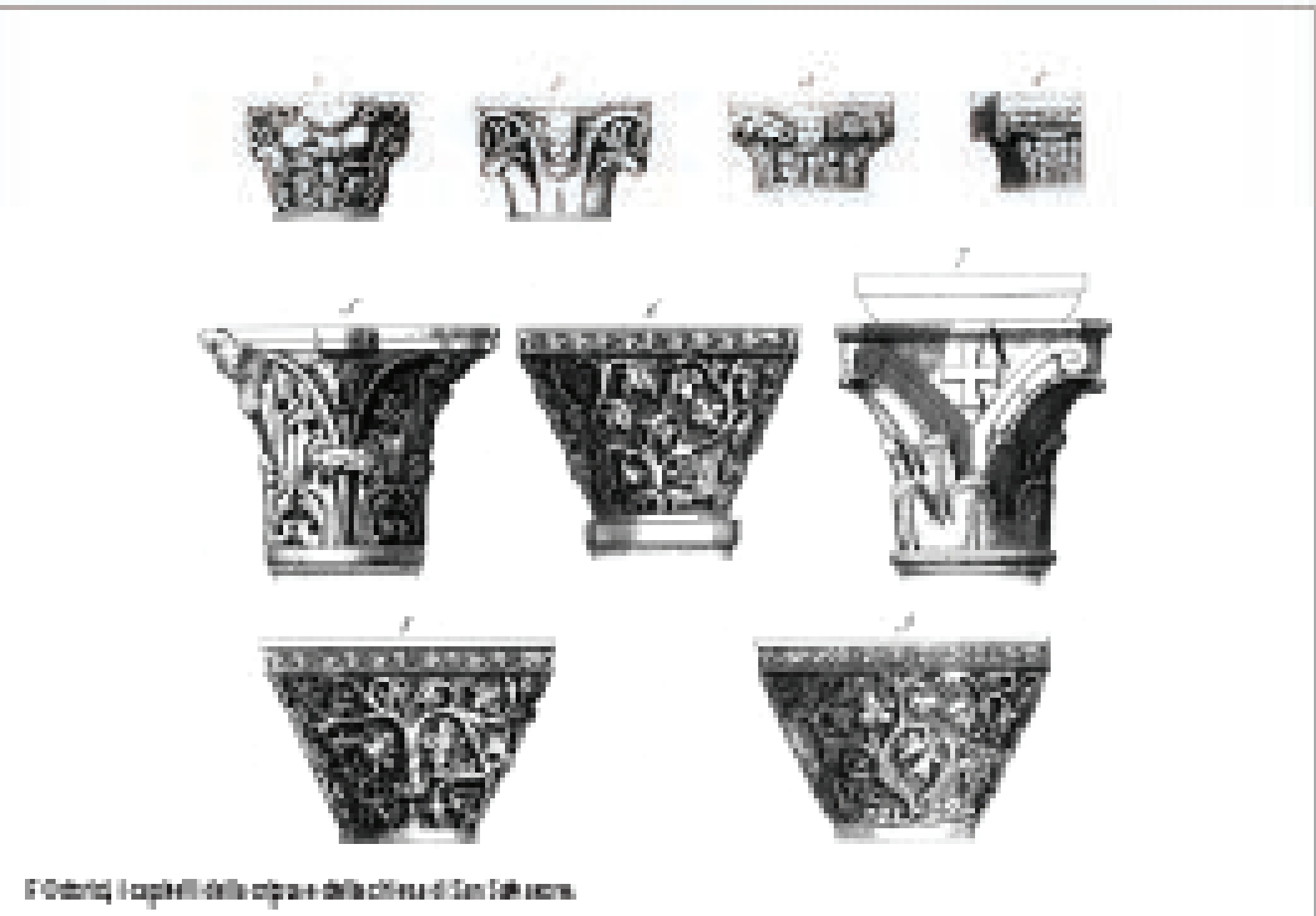



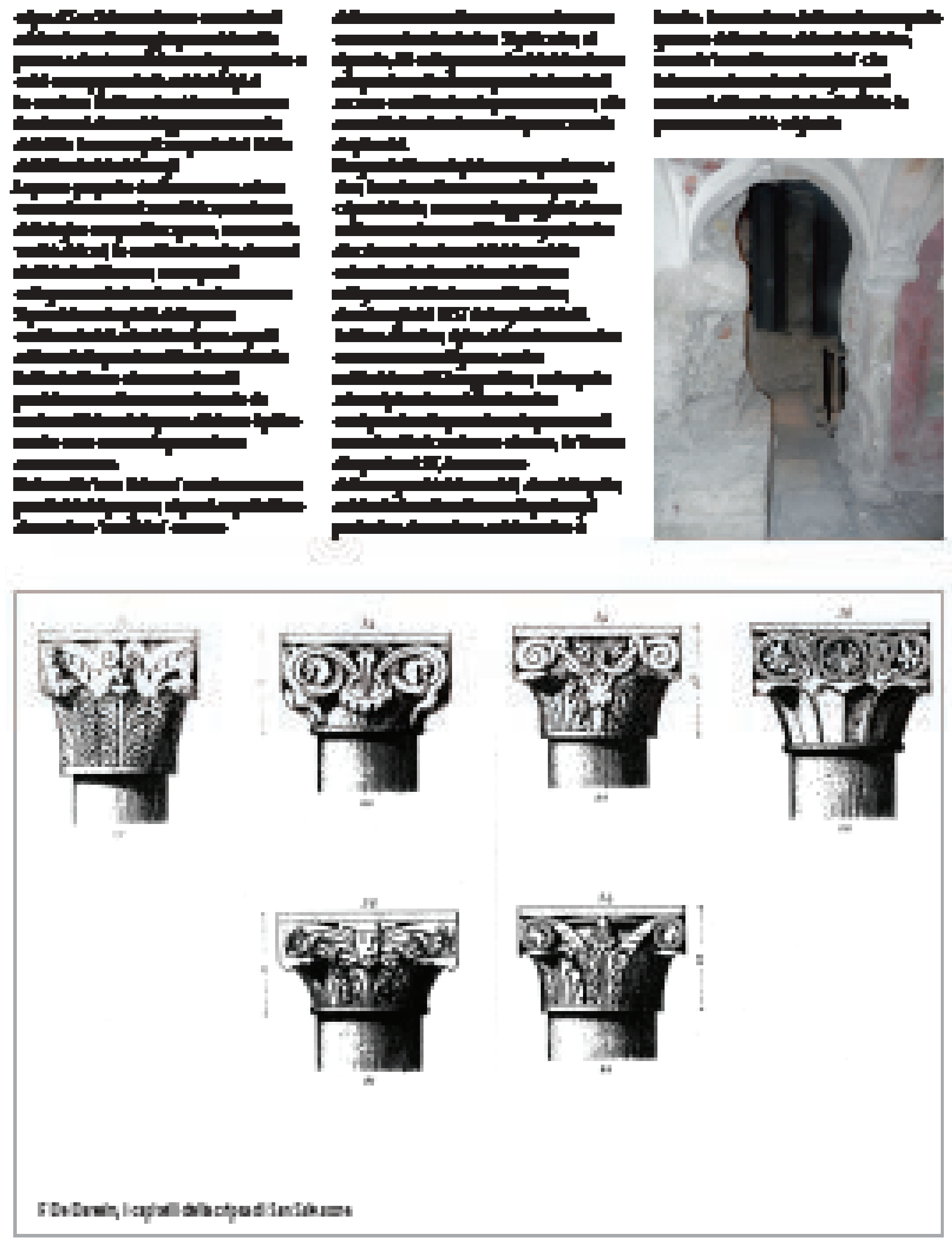

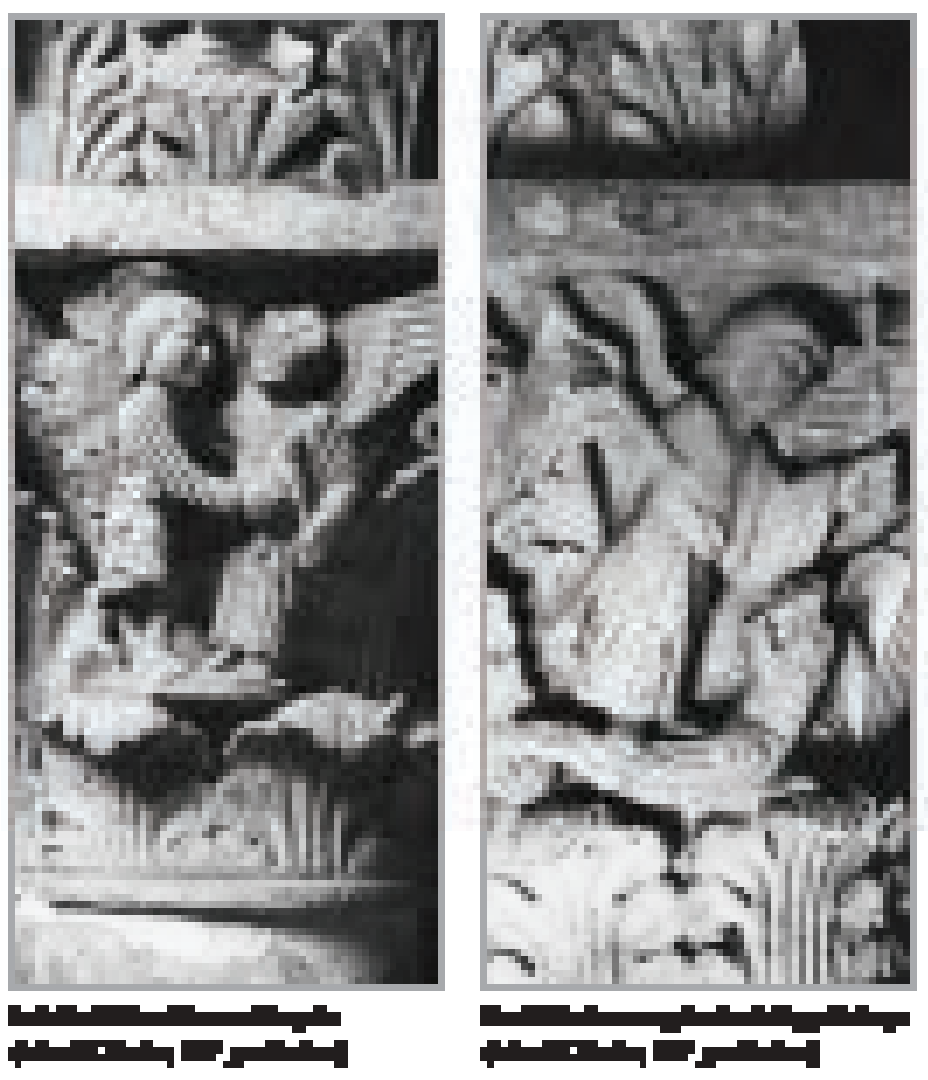
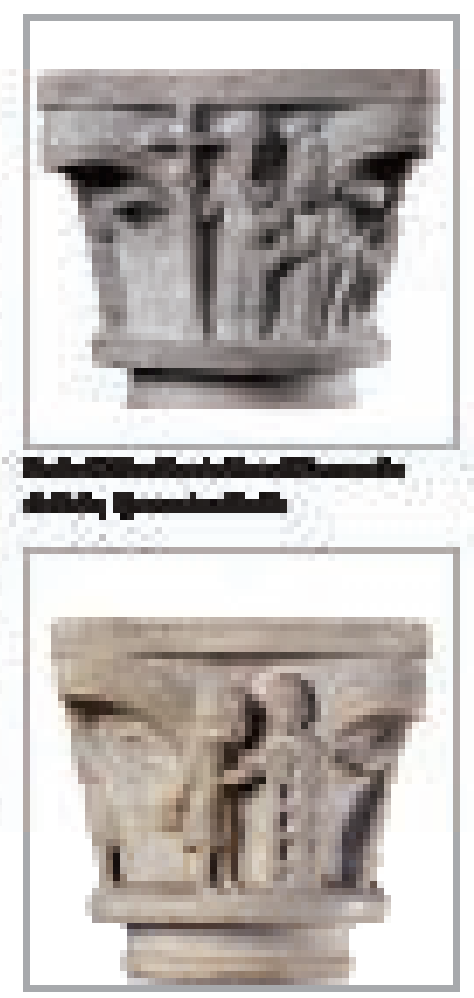

שn+1

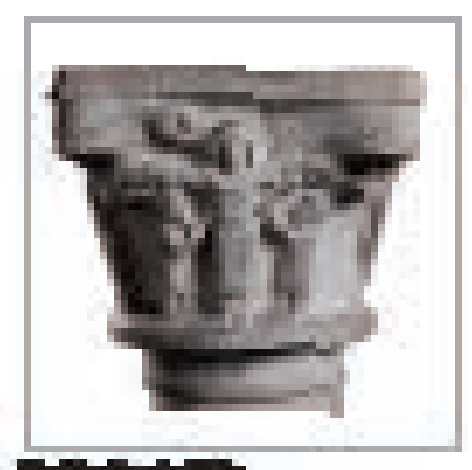

Crm-n

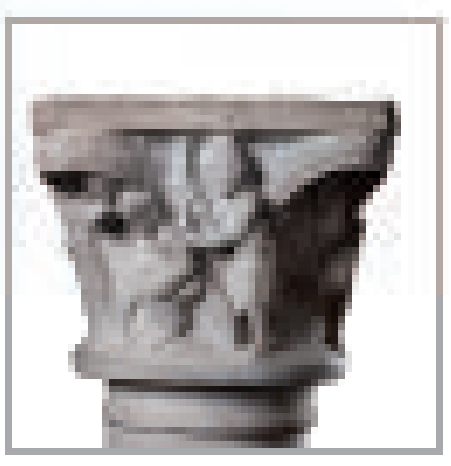

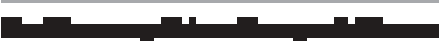
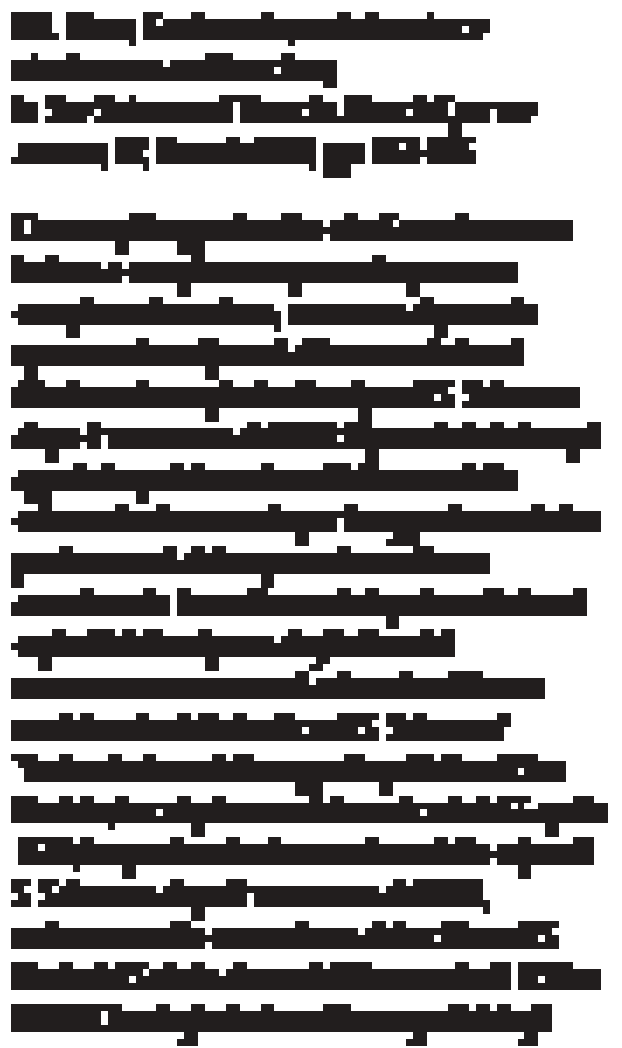

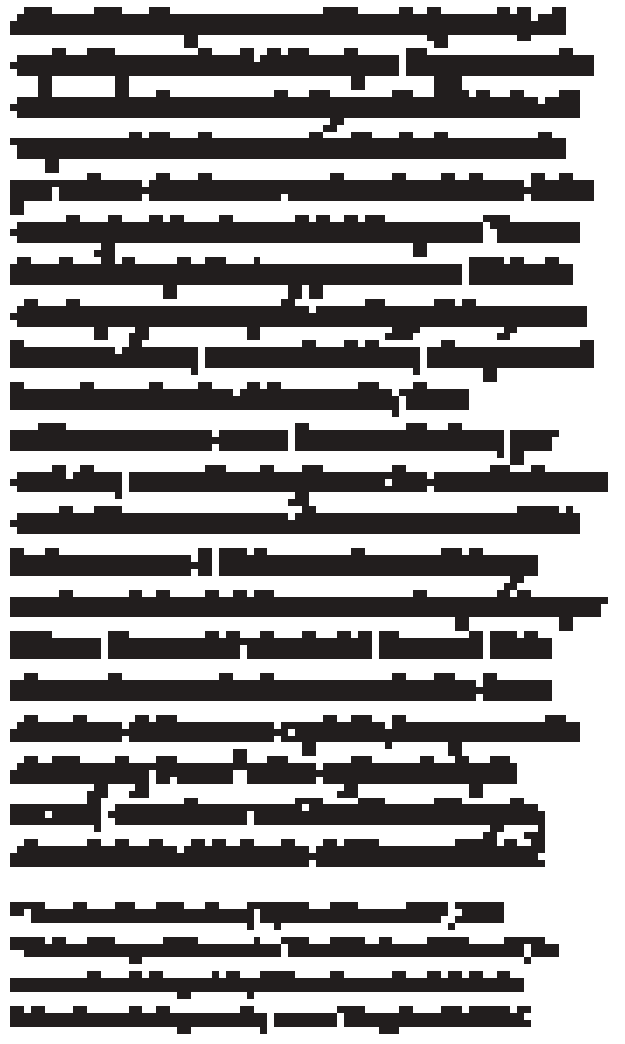

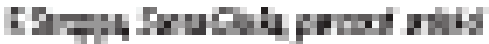

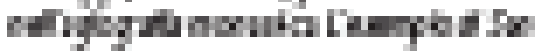

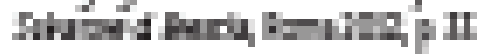

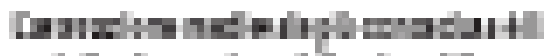

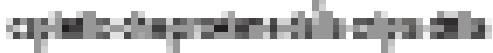

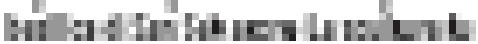

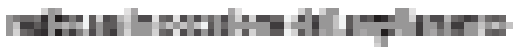

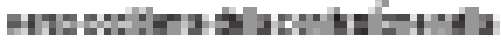

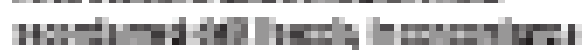

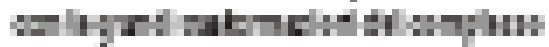

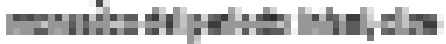

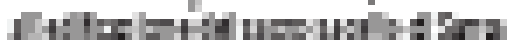

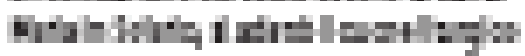

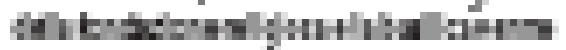

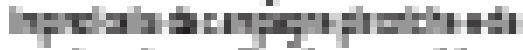

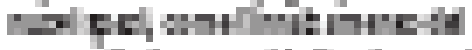

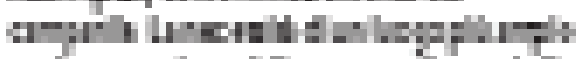

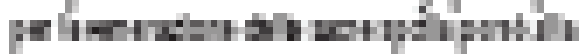

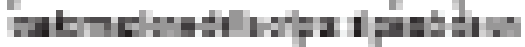

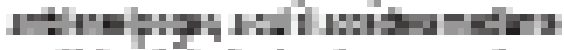

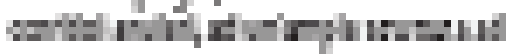

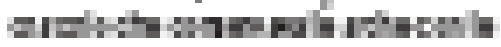

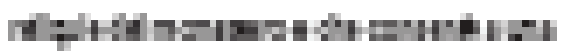

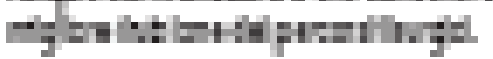




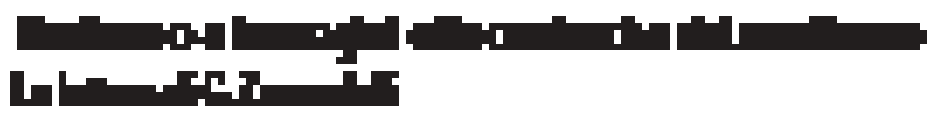
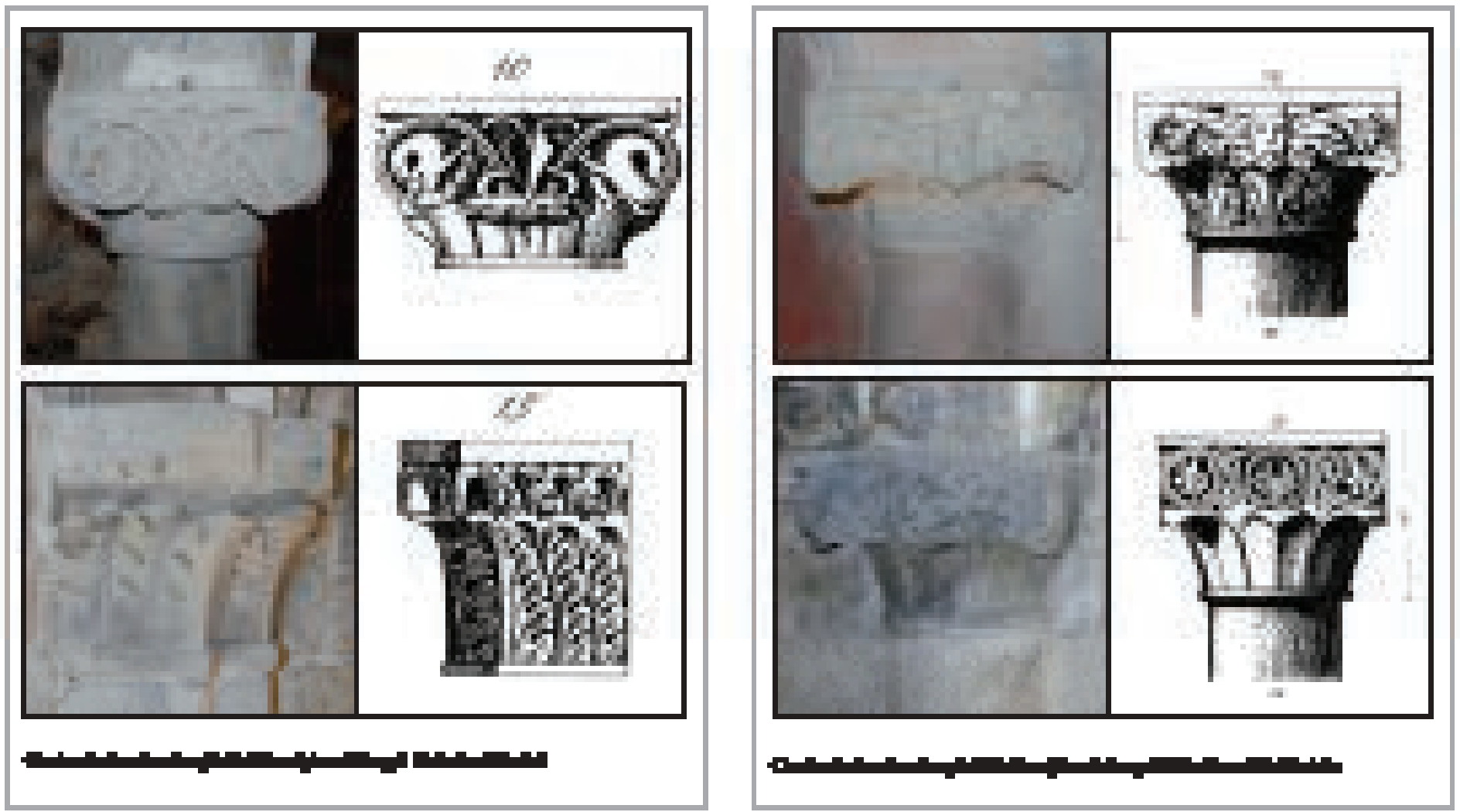

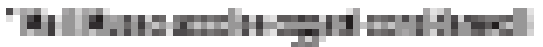

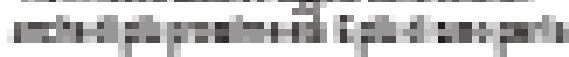

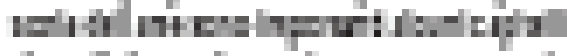

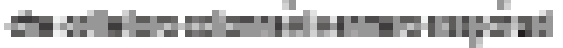

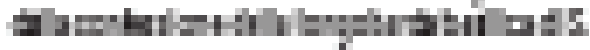

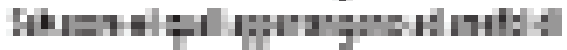

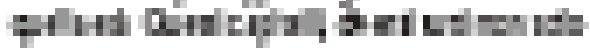

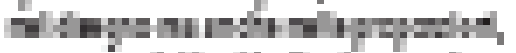

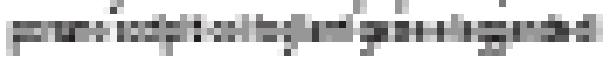

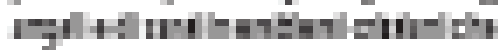

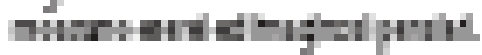

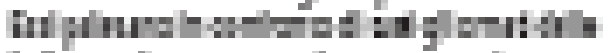

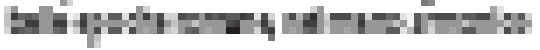

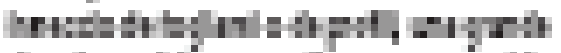

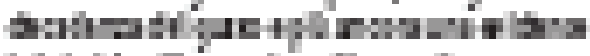

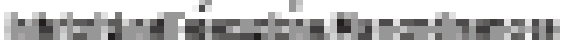

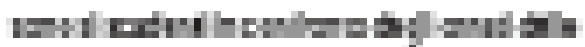

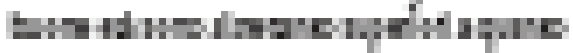

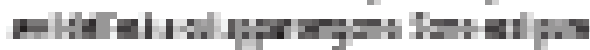

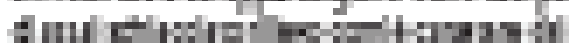

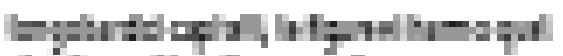

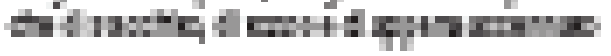

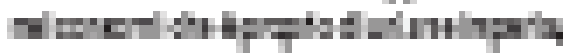

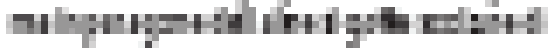

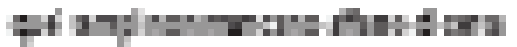

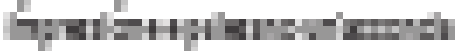

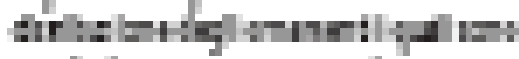

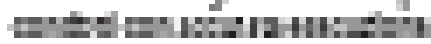

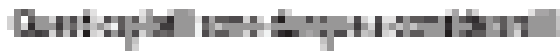

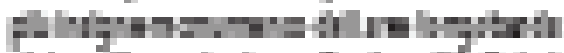
thrit;

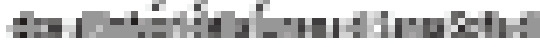

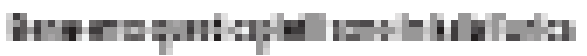

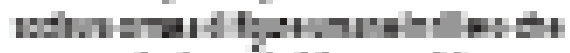

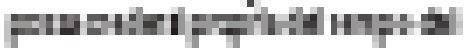

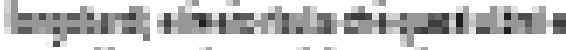

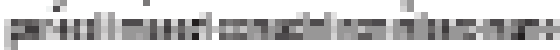

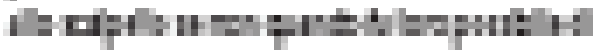

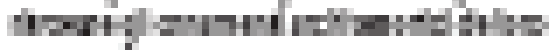

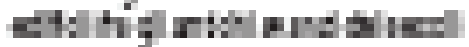

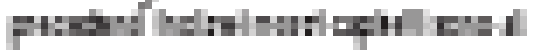

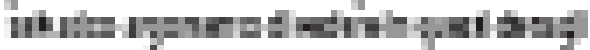

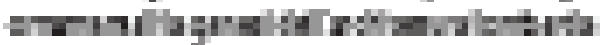

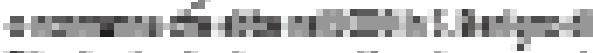

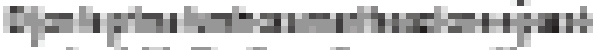

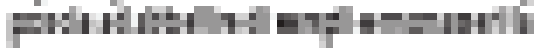

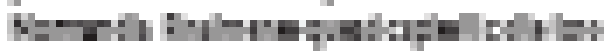

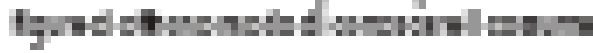

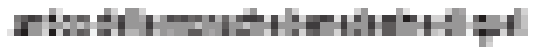

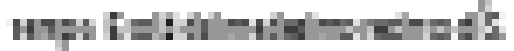

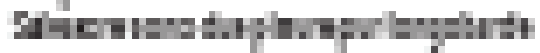

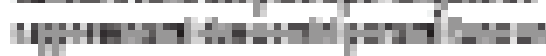

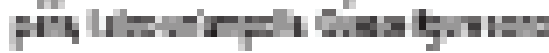

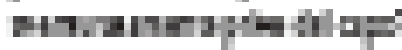

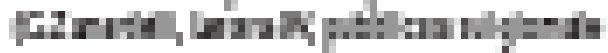

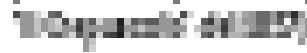


Loptad Sanshato

indels unerts
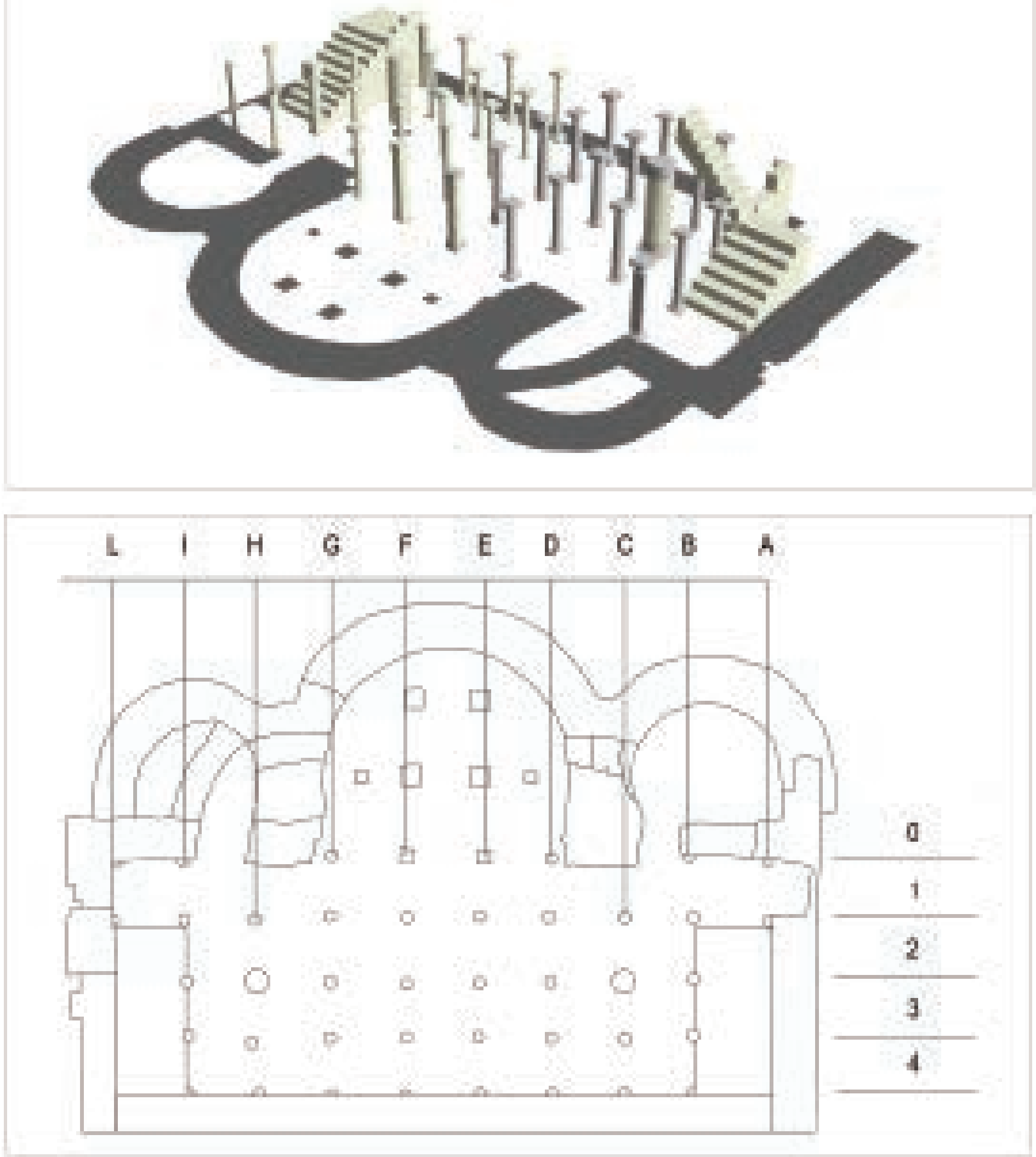


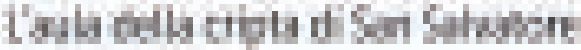 \\ Sonurpaticen}

Iform

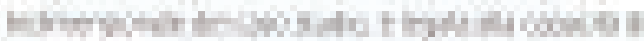

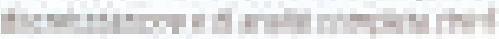

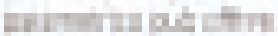

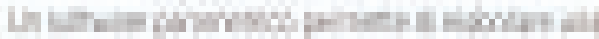

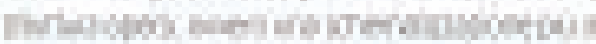

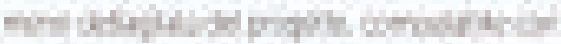

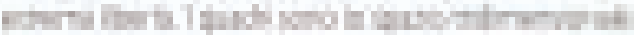

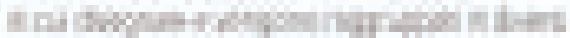

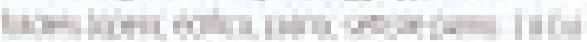

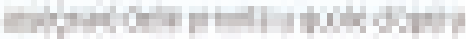

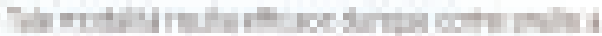

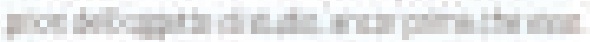

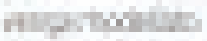

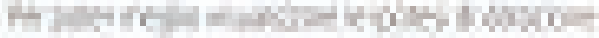

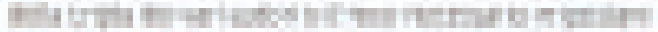
100.

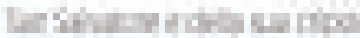

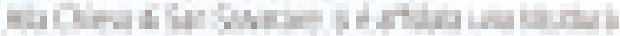

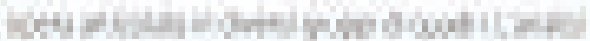

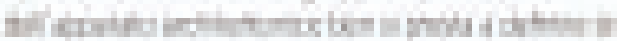

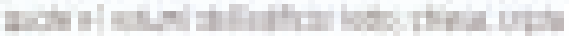

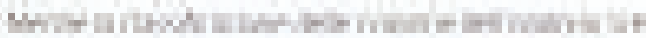

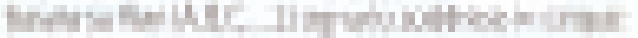

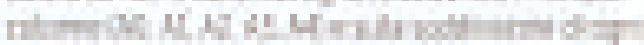

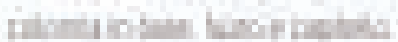

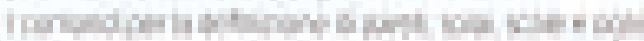

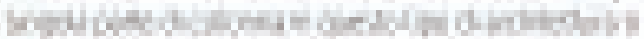

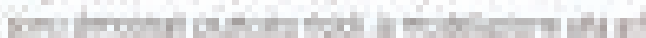

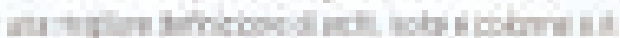

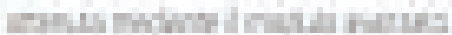

A

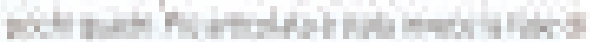

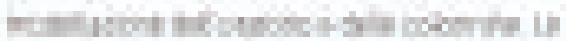

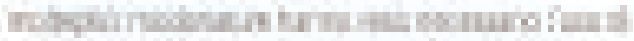

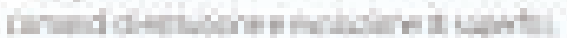

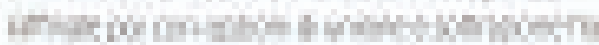

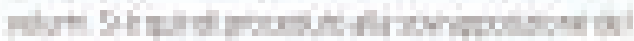

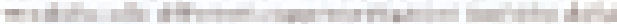

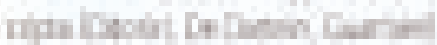

Hum

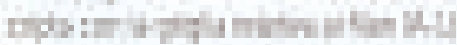

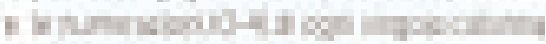

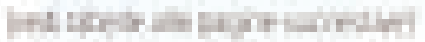

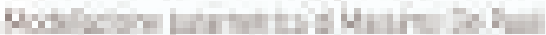
movirain
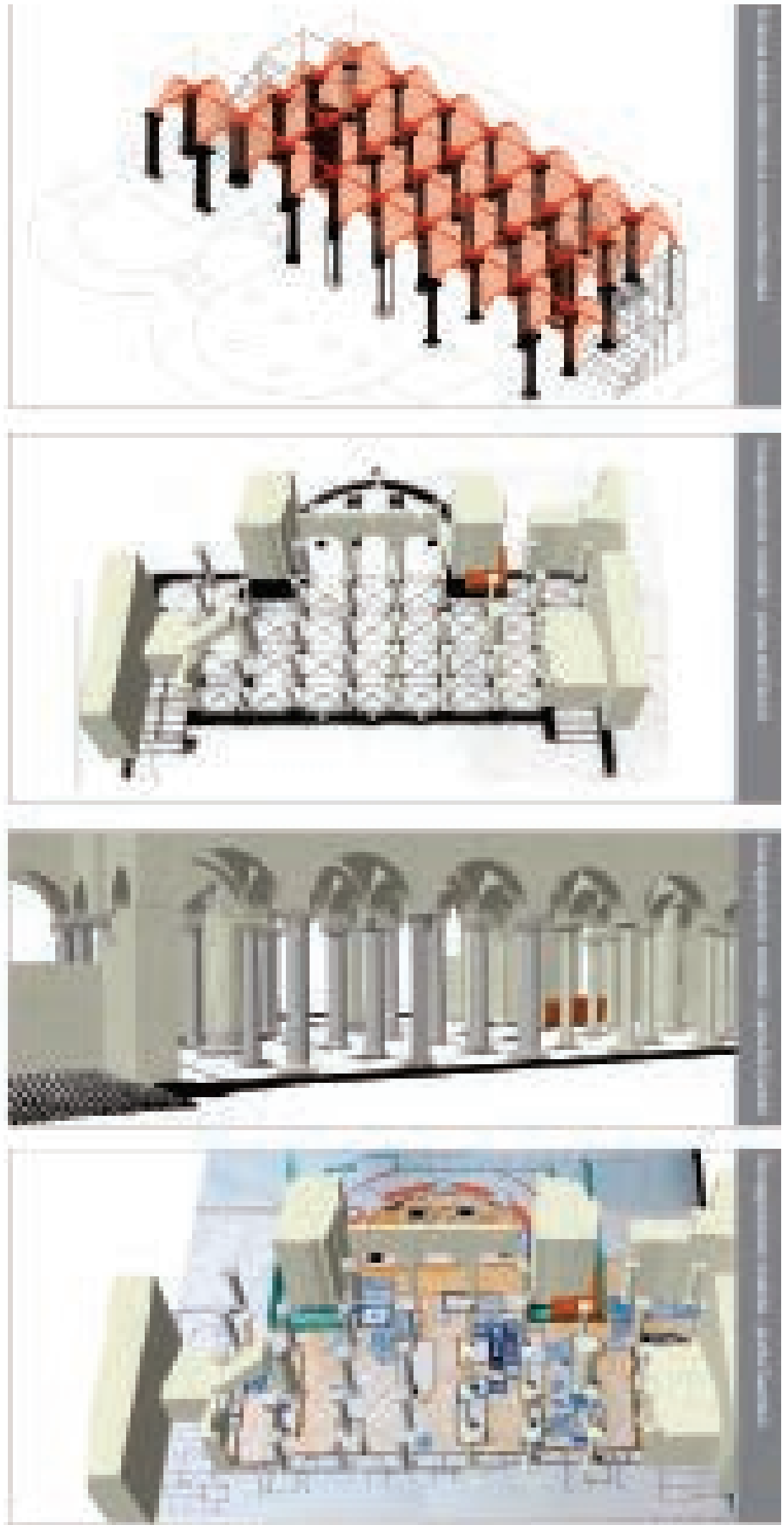


\begin{tabular}{|c|c|c|c|}
\hline A & FOTOGRAFIA & DESCRIZIONE & CAPITELLO \\
\hline & & $\begin{array}{l}\text { Ao-SEMICAPITELLO CON TRE } \\
\text { ROGLIE E FOGLIE ANGOLARI E } \\
\text { CON FACCINA CENTRALE: la parte } \\
\text { in feriore è caratterizata da un } \\
\text { tondinoe da tre foglie. Nella parte } \\
\text { superiore una testina con la lingua } \\
\text { fuori è affiancata ai lati da foglie } \\
\text { angolari. Un semplice abaco a } \\
\text { sezione rettangolare conclude la } \\
\text { composizione. Il capitello è uguale a } \\
\text { quello disegnatoda Federico Odorici } \\
\text { e anche da Ferdinand De Dartein. }\end{array}$ & \\
\hline & & $\begin{array}{l}\text { A1 - SEMICAPITELLO CON TRE } \\
\text { FOGLIE LISCIE E VOWUTE } \\
\text { ANGOLARI CON FIORE } \\
\text { CENTRALE: da notare lasimmetria } \\
\text { delb decorazione della voluta } \\
\text { angolare di destra decorata a } \\
\text { semplice voluta sul fronte e con un } \\
\text { motivo floreale sul lato. Il fiore sul } \\
\text { batodi sinistra è solosborza toe non } \\
\text { finito. }\end{array}$ & \\
\hline
\end{tabular}

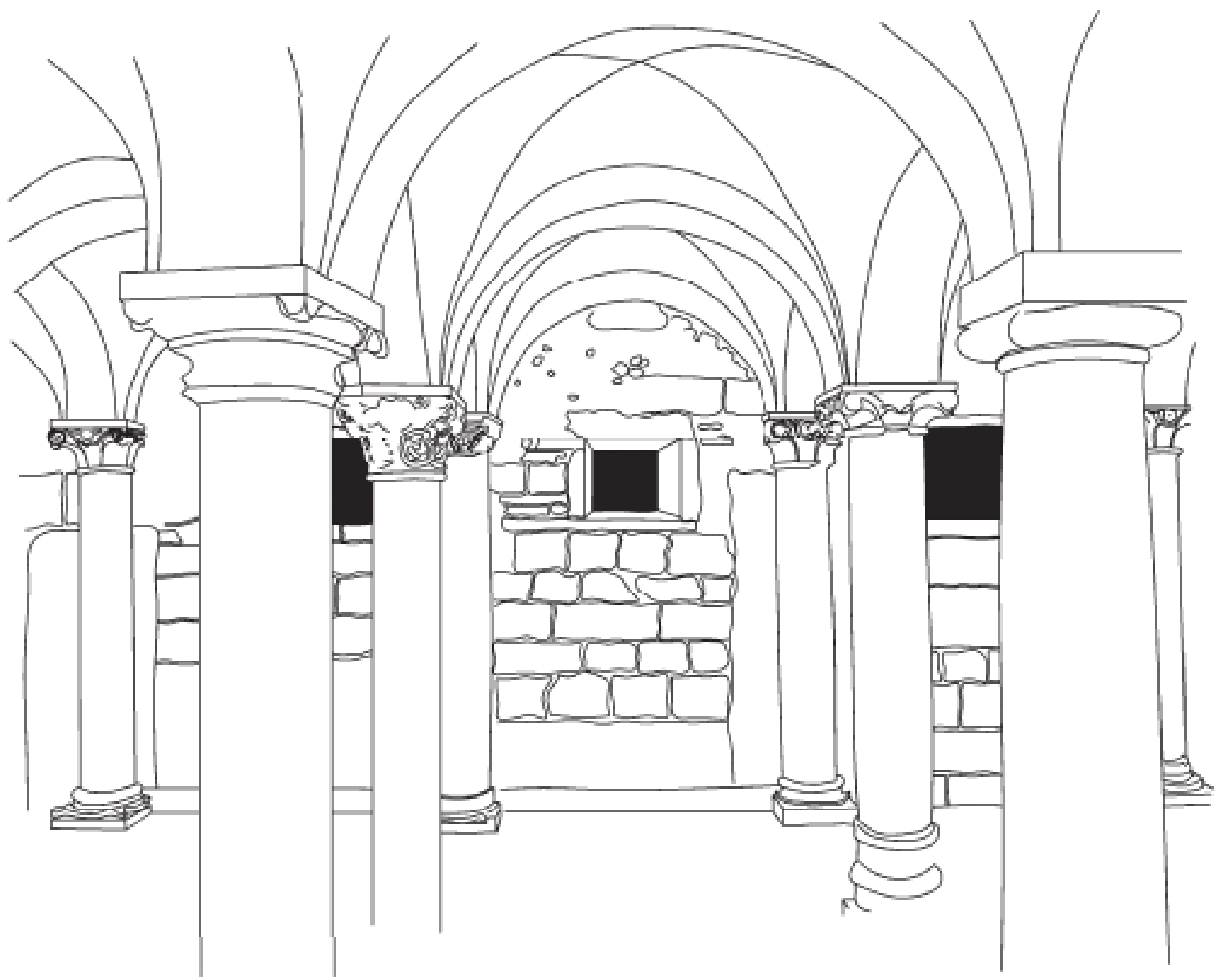




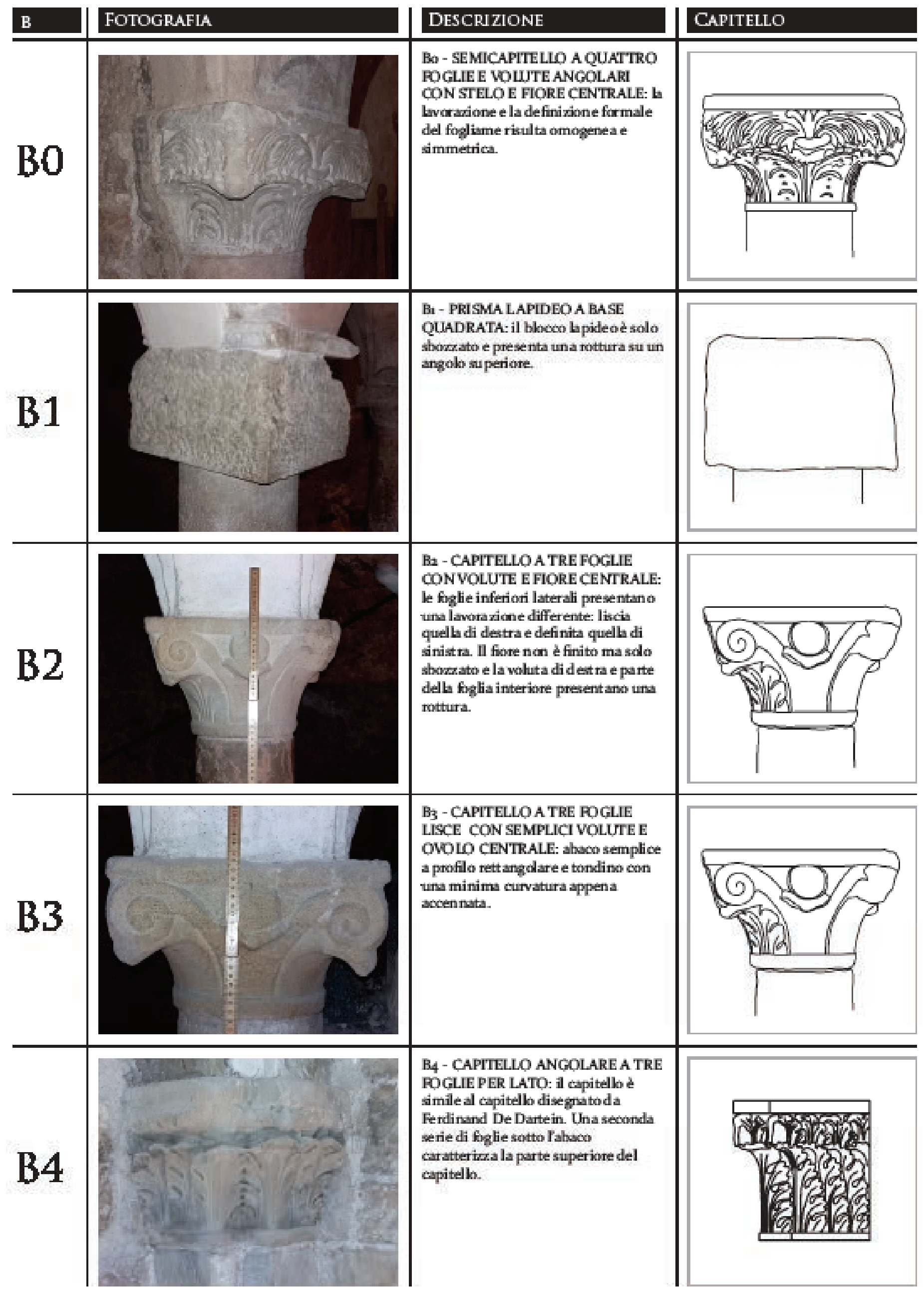




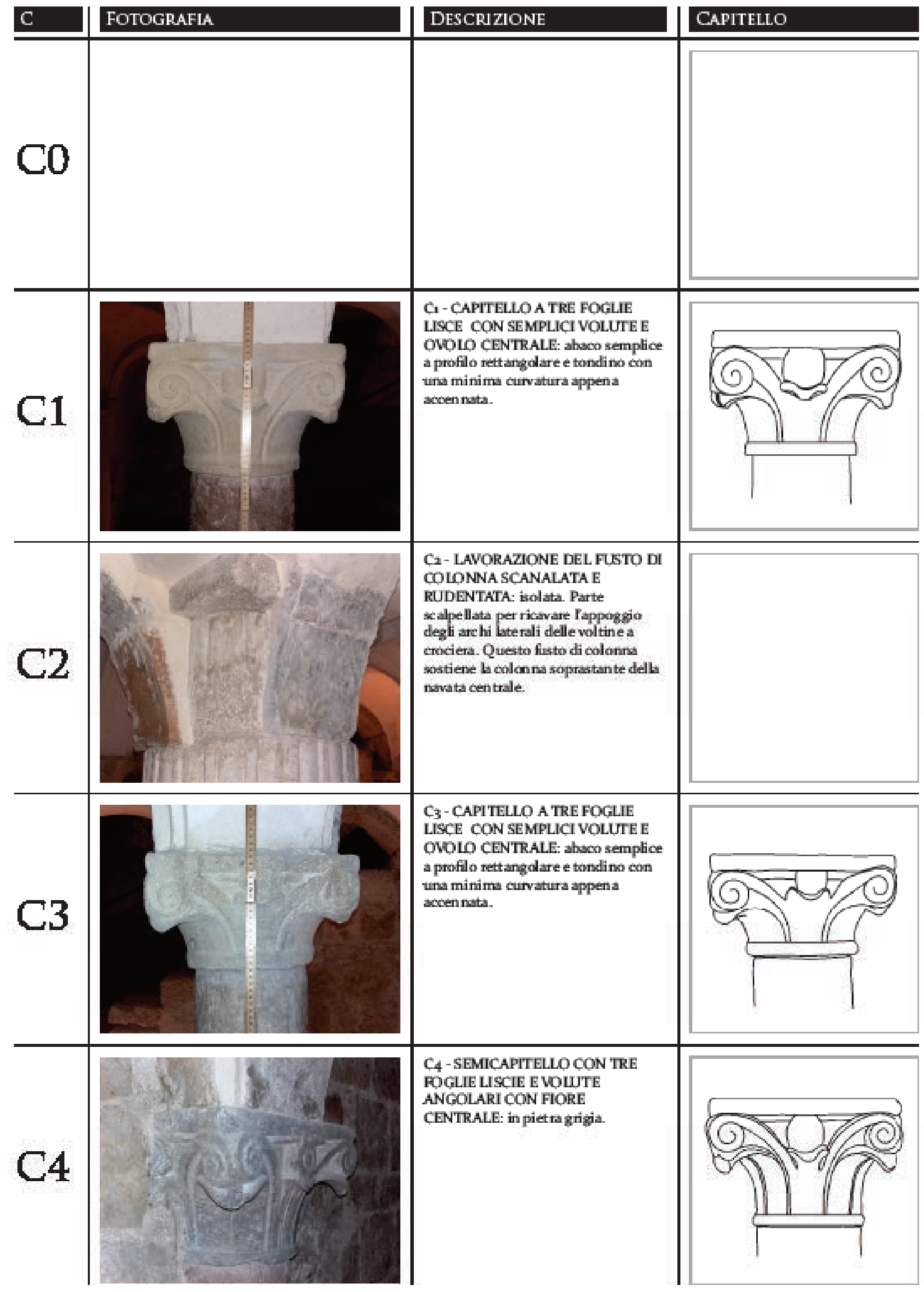




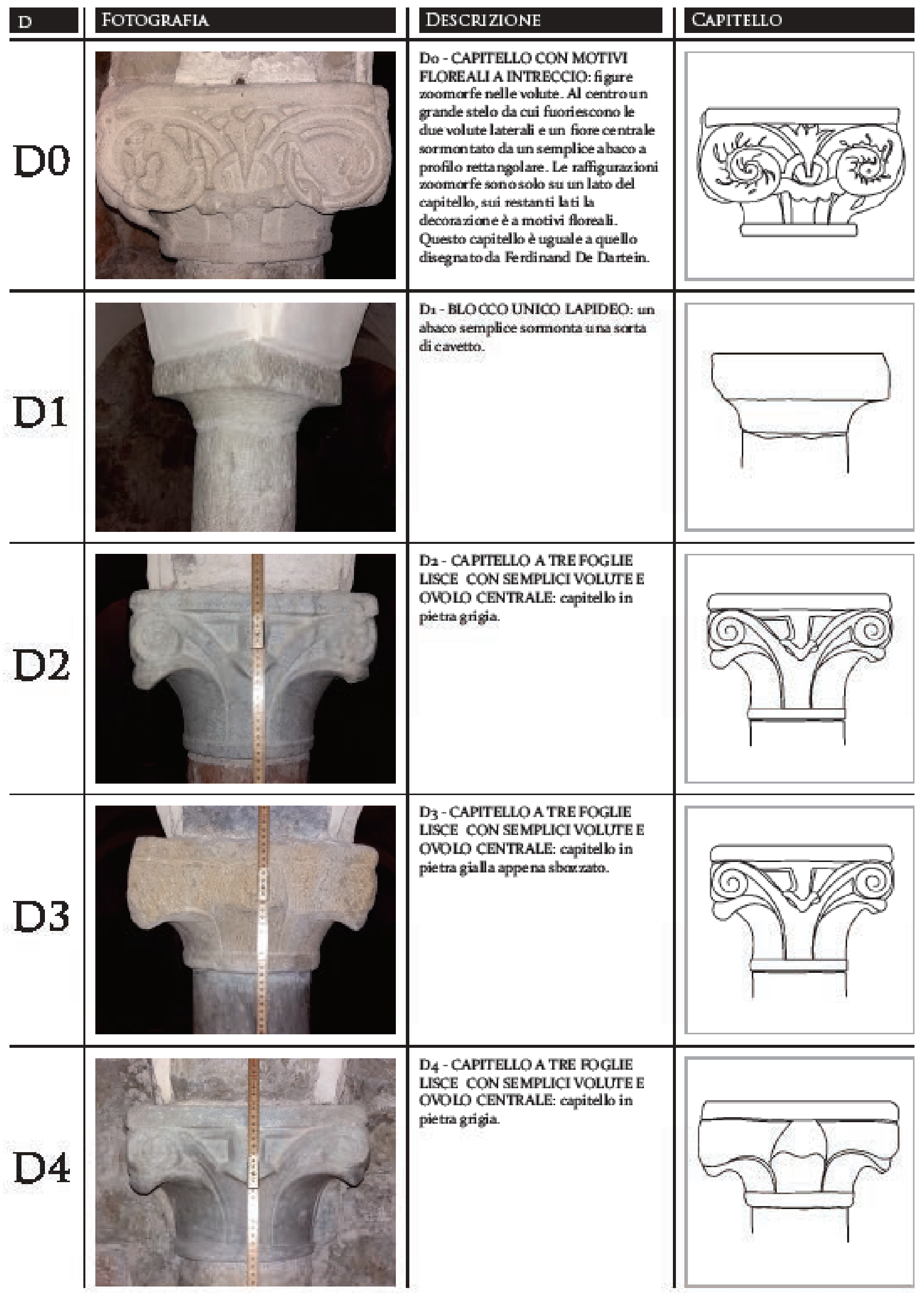

M. De Paoli: Strutture architettoniche... 171 


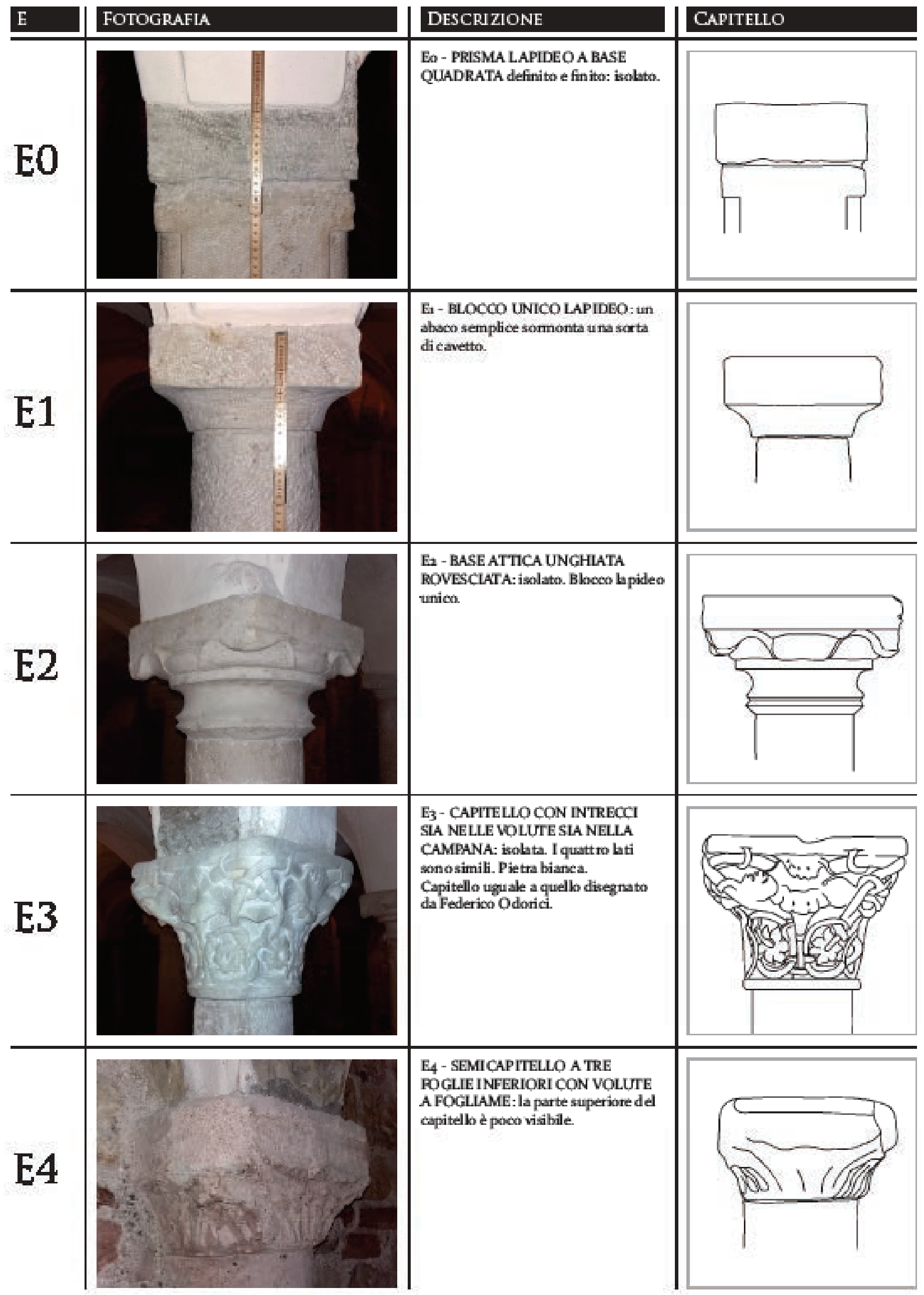




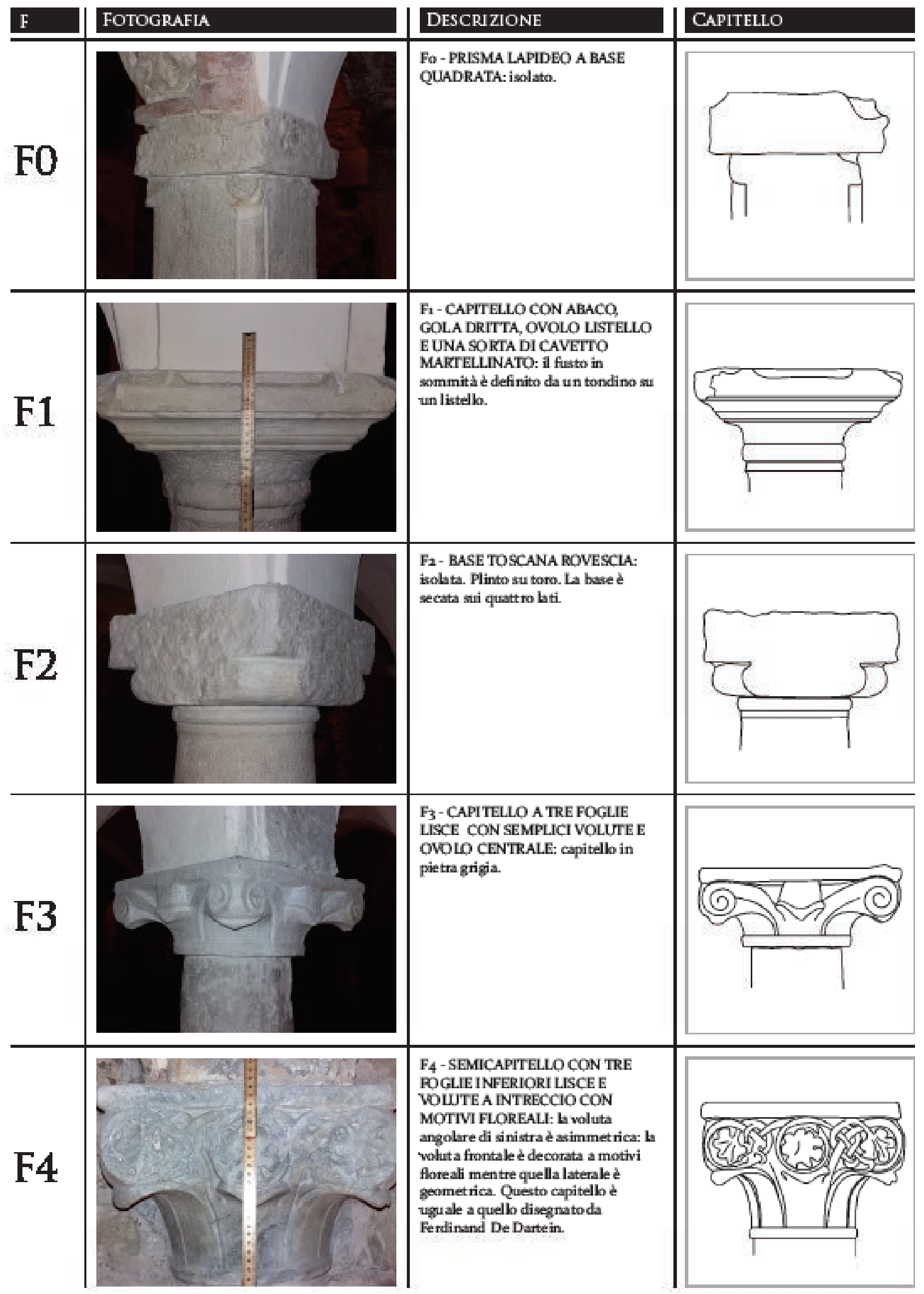




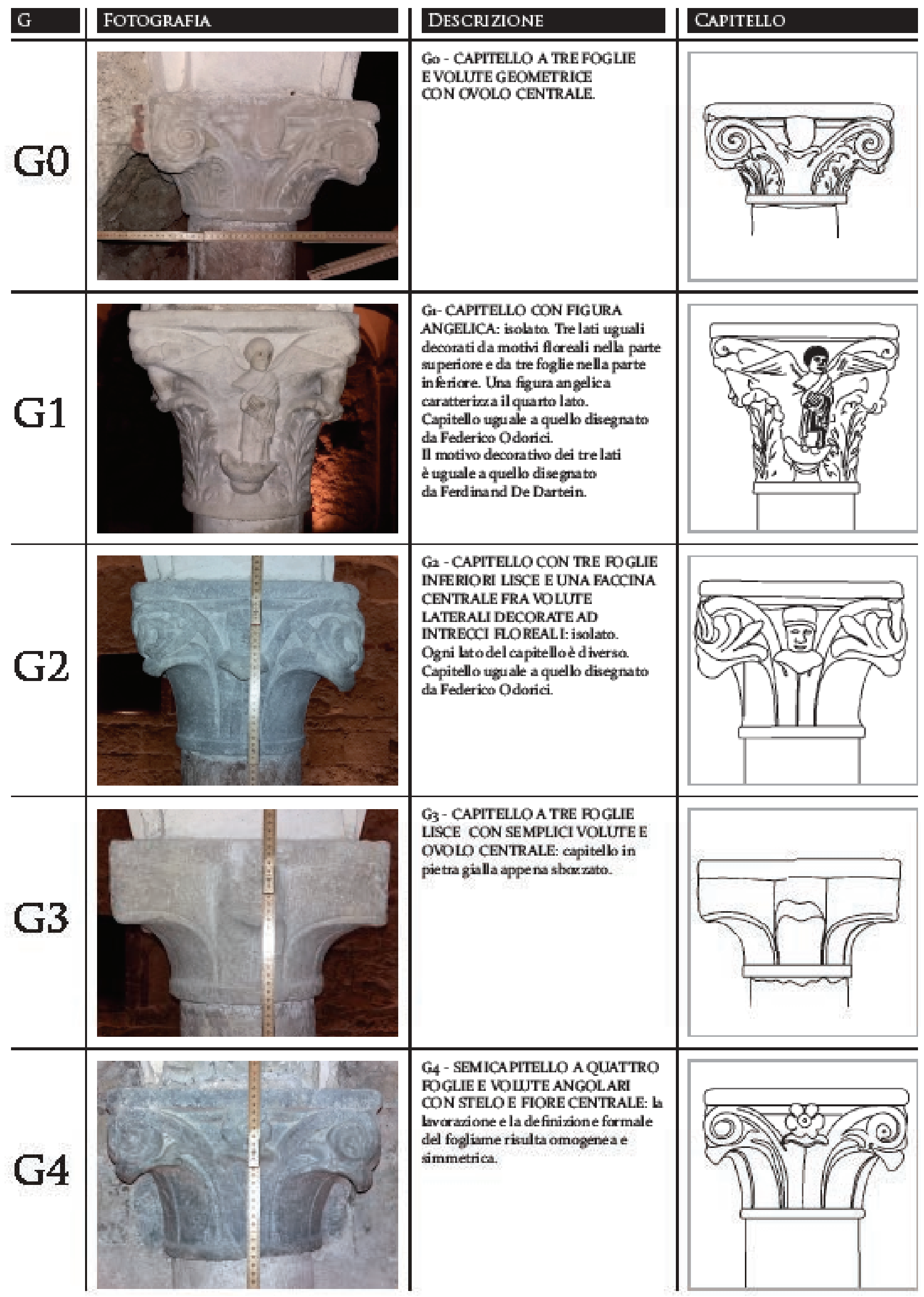




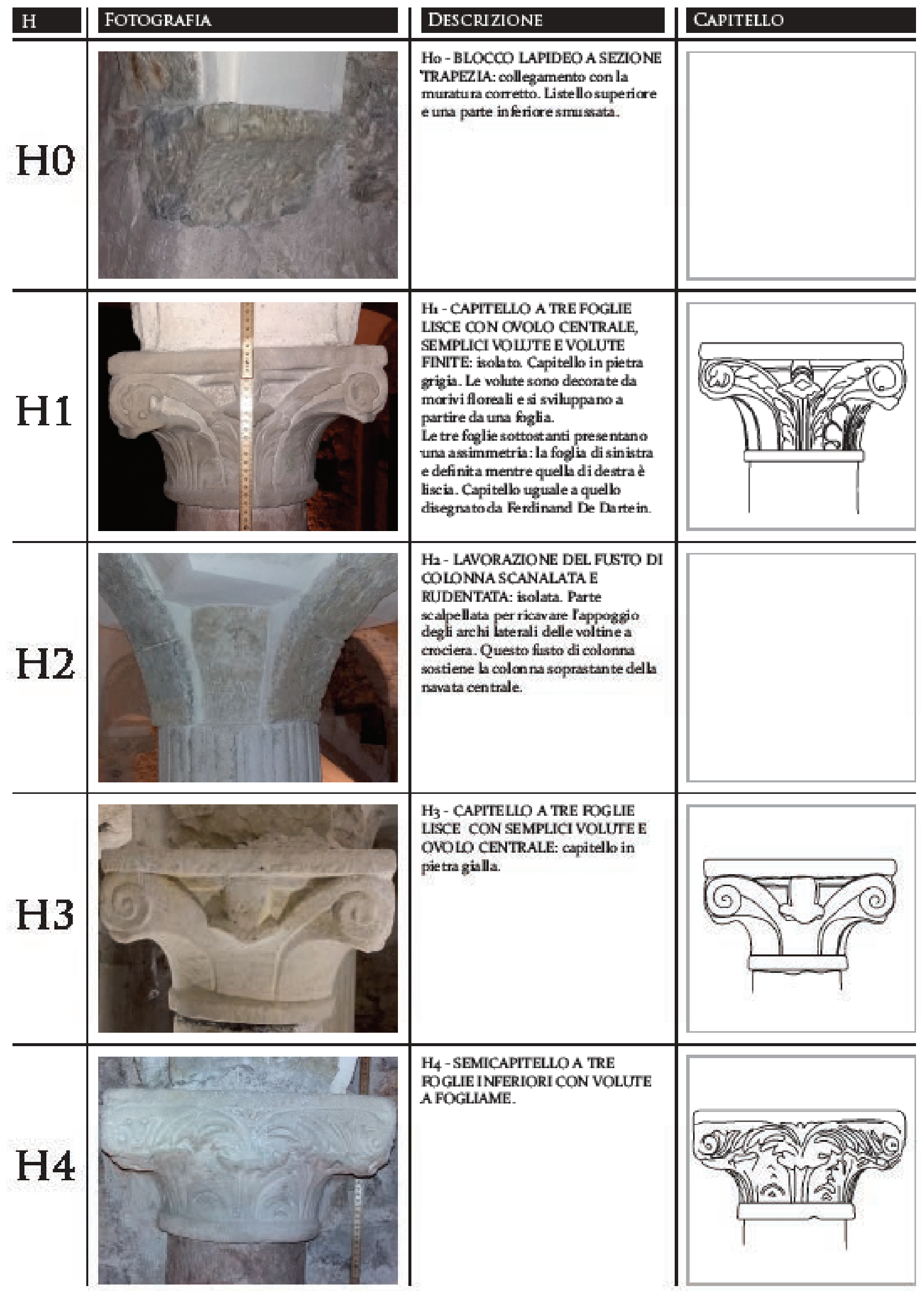

M. De Paoli: Strutture architettoniche... 175 


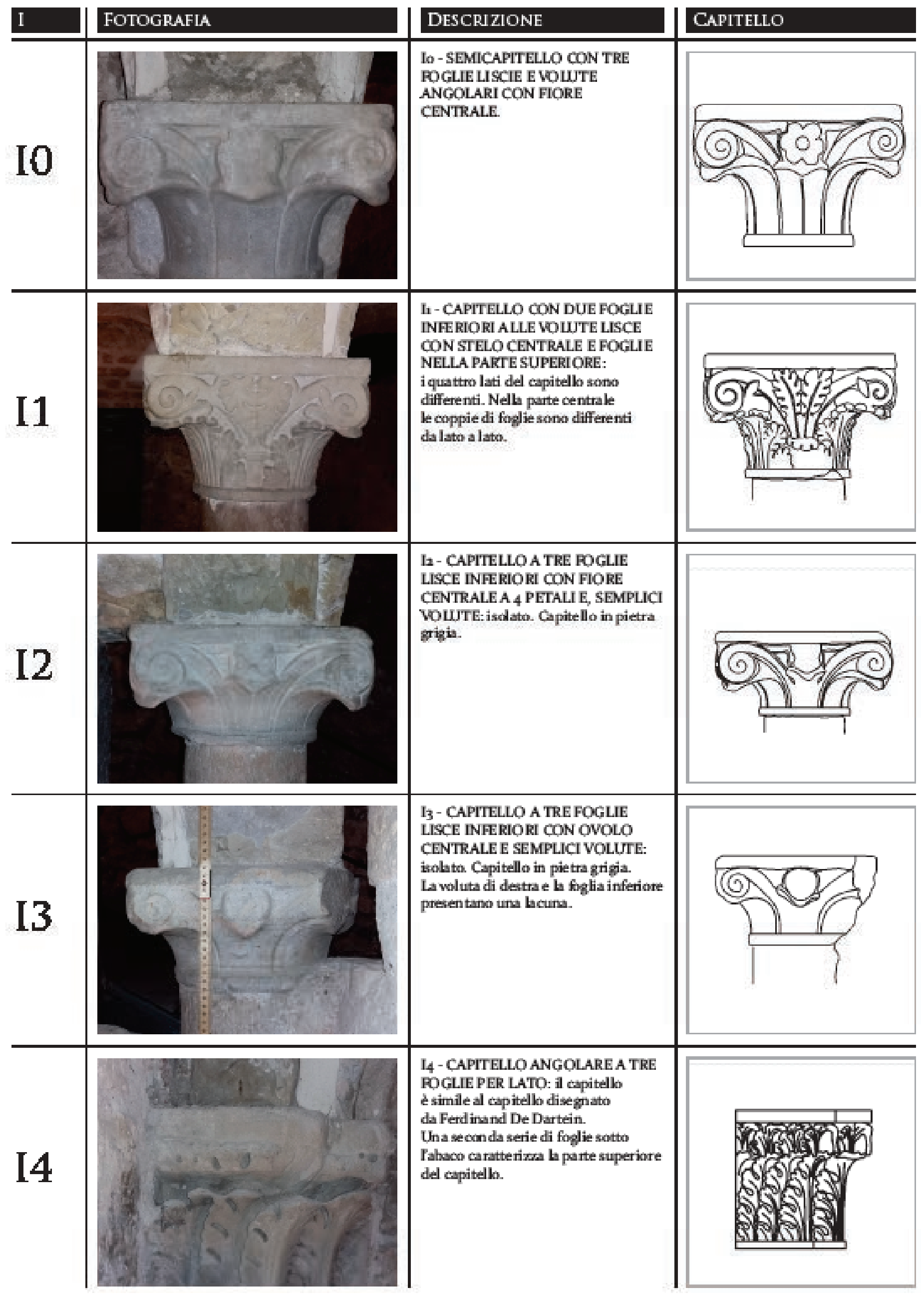




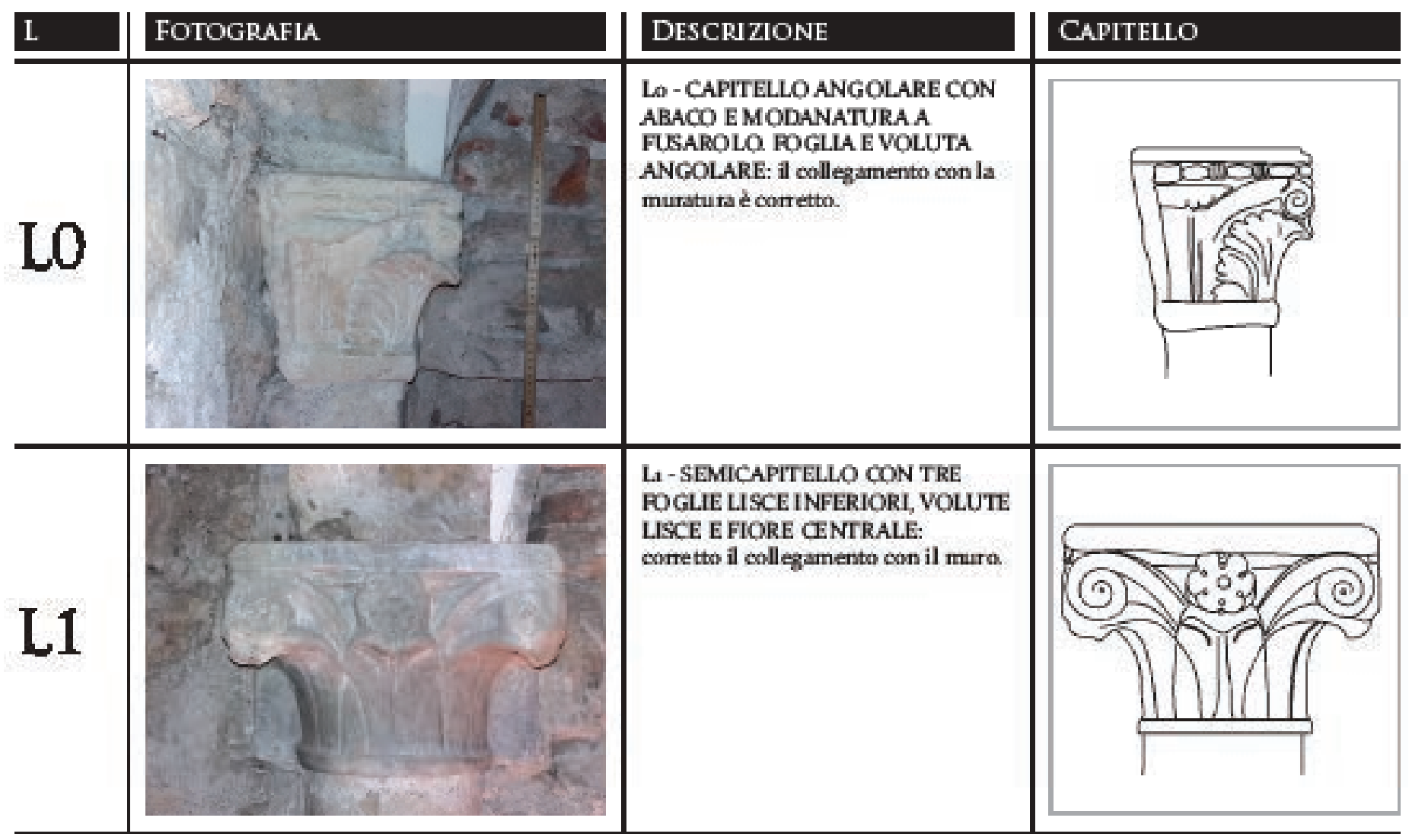

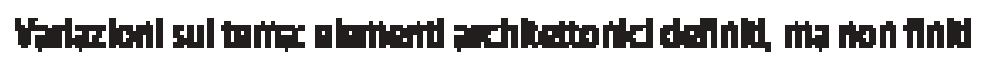

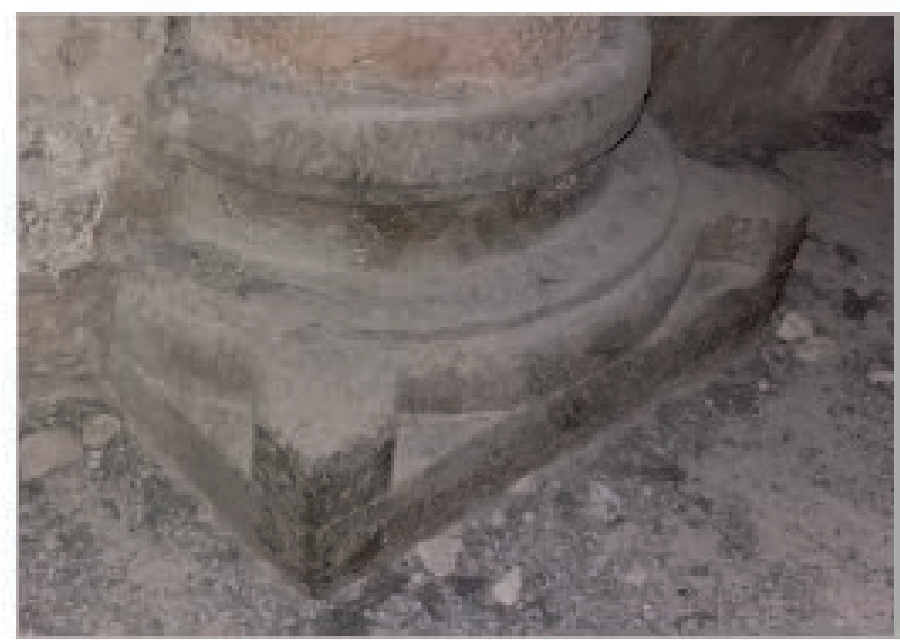

inemitic

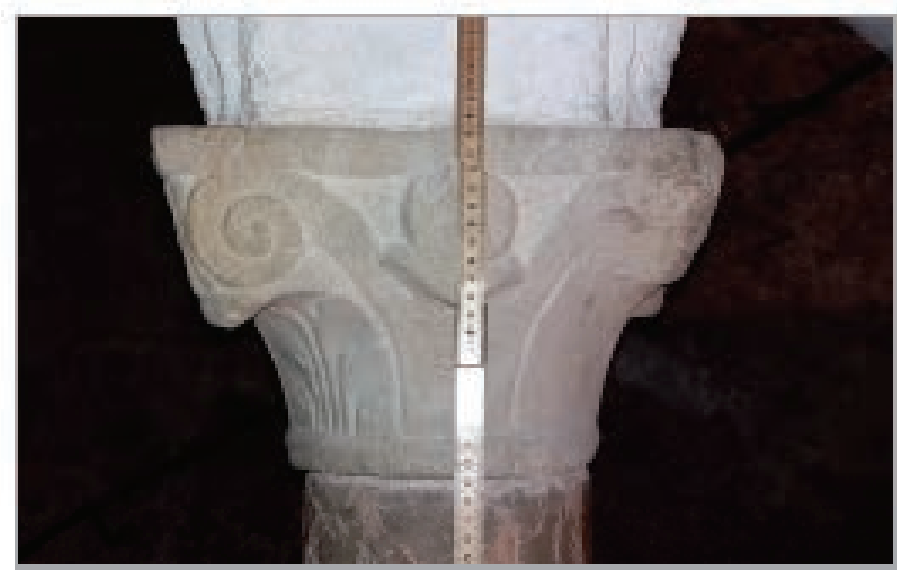

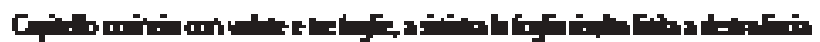

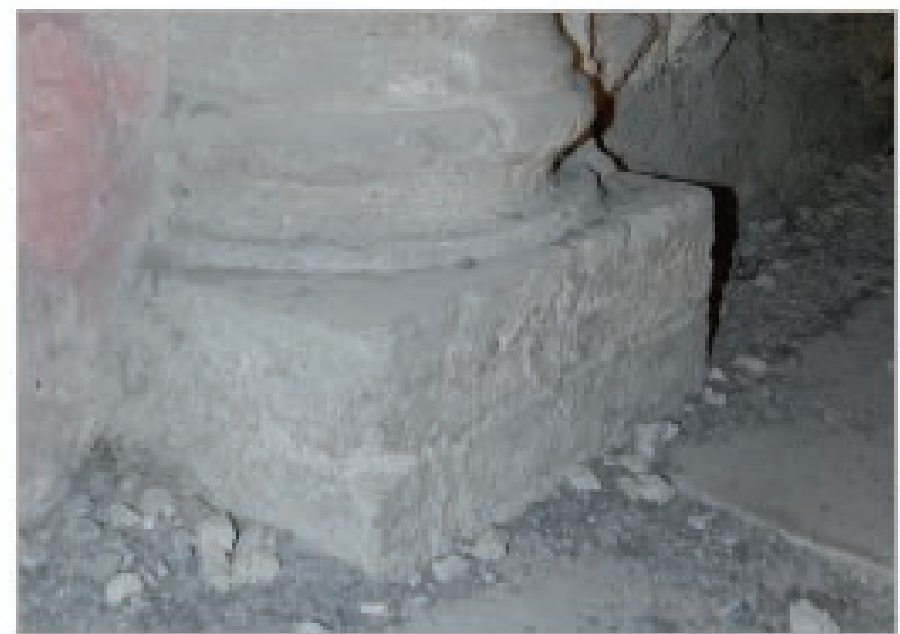

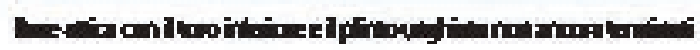

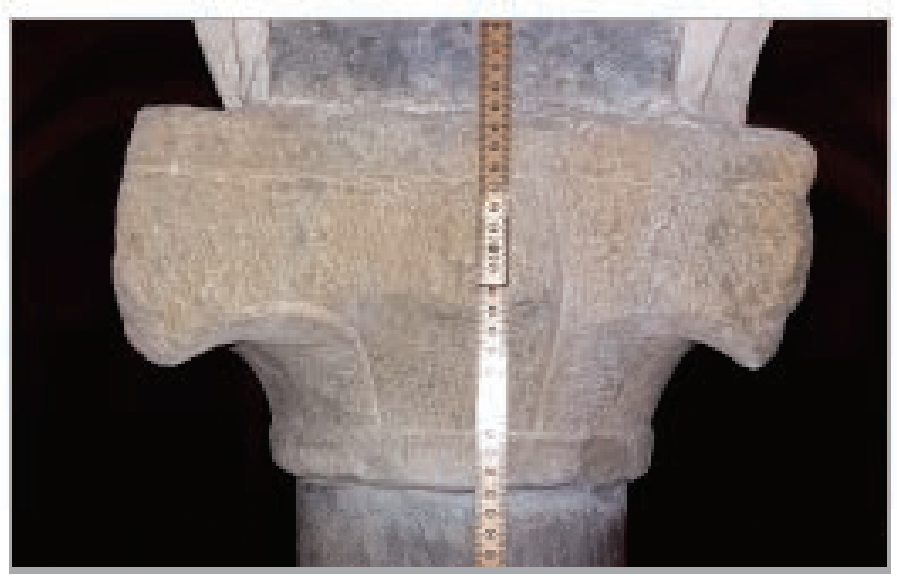

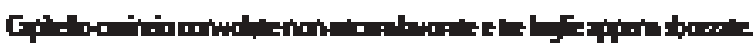

